\title{
Grotesque: Complex Geometric Arrangement of Unreflected HEU (93.15) Metal Pieces
}

Mackenzie L. Gorham John D. Bess

September 2011

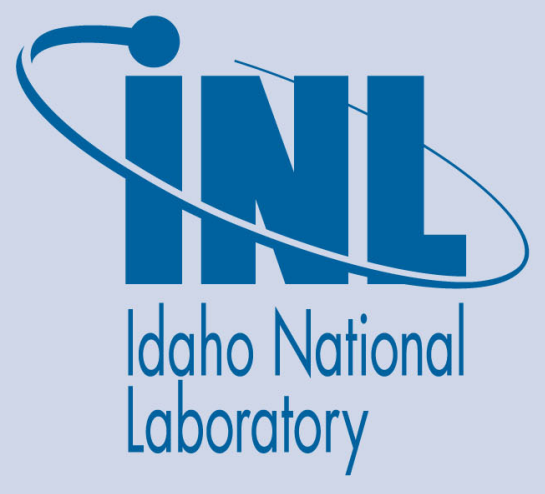

The INL is a U.S. Department of Energy National Laboratory operated by Battelle Energy Alliance 
INL/EXT-12-24628

\title{
Grotesque: Complex Geometric Arrangement of Unreflected HEU (93.15) Metal Pieces
}

\author{
Mackenzie L. Gorham \\ John D. Bess
}

September 2011

\section{Idaho National Laboratory \\ Idaho Falls, Idaho 83415}

http://www.inl.gov

Prepared for the

U.S. Department of Energy

Office of National Nuclear Security Administration

Under DOE Idaho Operations Office

Contract DE-AC07-05ID14517 


\title{
GROTESQUE: COMPLEX GEOMETRIC ARRANGEMENT OF UNREFLECTED HEU (93.15) METAL PIECES
}

\author{
Evaluators \\ Mackenzie L. Gorham \\ Idaho State University/ U.S. Department of Energy - Idaho \\ John D. Bess \\ Idaho National Laboratory \\ Internal Reviewers \\ John D. Bess \\ J. Blair Briggs \\ Idaho National Laboratory \\ Richard L. Dickson \\ U.S. Department of Energy - Idaho \\ Independent Reviewers \\ John T. Mihalczo \\ Oak Ridge National Laboratory \\ Daniel F. Hollenbach \\ Spectra Tech Inc.
}


NEA/NSC/DOC/(95)03/II

Volume II

HEU-MET-FAST-081

\section{GROTESQUE: COMPLEX GEOMETRIC ARRANGEMENT OF UNREFLECTED HEU (93.15) METAL PEICES}

IDENTIFICATION NUMBER: HEU-MET-FAST-081

SPECTRA

KEYWORDS: acceptable, bare, complex geometry, critical experiment, GROTESQUE, highlyenriched, unmoderated, unreflected, uranium

\subsection{DETAILED DESCRIPTION}

\subsection{Overview of Experiment}

The GROTESQUE experiments were designed specifically to develop and test neutronics for the GEOM subroutine of the $05 \mathrm{R}$ code. ${ }^{\mathrm{a}}$ Two complex arrangements of various highly enriched uranium metal cylinders, rectangular parallelepipeds, and spheres were arranged in a circular formation on a steel diaphragm. A centerpiece was raised remotely through a hole in the steel diaphragm to achieve criticality.

The first arrangement consisted of five major units, each major unit consisting of a stack of smaller uranium pieces. The second arrangement utilized nine major units, again consisting of stacks of smaller uranium pieces. The 9-unit arrangement is the only experiment discussed in this evaluation, since the five stack experiment never achieved criticality. The 9-unit arrangement is shown in Figure 1.1.

The experiments were performed at the Oak Ridge Critical Experiments Facility (ORCEF) in June 1964. The 9-unit configuration was later used as part of the development process for early versions of KENO and a model representing a variation of this experiment (Sample Problem 7: GROTESQUE without the Diaphragm) is released with modern versions of SCALE for testing the proper installation of the KENO module.

An experimental report for the GROTESQUE experiment has not been published; however there are two publications that describe the experiment (References 1 and 2). A separate report ${ }^{\mathrm{c}}$ discussing the conversion of the $05 \mathrm{r}$ model into a KENO model was published; however, the author did not consult with the experimenter for GROTESQUE. This report is considered unreliable (except for dimensions) by the experimenter and should not be used to obtain information pertinent to the GROTESQUE experiment. ${ }^{\text {d }}$ The Oak Ridge Critical Experiments Facility (ORCEF) Logbook 15r contains the primary documentation from the experimenter for this experiment. ${ }^{\mathrm{e}}$

The lower support structures were used in several other experiments, including those evaluated in HEU-MET-FAST-069 and HEU-MET-FAST-059. The upper support structure consisting of a thick aluminum plate is shown in Figure 8 of HEU-MET-FAST-076. The HEU metal cylinders were used

${ }^{a}$ D.C. Irving, et al. "05R, A General Purpose Monte Carlo Neutron Transport Code," ORNL-3622, Oak Ridge National Laboratory (1965). Dave Irving coined the name (GROTESQUE) for this assembly when he first saw the photograph.

${ }^{\text {b }}$ S. Goluoglu, D. F. Hollenbach, and L. M. Petrie, "CSAS6: Control Module for Enhanced Criticality Safety Analysis with KENO-VI,” ORNL/TM-2005/39 ver. 6, vol. I, sect. C6, Oak Ridge National Laboratory (2009).

c J. R. Knight, "GROTESQUE Without Tears," ORNL/CSD/TM-220, Oak Ridge National Laboratory (1984).

d Personal communication with John T. Mihalczo, April 2011.

' Oak Ridge Critical Experiments Facility Logbook 15r, "Book 4,” pp. 30-50. 


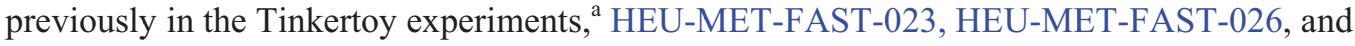
HEU-MET-FAST-054. The GROTESQUE arrangement of nine major units was evaluated and determined to be an acceptable benchmark experiment.

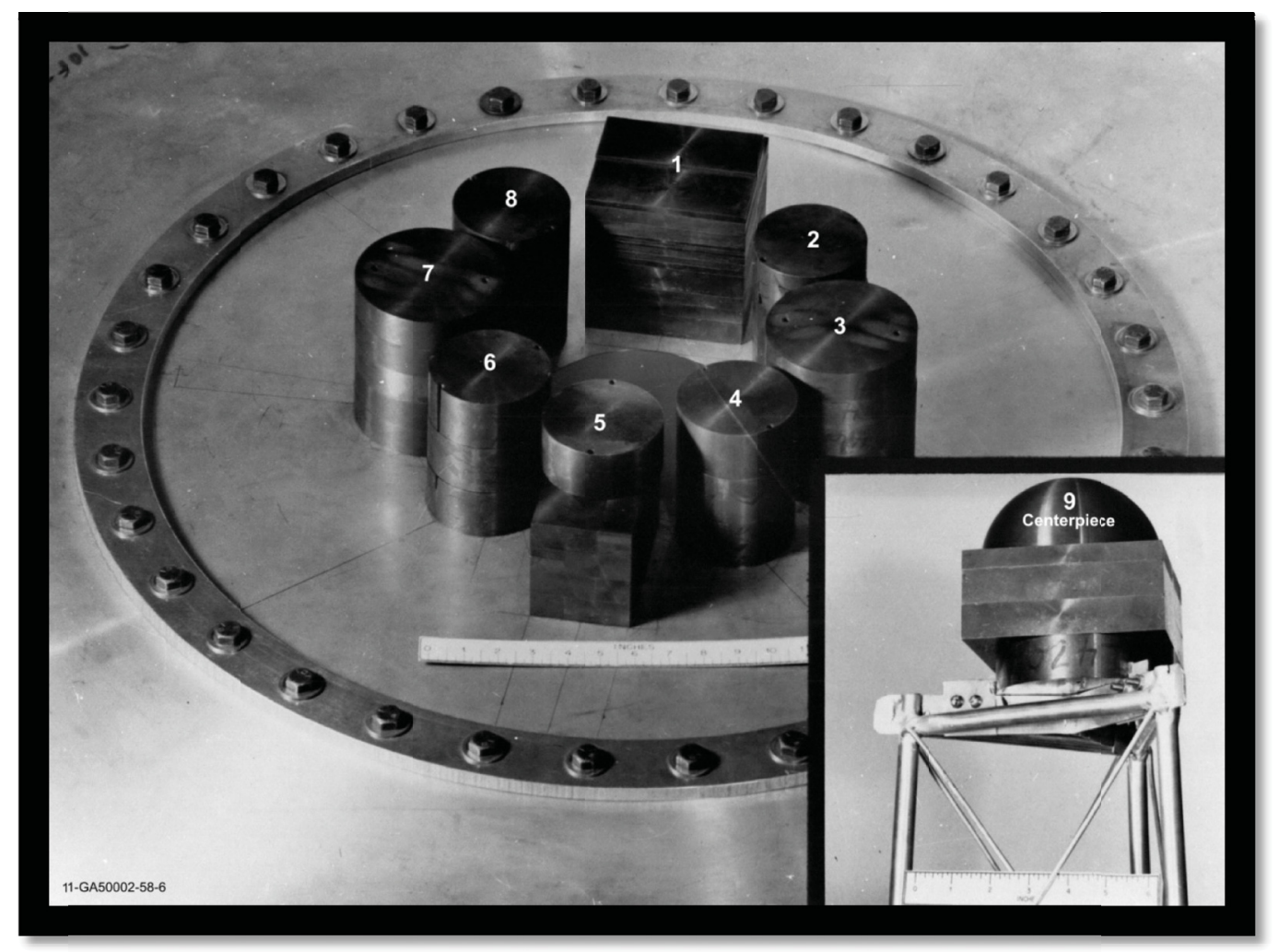

Figure 1.1. Photograph of GROTESQUE Experimental Assembly (inset not to scale). (Aluminum support plate is visible outside the clamping ring.)

\subsection{Description of Experimental Configuration}

1.2.1 HEU Units - This experiment uses nine numbered HEU units comprised of many smaller component pieces of HEU stacked together. The major units consist of six cylinder combinations; one irregular combination of three rectangular parallelepipeds (rpp); one hemisphere on top of a rectangular parallelepiped with a cylinder beneath it; and one cylinder and parallelepiped combination. There are two $0.508 \mathrm{~cm}$ diameter holes drilled through the cylinders at a spacing of $8.547 \mathrm{~cm}$ apart (as shown in Figures 1.2 through 1.10). All cylinders were located so that their holes were along a diameter through the center of the system. The 5-in. metal slabs used to assemble Units 1, 5, and 9 were reported to have been used in a previous experiment ${ }^{b}$ as well (Reference 3$){ }^{c}$ The experimenter that performed the experiments in HEU-MET-FAST-056 reported the densities of the cylinders as slightly lower than they actually are, because the small holes were calculated as having been homogenized into the units.

\footnotetext{
${ }^{\text {a }}$ Personal communication between J. Blair Briggs and John Mihalczo, July 2010.

b J. T. Mihalczo and J. J. Lynn, "Critical Parameters of Bare and Reflected 93.4 wt.\% U235-Enriched Uranium Metal Slabs,” ORNL-3016, Oak Ridge National Laboratory (December 1960), p. 73-76.

${ }^{c}$ ORCEF Logbooks 119R and 116R.
} 
HEU-MET-FAST-081

Table 1.1 contains the dimensions for each of the nine major units; in the cases of more complex geometries, Table 1.1 refers to the largest outer dimensions. The dimensions of the smaller component pieces were recorded in the experimental logbook, ${ }^{\mathrm{a}}$ and are shown in Tables 1.2 through 1.10. The order in which the smaller component pieces were stacked to create the larger major units is not specified, except for the centerpiece, which is clearly labeled in the logbook. ${ }^{b}$

Table 1.1. Nominal Dimensions of the Major HEU Units in $\mathrm{cm}^{(\mathrm{a}, \mathrm{b})}$

\begin{tabular}{|c|c|c|c|c|c|}
\hline $\begin{array}{c}\text { Unit } \\
\text { Number }\end{array}$ & Description & $\begin{array}{c}X \\
\text { Dimension } \\
\end{array}$ & $\begin{array}{c}\mathrm{Y} \\
\text { Dimension } \\
\end{array}$ & $\begin{array}{c}\mathrm{Z} \text { Dimension } \\
\text { (height) }\end{array}$ & Diameter \\
\hline 1 & $\begin{array}{l}\text { Irregular } \\
\mathrm{RPP}^{(\mathrm{c})}\end{array}$ & 12.703 & 12.703 & $13.377^{(\mathrm{d})}$ & - \\
\hline 2 & Cylinder & - & - & 12.918 & 9.111 \\
\hline 3 & Cylinder & - & - & 13.475 & 11.522 \\
\hline 4 & Cylinder & - & - & 12.969 & 9.105 \\
\hline 5 & $\begin{array}{l}\text { Complex } \\
\text { RPP }\end{array}$ & 12.703 & 7.620 & $13.229^{(\mathrm{d})}$ & $9.146^{(\mathrm{e})}$ \\
\hline 6 & Cylinder & - & - & 12.974 & 9.109 \\
\hline 7 & Cylinder & - & - & 13.475 & 11.499 \\
\hline 8 & Cylinder & - & - & 12.954 & 9.113 \\
\hline 9 & Centerpiece $^{(\mathrm{f})}$ & - & - & - & - \\
\hline
\end{tabular}

(a) ORCEF Logbook 15r, p. 44.

(b) J. R. Knight, "GROTESQUE Without Tears," ORNL/CSD/TM-220, Oak Ridge National Laboratory (1984).

(c) Rectangular Parallelepiped.

(d) Dimension for highest point of stack.

(e) The radius applied to the cylinder stacked on the RPP; refer to Figure 1.6 for clarification.

(f) The centerpiece is a complex combination of several units, and is described in Figure 1.10.

Figures 1.2 through 1.10 are detailed depictions of the major units. Please note that although in Figures 1.2 through 1.10 the units appear solid, many were actually stacks of smaller component pieces (see Figure 1.1).

Tables 1.2 through 1.10 summarize the dimensions of the component pieces that comprise each unit. Only nominal dimensions in inches, which were rounded, are provided for each individual piece. The overall dimensions in Figures 1.2 through 1.10 for each unit are more precisely known and are reported in centimeters. ${ }^{\mathrm{c}}$ Nominal part dimensions and masses were obtained from the experimental logbook. ${ }^{\mathrm{d}}$ Nominal dimensions for slabs were reported in Reference 3 as well; however, the manufacturing tolerances were reported as $\pm 0.002 \mathrm{in}$. The actual dimensional tolerances at $\mathrm{Y}-12$ machining during this time period were certainly less than 0.002 in. $^{\mathrm{e}}$

\footnotetext{
${ }^{\text {a }}$ ORCEF Logbook 15r, pp. 30-49.

${ }^{\mathrm{b}}$ ORCEF Logbook 15r, p. 44.

c J. R. Knight, "GROTESQUE Without Tears," ORNL/CSD/TM-220, Oak Ridge National Laboratory (1984).

${ }^{\mathrm{d}}$ ORCEF Logbook 15r, pp. 44-45.

${ }^{\mathrm{e}}$ Personal communication with John T. Mihalczo, August 2011.
} 
HEU-MET-FAST-081

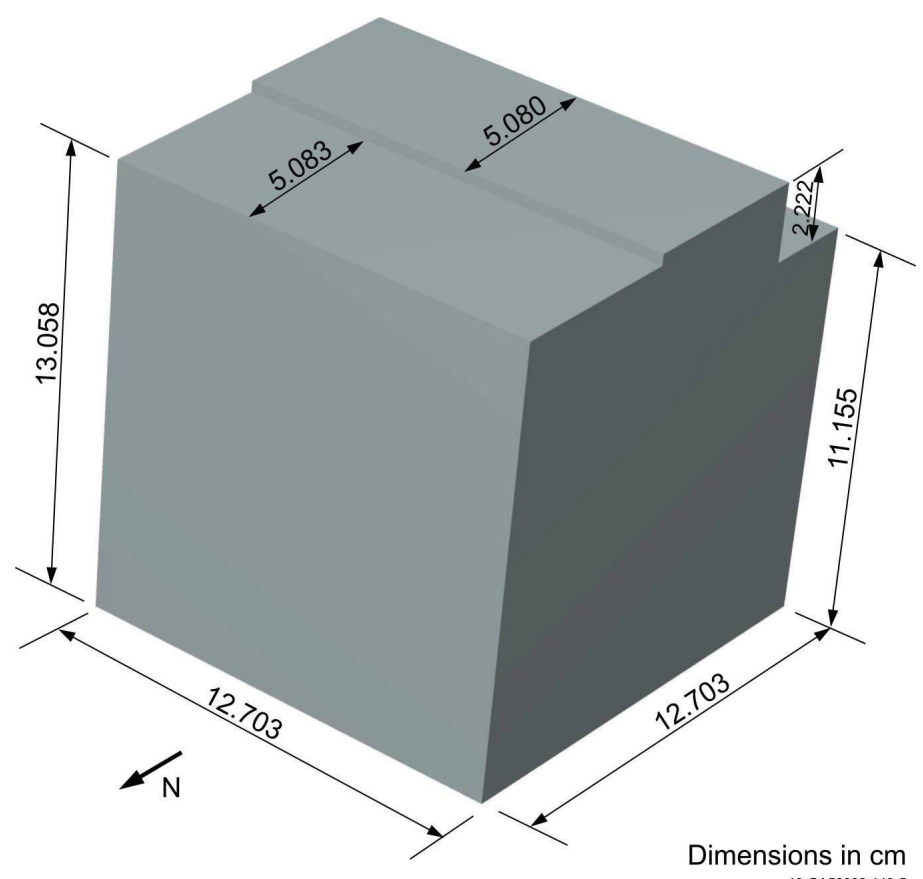

Figure 1.2. Unit 1.

Table 1.2. Nominal Dimensions of Unit 1 Component Pieces.

\begin{tabular}{|c|c|c|c|c|c|}
\hline $\begin{array}{c}\text { Part } \\
\text { Number }\end{array}$ & Type & $\begin{array}{c}\text { Length } \\
\text { (in.) }\end{array}$ & $\begin{array}{c}\text { Width } \\
\text { (in.) }\end{array}$ & $\begin{array}{c}\text { Height } \\
\text { (in.) }^{(\mathbf{a})}\end{array}$ & $\begin{array}{c}\text { Mass } \\
\text { (g) }\end{array}$ \\
\hline 1011 & $\mathrm{rpp}$ & 5 & 5 & $7 / 8$ & 6689 \\
\hline 0971 & $\mathrm{rpp}$ & 5 & 5 & $1 / 2$ & 3827 \\
\hline 0970 & $\mathrm{rpp}$ & 3 & 5 & $1 / 2$ & 3822 \\
\hline 1010 & $\mathrm{rpp}$ & 5 & 5 & $7 / 8$ & 6695 \\
\hline 0950 & $\mathrm{rpp}$ & 3 & 5 & $1 / 4$ & 1916 \\
\hline 0955 & $\mathrm{rpp}$ & 3 & 5 & $1 / 4$ & 1916 \\
\hline 1023 & $\mathrm{rpp}$ & 2 & 5 & $1 / 8$ & 963 \\
\hline 1024 & $\mathrm{rpp}$ & 2 & 5 & $1 / 8$ & 963 \\
\hline 1048 & $\mathrm{rpp}$ & 2 & 5 & $1 / 8$ & 961 \\
\hline 0957 & $\mathrm{rpp}$ & 3 & 5 & $1 / 4$ & 1918 \\
\hline 1916 & $\mathrm{rpp}$ & 3 & 5 & $1 / 2$ & 3846 \\
\hline 0974 & $\mathrm{rpp}$ & 3 & 5 & $1 / 5$ & 1534 \\
\hline 0975 & $\mathrm{rpp}$ & 3 & 5 & $1 / 5$ & 1533 \\
\hline 0948 & $\mathrm{rpp}$ & 2 & 5 & $1 / 10$ & 765 \\
\hline 0960 & $\mathrm{rpp}$ & 2 & 5 & $1 / 10$ & 768 \\
\hline 0995 & $\mathrm{rpp}$ & 1 & 5 & $1 / 10$ & 381 \\
\hline
\end{tabular}

(a) Nominal heights (Personal communication with John T. Mihalczo, August 2011. 
NEA/NSC/DOC/(95)03/II

Volume II

HEU-MET-FAST-081
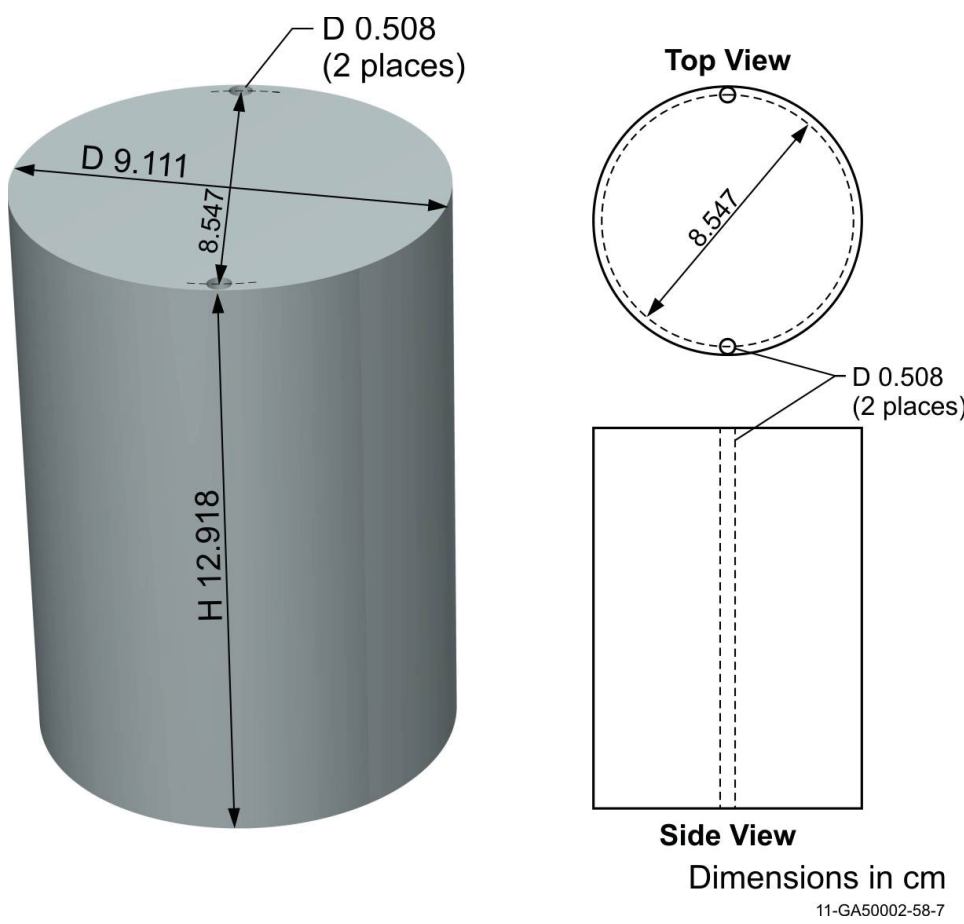

Figure 1.3. Unit 2.

Table 1.3. Nominal Dimensions of Unit 2 Component Pieces.

\begin{tabular}{|c|c|c|c|c|}
\hline $\begin{array}{c}\text { Part } \\
\text { Number }\end{array}$ & Type & $\begin{array}{c}\text { Height } \\
\text { (in.) }\end{array}$ & $\begin{array}{c}\text { Diameter } \\
\text { (in.) }\end{array}$ & $\begin{array}{c}\text { Mass } \\
\text { (g) }\end{array}$ \\
\hline \hline 2284 & Cylinder & 1.7 & 3.57 & 5195 \\
\hline 2285 & Cylinder & 1.7 & 3.57 & 5287 \\
\hline 2286 & Cylinder & 1.7 & 3.57 & 5286 \\
\hline
\end{tabular}


NEA/NSC/DOC/(95)03/II

Volume II

HEU-MET-FAST-081
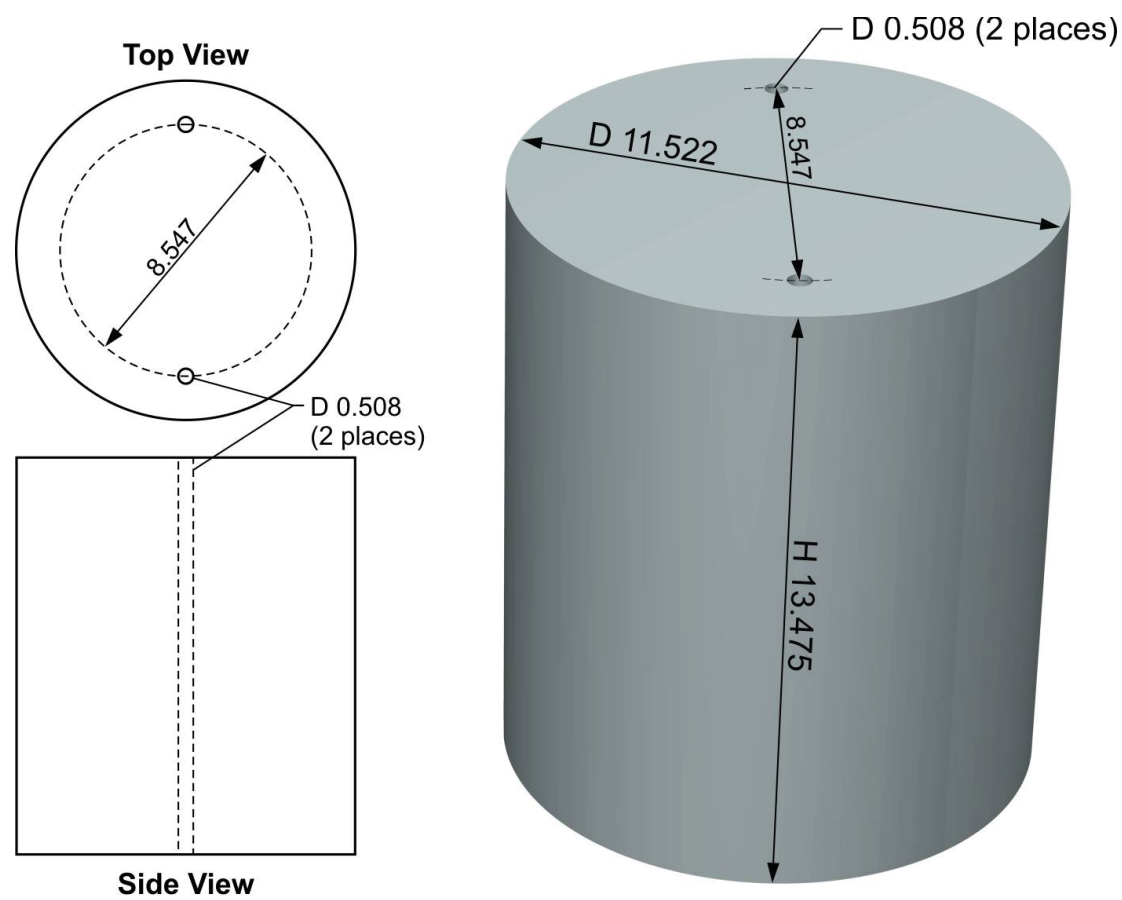

Dimensions in $\mathrm{cm}$ 11-GA50002-58-8

Figure 1.4. Unit 3.

Table 1.4. Nominal Dimensions of Unit 3 Component Pieces.

\begin{tabular}{|c|c|c|c|c||}
\hline $\begin{array}{c}\text { Part } \\
\text { Number }\end{array}$ & Type & $\begin{array}{c}\text { Height } \\
\text { (in.) }\end{array}$ & $\begin{array}{c}\text { Diameter } \\
\text { (in.) }\end{array}$ & $\begin{array}{c}\text { Mass } \\
\text { (g) }\end{array}$ \\
\hline \hline 2460 & Cylinder & 1.06 & 4.53 & 5250 \\
\hline 2462 & Cylinder & 1.06 & 4.53 & 5237 \\
\hline 2463 & Cylinder & 1.06 & 4.53 & 5258 \\
\hline 2464 & Cylinder & 1.06 & 4.53 & 5219 \\
\hline 2466 & Cylinder & 1.06 & 4.53 & 5252 \\
\hline
\end{tabular}


NEA/NSC/DOC/(95)03/II

Volume II

HEU-MET-FAST-081
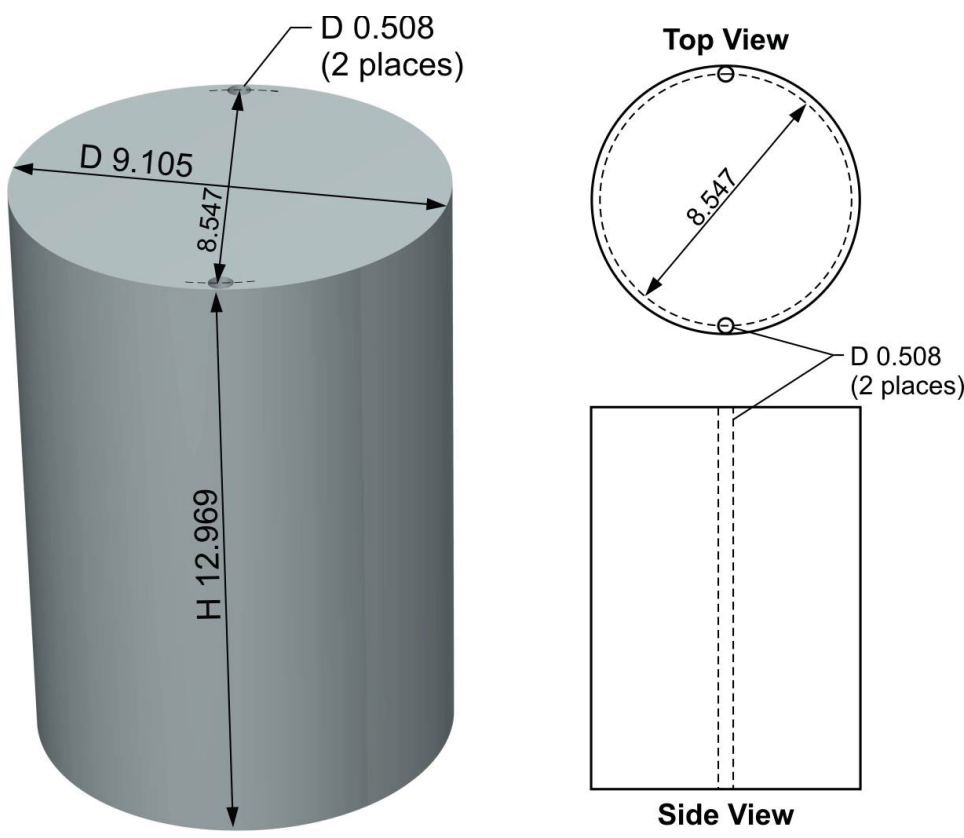

Dimensions in $\mathrm{cm}$ 11-GA50002-58-7

Figure 1.5. Unit 4.

Table 1.5. Nominal Dimensions of Unit 4 Component Pieces.

\begin{tabular}{|c|c|c|c|c||}
\hline $\begin{array}{c}\text { Part } \\
\text { Number }\end{array}$ & Type & $\begin{array}{c}\text { Height } \\
\text { (in.) }\end{array}$ & $\begin{array}{c}\text { Diameter } \\
\text { (in.) }\end{array}$ & $\begin{array}{c}\text { Mass } \\
\text { (g) }\end{array}$ \\
\hline \hline 2278 & Cylinder & 1.7 & 3.57 & 5267 \\
\hline 2279 & Cylinder & 1.7 & 3.57 & 5219 \\
\hline 2280 & Cylinder & 1.7 & 3.57 & 5234 \\
\hline
\end{tabular}


NEA/NSC/DOC/(95)03/II

Volume II

HEU-MET-FAST-081

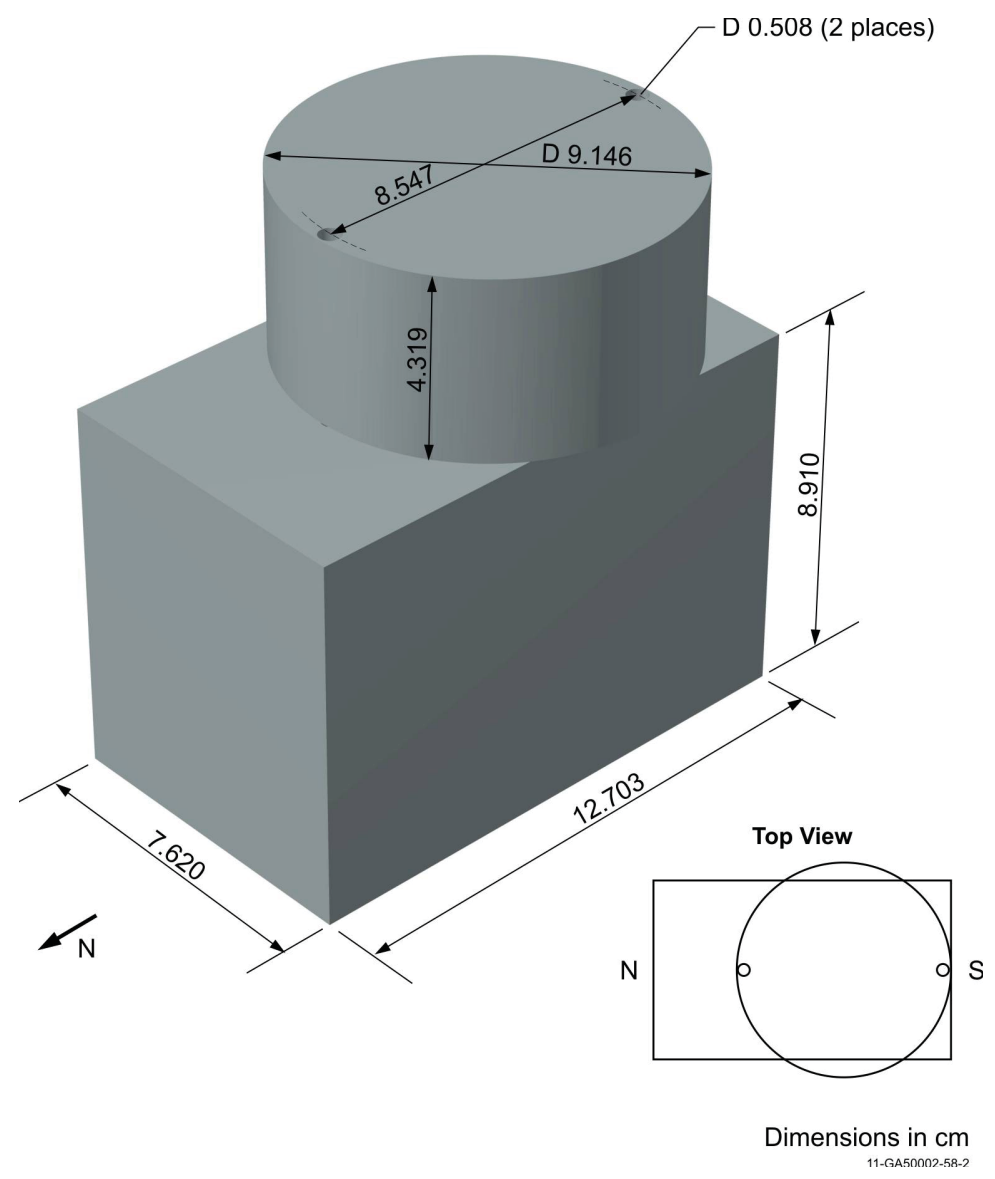

Figure 1.6. Unit 5.

(The cylinder was aligned along the center of the block with its edge flush with the end of the block.) 
NEA/NSC/DOC/(95)03/II

Volume II

HEU-MET-FAST-081

Table 1.6. Nominal Dimensions of Unit 5 Component Pieces.

\begin{tabular}{|c|c|c|c|c|c|c||}
\hline $\begin{array}{c}\text { Part } \\
\text { Number }\end{array}$ & Type & $\begin{array}{c}\text { Length } \\
\text { (in.) }\end{array}$ & $\begin{array}{c}\text { Width } \\
\text { (in.) }\end{array}$ & $\begin{array}{c}\text { Height } \\
\text { (in.) }^{(\mathbf{a})}\end{array}$ & $\begin{array}{c}\text { Diameter } \\
\text { (in.) }\end{array}$ & $\begin{array}{c}\text { Mass } \\
\text { (g) }\end{array}$ \\
\hline \hline 945 & $\mathrm{rpp}$ & 5 & 2 & - & - & 2679 \\
\hline 943 & $\mathrm{rpp}$ & 5 & 2 & - & - & 2680 \\
\hline 944 & $\mathrm{rpp}$ & 5 & 2 & - & - & 2682 \\
\hline 946 & $\mathrm{rpp}$ & 5 & 2 & - & - & 2682 \\
\hline 1085 & $\mathrm{rpp}$ & 5 & 1 & - & - & 1346 \\
\hline 942 & $\mathrm{rpp}$ & 5 & 1 & - & - & $1341^{(\mathrm{b})}$ \\
\hline 979 & $\mathrm{rpp}$ & 5 & 1 & - & - & 769 \\
\hline 962 & $\mathrm{rpp}$ & 5 & 1 & - & - & 383 \\
\hline 1032 & $\mathrm{rpp}$ & 5 & 1 & - & - & 192 \\
\hline 978 & $\mathrm{rpp}$ & 5 & 1 & - & - & 768 \\
\hline 963 & $\mathrm{rpp}$ & 5 & 1 & - & - & 383 \\
\hline 1014 & $\mathrm{rpp}$ & 5 & 1 & - & - & 193 \\
\hline 2572 & cylinder & - & - & 1.7 & 3.57 & 5286 \\
\hline
\end{tabular}

(a) Height measurements were not provided for each piece. Slab piece heights could be $7 / 8,1 / 2,1 / 4$, or $1 / 8$ in. (Reference 3 ).

(b) Page 36 of the experimental logbook lists this value as $1161 \mathrm{~g}$ whereas Page 45 lists the value as $1341 \mathrm{~g}$. The correct value was $1341 \mathrm{~g}$. 
NEA/NSC/DOC/(95)03/II

Volume II

HEU-MET-FAST-081
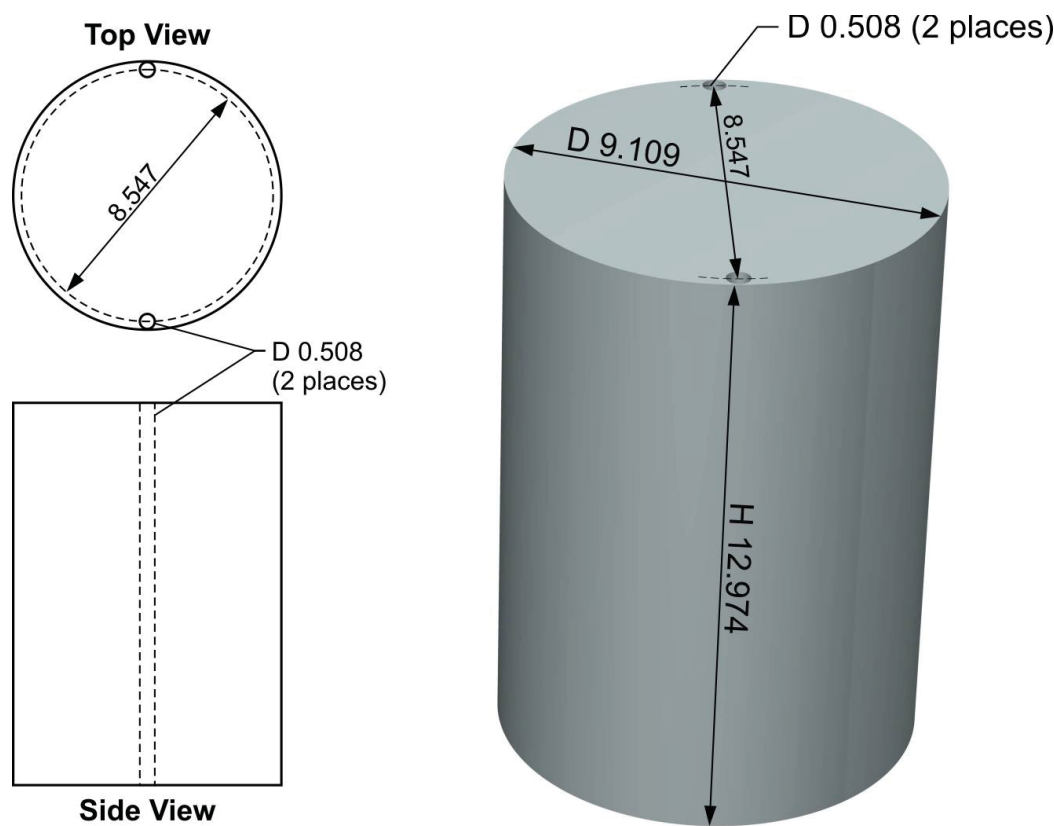

Dimensions in $\mathrm{cm}$ 11-GA.50กก?-58-8

Figure 1.7. Unit 6.

Table 1.7. Dimensions of Unit 6 Component Pieces.

\begin{tabular}{|c|c|c|c|c|}
\hline $\begin{array}{c}\text { Part } \\
\text { Number }\end{array}$ & Type & $\begin{array}{c}\text { Height } \\
\text { (in.) }\end{array}$ & $\begin{array}{c}\text { Diameter } \\
\text { (in.) }\end{array}$ & $\begin{array}{c}\text { Mass } \\
\text { (g) }\end{array}$ \\
\hline \hline 2281 & cylinder & 1.7 & 3.57 & 5259 \\
\hline 2282 & cylinder & 1.7 & 3.57 & 5220 \\
\hline 2283 & cylinder & 1.7 & 3.57 & 5248 \\
\hline
\end{tabular}


NEA/NSC/DOC/(95)03/II

Volume II

HEU-MET-FAST-081
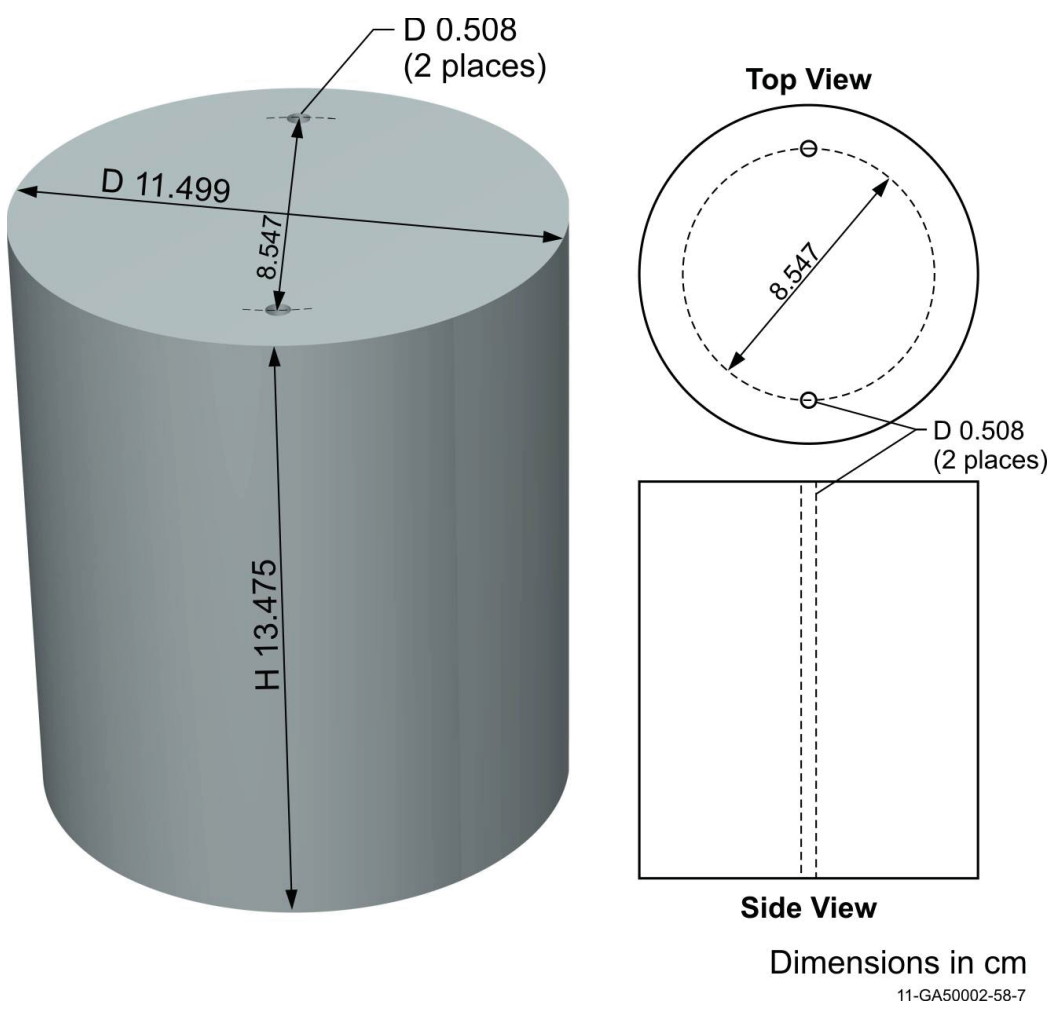

Figure 1.8. Unit 7.

Table 1.8. Nominal Dimensions of Unit 7 Component Pieces.

\begin{tabular}{|c|c|c|c|c||}
\hline $\begin{array}{c}\text { Part } \\
\text { Number }\end{array}$ & Type & $\begin{array}{c}\text { Height } \\
\text { (in.) }\end{array}$ & $\begin{array}{c}\text { Diameter } \\
\text { (in.) }\end{array}$ & $\begin{array}{c}\text { Mass } \\
\text { (g) }\end{array}$ \\
\hline \hline 2467 & cylinder & 1.06 & 4.53 & 5251 \\
\hline 2468 & cylinder & 1.06 & 4.53 & 5224 \\
\hline 2469 & cylinder & 1.06 & 4.53 & 5217 \\
\hline 2471 & cylinder & 1.06 & 4.53 & 5226 \\
\hline 2472 & cylinder & 1.06 & 4.53 & 5242 \\
\hline
\end{tabular}


NEA/NSC/DOC/(95)03/II

Volume II

HEU-MET-FAST-081
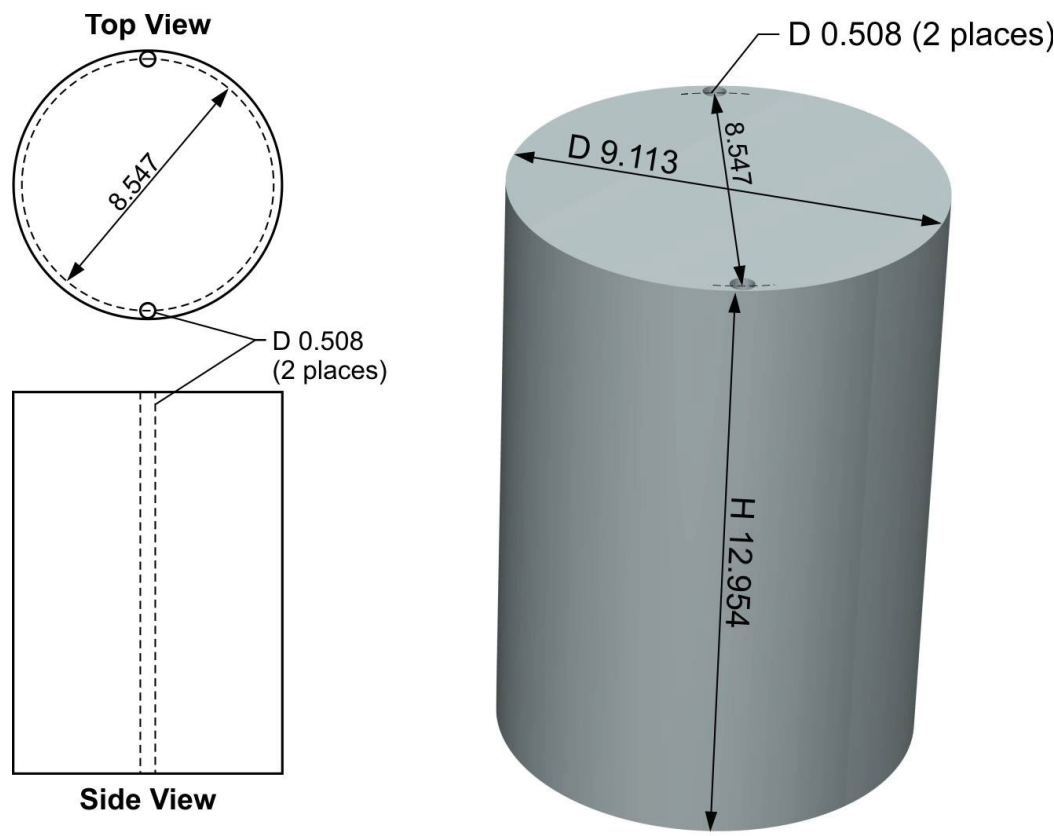

Side View

Dimensions in $\mathrm{cm}$

11-GA50002-58-8

Figure 1.9. Unit 8.

Table 1.9. Nominal Dimensions of Unit 8 Component Pieces.

\begin{tabular}{|c|c|c|c|c|}
\hline $\begin{array}{c}\text { Part } \\
\text { Number }\end{array}$ & Type & $\begin{array}{c}\text { Height } \\
\text { (in.) }\end{array}$ & $\begin{array}{c}\text { Diameter } \\
\text { (in.) }\end{array}$ & $\begin{array}{c}\text { Mass } \\
\text { (g) }\end{array}$ \\
\hline \hline 2571 & cylinder & 1.7 & 3.57 & 5231 \\
\hline 2276 & cylinder & 1.7 & 3.57 & 5254 \\
\hline 2277 & cylinder & 1.7 & 3.57 & 5270 \\
\hline
\end{tabular}



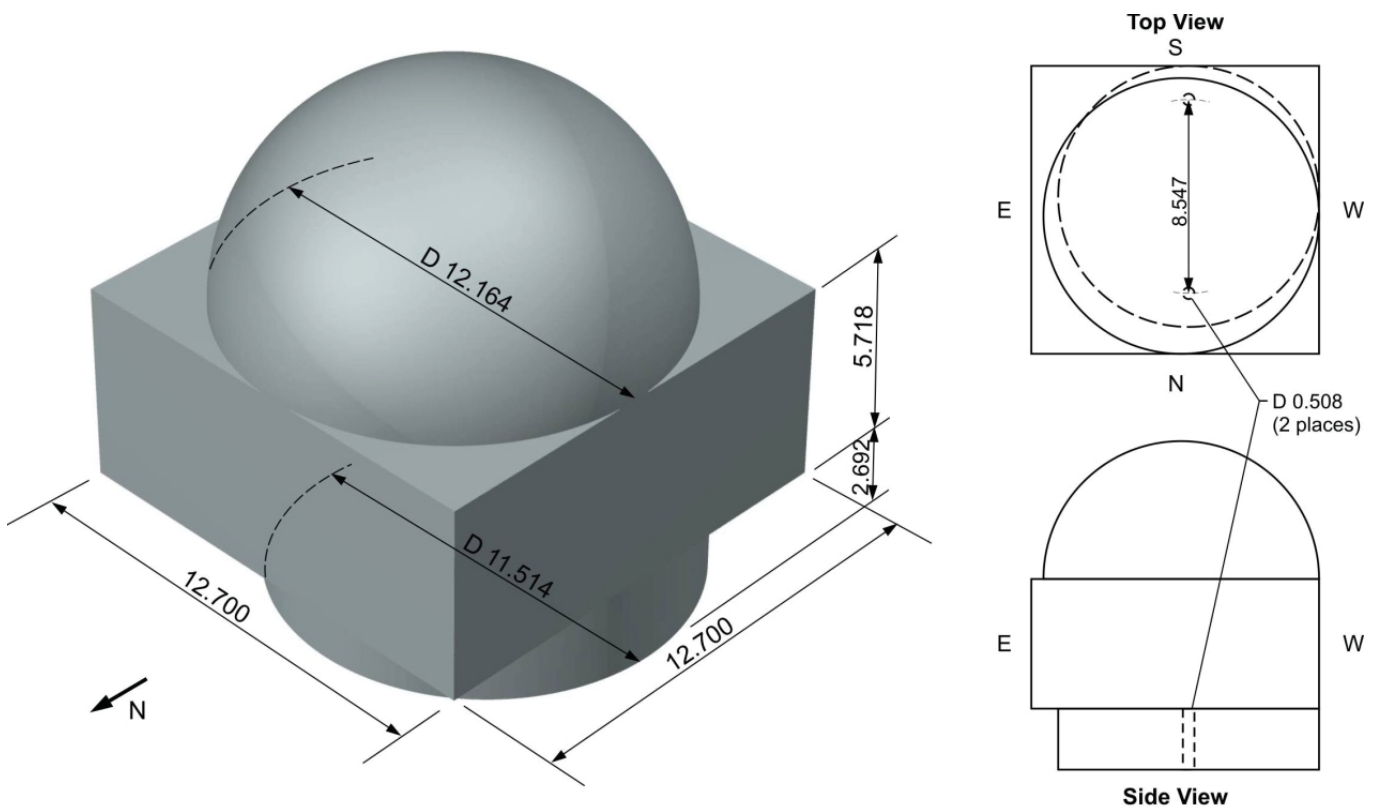

Dimensions in $\mathrm{cm}$ 10-GA50002-143-3

Figure 1.10. Unit 9 (Centerpiece).

Table 1.10. Nominal Dimensions of Unit 9 Component Pieces.

\begin{tabular}{|c|c|c|c|c|c|c||}
\hline $\begin{array}{c}\text { Part } \\
\text { Number }\end{array}$ & Type & $\begin{array}{c}\text { Length } \\
\text { (in.) }\end{array}$ & $\begin{array}{c}\text { Width } \\
\text { (in.) }\end{array}$ & $\begin{array}{c}\text { Height } \\
\text { (in.) }\end{array}$ & $\begin{array}{c}\text { Diameter } \\
\text { (in.) }\end{array}$ & $\begin{array}{c}\text { Mass } \\
\text { (g) }\end{array}$ \\
\hline \hline 2470 & cylinder & - & - & 1.06 & 4.53 & 5247 \\
\hline 1008 & rpp & 5 & 5 & $7 / 8$ & - & 6693 \\
\hline 1012 & rpp & 5 & 5 & $7 / 8$ & - & 6684 \\
\hline 967 & rpp & 5 & 5 & $1 / 2$ & - & 3833 \\
\hline 3380 & hemisphere & - & - & - & 4.8 & 8838 \\
\hline
\end{tabular}

The experimenter rounded in some cases when reporting the summed total mass for each unit in the logbook. The most accurate total mass is calculated by adding the mass reported in the logbook for each of the individual component pieces without rounding, which is the procedure used in this report. 
HEU-MET-FAST-081

It should be noted that the large mass of the HEU units caused the steel diaphragm that supported them to sag when all the units were placed on the assembly. This caused the pieces to be slightly tilted towards the center of the assembly. The tilt angle for each major unit is described in Table 1.11. ${ }^{\mathrm{a}}$

Tilt angles were measured using a dial gauge accurate to one-thousandth of an inch to determine the deflection of the units due to the diaphragm sag. The placement of the units was also measured. Reported uncertainty in the measurement of the deflection of the steel diaphragm is $0.005 \mathrm{in} .(0.0127 \mathrm{~cm})$ and the uncertainty in the placement of the HEU units is 0.010 in. $(0.0254 \mathrm{~cm}){ }^{\mathrm{b}}$ The distance from the hole in the diaphragm to the bottom face of Units 1 through 8 were $0.750,0.624,0.579,0.365,0.755$, $0.380,0.588$, and 0.591 in., respectively. ${ }^{\mathrm{c}}$

Table 1.11. Measured Tilt Angle for HEU Units. ${ }^{(a)}$

\begin{tabular}{|c|c|c|c|c|c|c|c|c|c|}
\hline \hline Unit & 1 & 2 & 3 & 4 & 5 & 6 & 7 & 8 & 9 \\
\hline $\begin{array}{c}\text { Tilt } \\
\text { Angle } \\
(\mathbf{(})\end{array}$ & 1.350 & 1.400 & 1.173 & 1.970 & 2.580 & 1.680 & 1.400 & 1.100 & 0.0 \\
\hline \hline
\end{tabular}

(a) Knight, J.R., “GROTESQUE Without Tears,” ORNL/CSD/TM-220, Oak Ridge National Laboratory (1984). The values were calculated using the measurements reported in the previous paragraph and unit dimensions.

1.2.2 Steel Diaphragm - The stainless steel diaphragm is 10 mil thick $(0.0254 \mathrm{~cm})$ and secured by a clamping ring apparatus bolted to a 0.50-in.-thick aluminum plate (see Figure 1.12) that has a 30 in. (76.2 $\mathrm{cm})$ inside diameter. ${ }^{\mathrm{d}}$ There is a 7.25 in. $(18.415 \mathrm{~cm})$ diameter hole cut in the center of the diaphragm through which the centerpiece is passed via remote operation. ${ }^{\mathrm{b}}$ The diaphragm support assembly was used in other ORCEF benchmark experiments, including HEU-MET-FAST-076. The Vertical Assembly Machine used to support the aluminum plate is shown in Figure 1.11.

1.2.3 Other Supports - Certain components from this experiment were used in other benchmark experiments (HEU-MET-FAST-059 and HEU-MET-FAST-069). The detailed drawings of the lower support stand that held the centerpiece is provided as Figure 17 in HEU-MET-FAST-059. The apparatus used in this experiment (see Figure 1.11) was a "vertical assembly machine, which primarily consisted of a hydraulic lift (22-inch vertical motion) to support the lower section and a stationary upper section." A typical support structure for bare HEU experiments performed at the ORCEF is shown in Figure 1.12. A low mass lower support stand like the one mounted on the vertical lift in Figure 1.12 was also mounted on the vertical lift for this measurement. The upper support apparatus shown in Figure 1.11 held an aluminum plate with a 30 -in.-diameter hole. The interior of this plate was machined to accept the clamping ring which, when attached (bolted), held the stainless steel (304L) diaphragm in place and in tension. $^{\mathrm{e}}$ The plate was shaped to hold the diaphragm in tension when the bolts were tightened in a prescribed manner. ${ }^{\mathrm{f}}$

\footnotetext{
a Personal communication with John T. Mihalczo, May 2010; use angle values reported in J. R. Knight, “GROTESQUE Without Tears,” ORNL/CSD/TM-220, Oak Ridge National Laboratory (1984).

${ }^{\mathrm{b}}$ Personal communication with John T. Mihalzco, August 2010.

${ }^{\mathrm{c}}$ ORCEF Logbook 15r, p 44.

${ }^{\mathrm{d}}$ ORCEF Logbook 15r, p. 35.

e Personal communication with John T. Mihalzco, April 2011.

${ }^{\mathrm{f}}$ Personal communication with John T. Mihalczo, August 2011.
} 


\section{NEA/NSC/DOC/(95)03/II \\ Volume II}

HEU-MET-FAST-081

The entire support structure consisted of at least a support plate, a support ring, and a support stand, in addition to the diaphragm discussed in Section 1.2.2. There are measurements recorded in the logbook that were performed to determine the worth of the different support structures. ${ }^{\mathrm{a}}$ The diaphragm was measured individually to be worth $10.19 \phi$ of reactivity $^{\mathrm{b}}$ and the entire support structure was valued at $10.2 \varnothing$ of reactivity. An additional measurement using two 10-mil diaphragms was also reported. The second diaphragm was attached under the first one; since it was so light compared to what was on the diaphragm already, it did not change the deflection. This configuration was used to measure the worth of the diaphragms as $19.29 \notin$. Those measurements clearly show that the diaphragm is the primary contributor to the worth of the support structures.

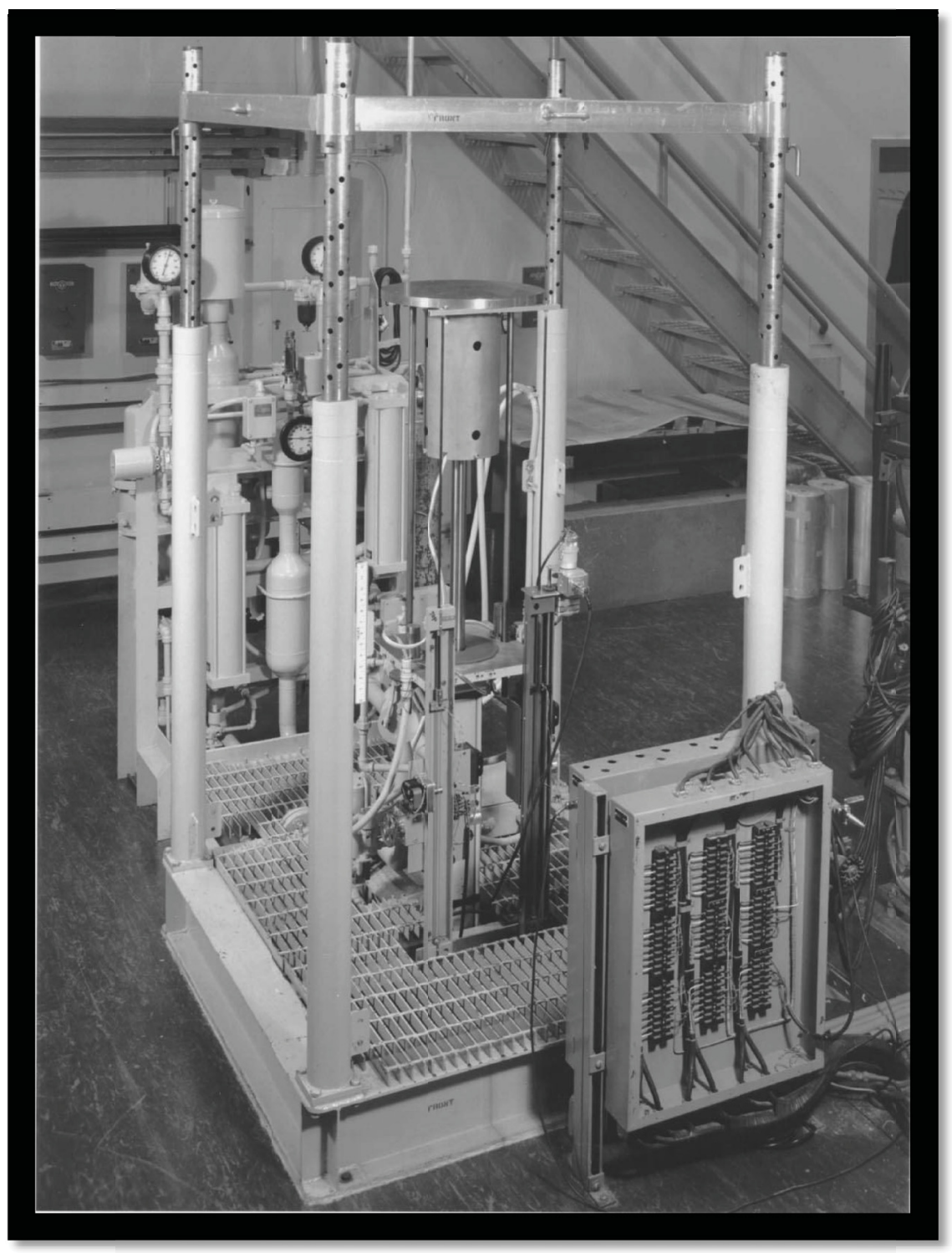

Figure 1.11. Photograph of the Vertical Assembly Machine.

(The upper support shown was used to hold the 0.5 -in.-thick aluminum plate that supported the upper section for this experiment and a low mass support stand was mounted on the vertical lift.)

\footnotetext{
${ }^{a}$ ORCEF Logbook 15r, p. 49.

${ }^{\mathrm{b}}$ ORCEF Logbook 15r, p. 48.
} 


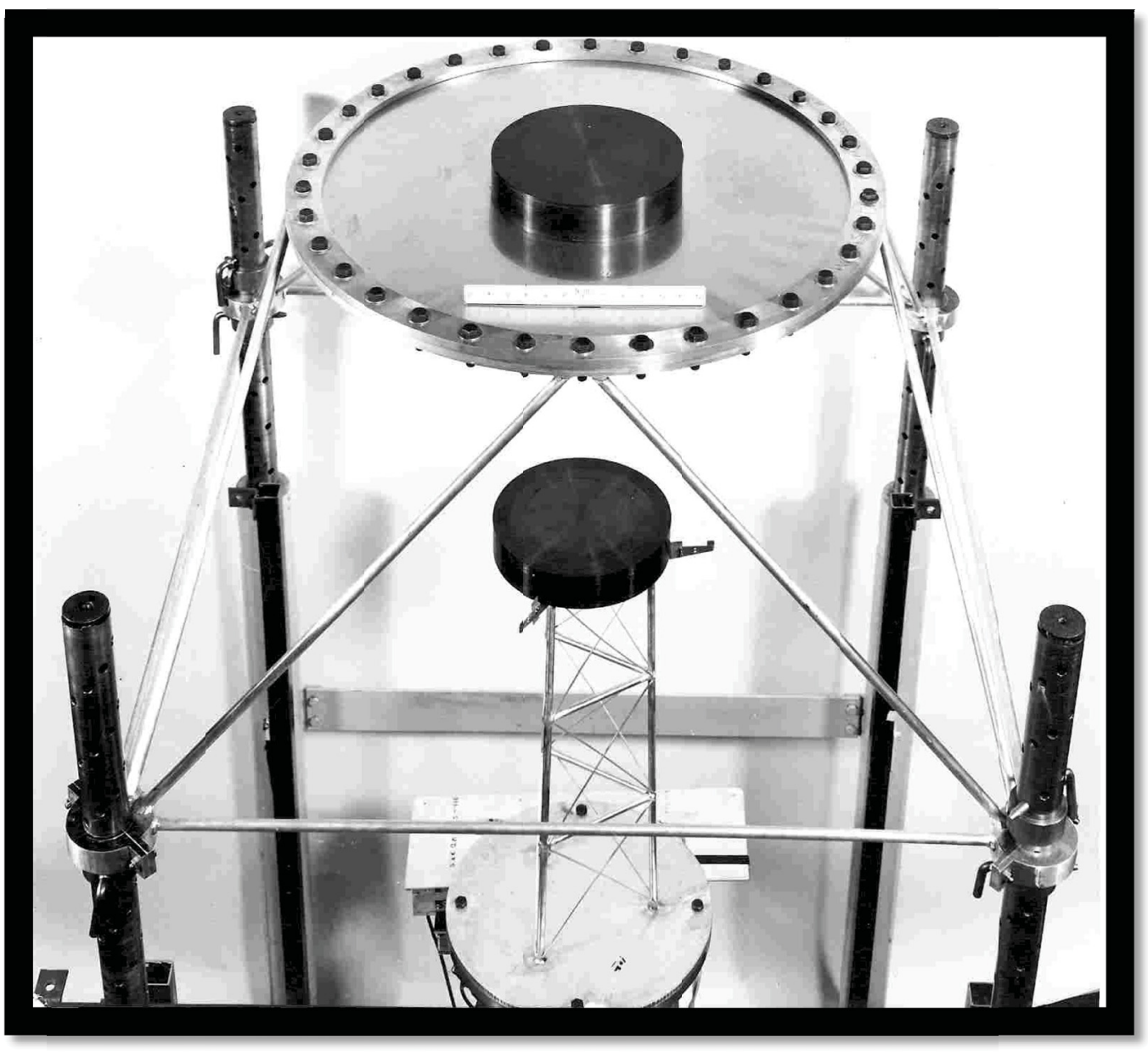

Figure 1.12. A Typical Uranium Metal Assembly of Two Interacting 11-inch -Diameter Cylinders at Close Spacing on the Vertical Assembly Machine. ${ }^{\mathrm{a}}$ (The experiment shown is an example of the typical support structure used and does not represent the actual GROTESQUE experiment except for the lower support stand, vertical lift, and four support poles.)

1.2.4 Assembly Description - The pieces were arranged in a circular manner on a thin steel diaphragm with a hole through its center, as shown in Figure 1.1. The inset on the figure shows the centerpiece, and is not to scale; however, it is comparable in size to the other major units.

The centerpiece rises through the hole that is slightly visible in the center of the major units in Figure 1.1. Raising the centerpiece from the bottom side of the diaphragm into the ring of HEU units to increase the system $\mathrm{k}_{\mathrm{eff}}$ was done remotely.

Figure 1.13 shows the top view of the experimental configuration, as well as the numbering scheme for the major units. The north-pointing arrow aligns with the y-axis and dimensions presented in tables reflect this. The upper dimension refers to the distance of the base of the units from the corresponding axis. The lower dimension reported indicate the distance to the midplane of the unit. Figure 1.13 was created using the information from Table 1.12 to determine the coordinates of each unit and its placement

\footnotetext{
${ }^{\text {a }}$ Photo 39380, Oak Ridge National Laboratory photo of a bare uranium assembly.
} 


\section{NEA/NSC/DOC/(95)03/II \\ Volume II}

HEU-MET-FAST-081

within the circle of units. This information is from the primary reference and detailed sketches in the logbook.

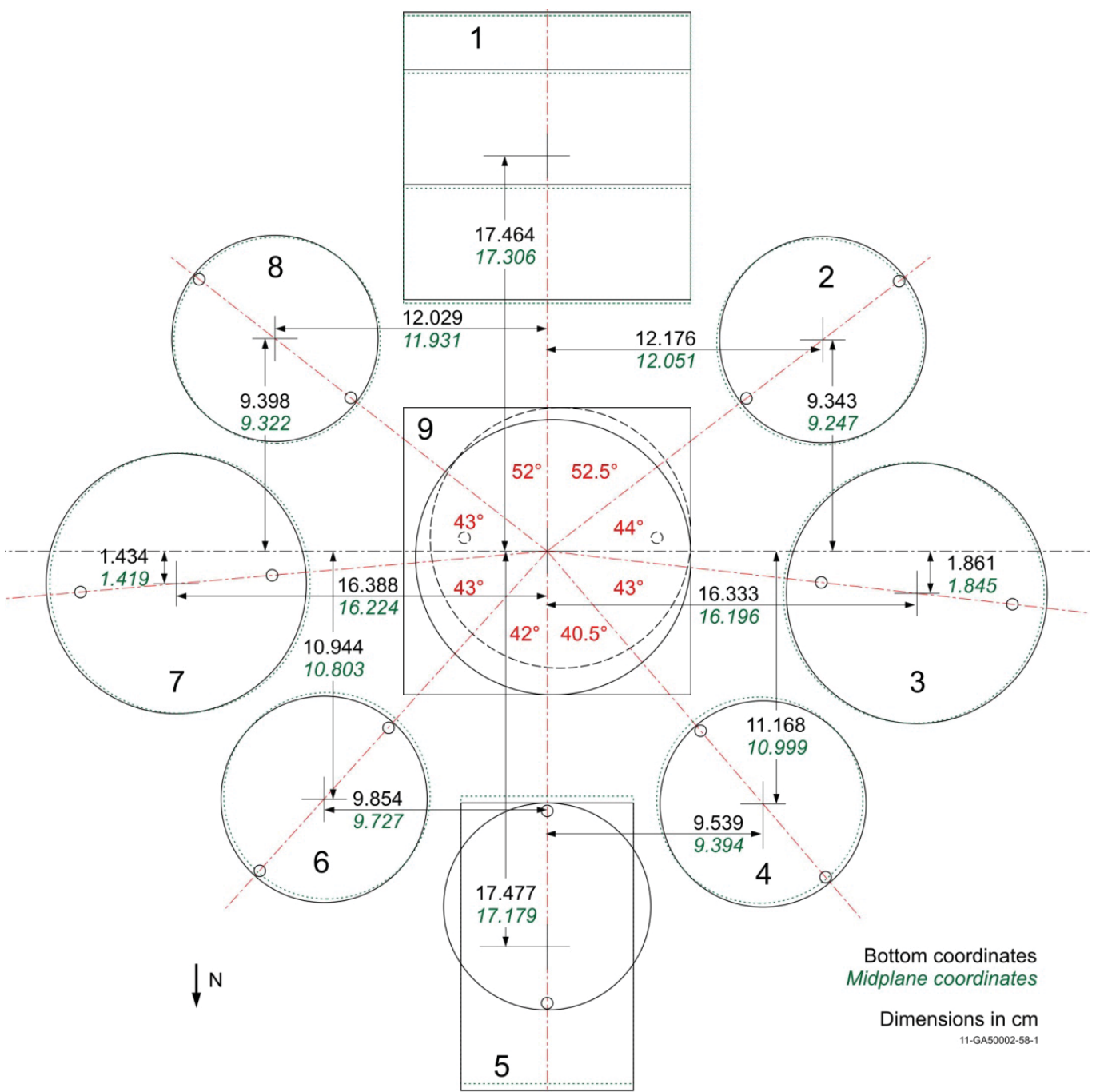

Figure 1.13. Placement of GROTESQUE Experimental Assembly Units (top view). 
$\mathrm{NEA} / \mathrm{NSC} / \mathrm{DOC} /(95) 03 / \mathrm{II}$

Volume II

HEU-MET-FAST-081

Table 1.12. Assembly Geometry Positioning. ${ }^{(a)}$

\begin{tabular}{|c|c|c|c|c|c||}
\hline $\begin{array}{c}\text { Unit } \\
\text { Number }\end{array}$ & $\begin{array}{c}\text { Distance } \\
\text { from Hole } \\
(\mathbf{c m})^{(\mathrm{e})}\end{array}$ & $\begin{array}{c}\text { Angular } \\
\text { Spacing } \mathbf{(}^{\mathbf{9}} \mathbf{)}\end{array}$ & $\begin{array}{c}\text { Center Bottom X } \\
\text { Coordinate (cm) }\end{array}$ & $\begin{array}{c}\text { Center Bottom Y } \\
\text { Coordinate (cm) }\end{array}$ & $\begin{array}{c}\text { Center Bottom Z } \\
\text { Coordinate (cm) }\end{array}$ \\
\hline \hline 1 & 1.905 & 270.0 & 0.0 & -17.464 & 0.150 \\
\hline 2 & 1.585 & 217.5 & -12.176 & -9.343 & 0.111 \\
\hline 3 & 1.471 & 173.5 & -16.333 & 1.861 & 0.174 \\
\hline 4 & 0.927 & 130.5 & -9.539 & 11.168 & 0.156 \\
\hline $5^{(\mathrm{b})}$ & 1.918 & 90.0 & 0.0 & 17.477 & 0.290 \\
\hline $5^{(\mathrm{c})}$ & 3.464 & 90.0 & 0.0 & $15.698^{(\mathrm{c})}$ & 9.2 \\
\hline 6 & 0.965 & 48.0 & 9.854 & $10.944^{(\mathrm{f})}$ & 0.134 \\
\hline 7 & 1.494 & 5.0 & 16.388 & 1.434 & 0.140 \\
\hline 8 & 1.501 & 322.0 & 12.029 & -9.398 & 0.087 \\
\hline $9^{(\mathrm{c})}$ & 0.0 & - & -0.593 & -0.593 & -1.755 \\
\hline $9^{(\mathrm{b})}$ & 0.0 & - & 0.0 & 0.0 & 0.937 \\
\hline $9^{(\mathrm{d})}$ & 0.0 & - & -0.268 & 0.268 & 6.655 \\
\hline \hline
\end{tabular}

(a) Knight, J.R., "GROTESQUE Without Tears," ORNL/CSD/TM-220, Oak Ridge National Laboratory (1984). The $\mathrm{x}, \mathrm{y}$ coordinates were derived from the hole distance, angular spacing, and unit dimensions.

(b) Rectangular parallelepiped component piece.

(c) Cylinder component piece.

(d) Hemisphere component piece.

(e) The distance from the hole in the diaphragm to the bottom faces of the peripheral units. These values had been calculated from the original measurements in inches by converting to centimeters; the number of decimal places had been truncated.

(f) This value was incorrectly reported as 10.964 . The correct value, which corresponds to the angular spacing and distance from the hole reported in this table, is provided here.

1.2.5 $\mathrm{k}_{\text {eff }}$ Data - The experimental $\mathrm{k}_{\text {eff }}$ value was reported in the experimental logbook ${ }^{\mathrm{a}}$ and was determined through stable reactor period measurements. The reactivity was obtained from the reactor period using the Inhour equation. The logbook also provides information on a repeatability measurement. The inferred $\mathrm{k}_{\mathrm{eff}}$ value of the primary experiment and the value inferred for the repeatability measurements are presented below in Table 1.13 . There were several additional $k_{\text {eff }}$ values . published for this experiment; however, they were from models created in various codes (References 1 and 2) and not direct measurements. ${ }^{\mathrm{b}, \mathrm{c}}$ Uncertainties were not provided for individual measurements. However, the uncertainty in the measurement of $\mathrm{k}_{\mathrm{eff}}$ is evaluated in Section 2.6.

${ }^{\text {a }}$ ORCEF Logbook 15r, pp. 47-48.

b J. T. Mihalczo, "Prompt-Neutron Lifetime in Critical Enriched-Uranium Metal Cylinders and Annuli," Nucl. Sci. Eng., 20, 60-65 (1965).

c J. T. Mihalczo, "Critical Experiments and Calculations with Annular Cylinders of U(93.2) Metal," ORNL-3499, Oak Ridge National Laboratory (1963). 
NEA/NSC/DOC/(95)03/II

Volume II

HEU-MET-FAST-081

Table 1.13. Measured Reactivity Data. ${ }^{(a)}$

\begin{tabular}{||c|c|c||}
\hline Experiment & Date & $\begin{array}{c}\text { Measured } \\
\text { Reactivity (d) }\end{array}$ \\
\hline Experiment 4 $^{(\mathrm{b})}$ & $6-15-64$ & -9.20 and -9.05 \\
\hline Experiment $1^{(\mathrm{c})}$ & $6-16-64$ & -7.87 and -8.47 \\
\hline
\end{tabular}

(a) There were additional reactivity measurements recorded on pp. 49-50 of the logbook, but they do not represent repeatability measurements. They were measurements for different configurations with varying heights of the centerpiece (Personal Communication with John T. Mihalzco, March 2011).

(b) ORCEF Logbook 15r, p. 47.

(c) ORCEF Logbook 15r, p. 48, repeat of Experiment 4 from p. 47.

\subsection{Description of Material Data}

1.3.1 HEU Metal Pieces - The uranium pieces were all reported to be enriched to $93.15 \mathrm{wt} . \%$, ${ }^{\mathrm{a}, \mathrm{b}}$ Often enrichments of $93.15 \mathrm{wt} \% \%$ were sometimes rounded to $93.2 \mathrm{wt} \%$ when reported. Two different uranium mixtures are actually present in the GROTESQUE experiment. The HEU cylinders were used in the Tinkertoy experiments and have been evaluated in HEU-MET-FAST-023 and HEU-MET-FAST-026. ${ }^{\text {}}$ In addition, the metal slabs stacked to create the rectangular pieces of the units were also used in previous experiments (Reference 3 ). The slab pieces were earlier incorrectly reported elsewhere as enriched to 93.4 wt. $\%{ }^{235} \mathrm{U}^{\mathrm{c}}$ but were also enriched to $93.15 \mathrm{wt} . \%{ }^{\mathrm{d}}$. The uranium metal enrichments are listed in Table 1.14 .

Table 1.14. GROTESQUE Isotopic Composition (References 1 and 3).

\begin{tabular}{|c|c|c|}
\hline Isotope & $\begin{array}{c}\text { Cylinder Content } \\
\text { (wt.\%) }^{\text {(a) }}\end{array}$ & $\begin{array}{c}\text { Slab Content } \\
\text { (wt.\%) }\end{array}$ \\
\hline \hline${ }^{234} \mathrm{U}$ & 0.97 & 1.07 \\
\hline${ }^{235} \mathrm{U}$ & 93.15 & 93.15 \\
\hline${ }^{236} \mathrm{U}$ & 0.24 & 0.68 \\
\hline${ }^{238} \mathrm{U}$ & 5.64 & 5.10 \\
\hline
\end{tabular}

(a) These values are rounded in Reference 1 and are reported in the Tinkertoy experiments: HEU-MET-FAST-023 and HEU-MET-FAST-026.

The isotopic composition of the hemisphere in Unit 9 is not recorded but is very close to those in other oralloy measurements in the East cell of ORCEF.

The total masses of each unit are given in Table 1.15, and the densities calculated from the masses and dimensions (Figure 1.2 through 1.10) are also provided.

\footnotetext{
a J. T. Mihalczo, "Prompt-Neutron Lifetime in Critical Enriched-Uranium Metal Cylinders and Annuli," Nucl. Sci. Eng., 20, 60-65 (1965).

${ }^{\mathrm{b}}$ Personal communication between John T. Mihalczo and J. Blair Briggs, July 2010.

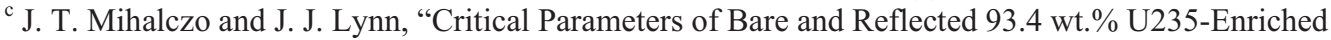
Uranium Metal Slabs,” ORNL-3016, Oak Ridge National Laboratory (December 1960), p. 73-76.

d Personal communication with John T. Mihalczo, June 2011.

${ }^{\text {e }}$ Personal communication with John T. Mihalczo, August 2011.
} 
NEA/NSC/DOC/(95)03/II

Volume II

HEU-MET-FAST-081

Table 1.15. Total Mass and Density of the HEU Units.

\begin{tabular}{||c|c|c||}
\hline Unit Number & Total Mass (g) & Unit Density $\left(\mathbf{g} / \mathbf{c m}^{\mathbf{3}}\right)^{(\mathrm{d})}$ \\
\hline \hline 1 & 38497 & 18.63085 \\
\hline 2 & 15768 & $18.83944^{(\mathrm{e})}$ \\
\hline 3 & 26216 & 18.73198 \\
\hline 4 & 15720 & 18.73305 \\
\hline 5 & $21384^{(\mathrm{a})}$ & 18.68481 \\
\hline 6 & 15727 & 18.71762 \\
\hline 8 & 26160 & 18.76711 \\
\hline 9 & 15755 & 18.76331 \\
\hline Total & $31295^{(\mathrm{b})}$ & 18.70980 \\
\hline & $206522^{(\mathrm{c})}$ & $18.71875^{(\mathrm{f})}$ \\
\hline
\end{tabular}

(a) The mass of the rectangular parts sum to $16098 \mathrm{~g}$, but the summation of these parts is reported as $16100 \mathrm{~g}$ in the logbook. The mass of the entire stack, including the cylindrical component, sums to $21384 \mathrm{~g}$ even though the logbook reports $21386 \mathrm{~g}$.

(b) The logbook rounds to $31300 \mathrm{~g}$ when the summation of the individual pieces is $31295 \mathrm{~g}$.

(c) The total mass loading is reported as $216.529 \mathrm{~kg}$ in the logbook, which is slightly larger than the summation of the individual parts.

(d) Mass density of the units was calculated by the evaluator. The number of significant figures retained in the mass density does not represent the precision of the measurements but enables duplication of atom densities in the benchmark specifications.

(e) This mass density is higher than typical HEU material; however, it was computed directly from available mass and volume data.

(f) The standard density of oralloy at this time from Y-12 data sheets was 18.75 $\mathrm{g} / \mathrm{cm}^{3}$; personal communication with John T. Mihalczo, April 2011.

Impurity data for the uranium units were not available. Typical impurity data for HEU metal used at ORCEF during this time period are shown in Table 2.11.

1.3.2 Steel Diaphragm - The stainless steel diaphragm was Type 304L. ${ }^{a}$

1.3.3 Support Structure - An aluminum clamping ring with stainless steel bolts was used to hold the stainless steel diaphragm. A description of these materials is not relevant since the reactivity effect was measured and the experimental configuration reactivity was corrected for their removal. ${ }^{b}$

\subsection{Temperature Data}

No mention of the system temperature was made in the report or logbook. According to the experimenter, the ORCEF operated at a nominal temperature of $293 \mathrm{~K}^{\mathrm{c}}$. The fission rate in the measurements usually corresponded to much less than 0.01 watts, so there was no appreciable heating of the experimental components. Typically the dimensions of the uranium component pieces used in ORCEF experiments were measured at $70^{\circ} \mathrm{F}$ and the experiments were performed at $72^{\circ} \mathrm{F}$. The reactivity coefficient for temperature for these assemblies is approximately $-0.3 \notin /{ }^{\circ} \mathrm{C}$. ${ }^{\mathrm{d}}$

\footnotetext{
${ }^{\text {a }}$ Personal communication with John T. Mihalczo, April 2011.

${ }^{\mathrm{b}}$ Personal communication with John T. Mihalzco, January 2011.

${ }^{c}$ Personal communication with John T. Mihalczo, February 2010.

${ }^{\mathrm{d}}$ Personal communication with John T. Mihalczo, March 2010 and August 2010.
} 
NEA/NSC/DOC/(95)03/II

Volume II

HEU-MET-FAST-081

\subsection{Supplemental Experimental Measurements}

Rossi alpha measurements at delayed criticality were performed but were never formally documented and the results do not appear in the logbook. ${ }^{a}$

\footnotetext{
${ }^{\text {a }}$ Personal communication with John T. Mihalczo, August 2011.
} 


\subsection{EVALUATION OF THE EXPERIMENTAL DATA}

Monte Carlo N-Particle (MCNP) version 5-1.51 a calculations were utilized to estimate the biases and uncertainties associated with the experimental results in this evaluation. MCNP is a general-purpose, continuous-energy, generalized-geometry, time-dependent, coupled n-particle Monte Carlo transport code. The Evaluated Neutron Data File library, ENDF/B-VII.0, ${ }^{b}$ was utilized in this evaluation. The $1 \sigma$ statistical uncertainty associated with the MCNP calculations was \pm 0.00002 for all calculations. The uncertainty in $\Delta \mathrm{k}$ is 0.00003 . Calculations were performed with $1,000,000$ neutrons per cycle for 1,000 active cycles after skipping 50 cycles; the total number of neutron histories was $1,000,000,000$. For this report, an uncertainty is considered negligible if $\Delta \mathrm{k}$ is $\leq 0.00010$.

The detailed benchmark model provided in Section 3 was utilized with perturbations of the model parameters to estimate uncertainties in $\mathrm{k}_{\mathrm{eff}}$ due to uncertainties in parameter values defining the experimental configuration. Where applicable, comparison of the upper and lower perturbation $\mathrm{k}_{\mathrm{eff}}$ values to evaluate the uncertainty in the eigenvalue were utilized to minimize correlation effects, if any, induced by comparing all perturbations to the original benchmark model configuration, as discussed elsewhere. ${ }^{\mathrm{c}}$

Unless specifically stated otherwise, all uncertainty values in this section correspond to $1 \sigma$. When the change in $\mathrm{k}_{\text {eff }}$ between the base case and the perturbed model, or two perturbed models, was less than the statistical uncertainty of the Monte Carlo results, the changes in the variable were amplified, if possible, and the calculations repeated. The resulting calculated change was then scaled back corresponding to the actual uncertainty, assuming linearity.

The total evaluated uncertainty for this experiment is provided in Section 2.7. The square root of the sum of the squares of all the individual uncertainties assessed in this section is used to obtain the total uncertainty in the experimental $\mathrm{k}_{\text {eff. }}$. As discussed in Section 2.1.1, all uncertainties are treated as $100 \%$ systematic, with no reduction due to randomness in the uncertainty values.

The GROTESQUE experiment has been evaluated and judged to be an acceptable benchmark experiment.

\section{$2.1 \underline{\beta}_{\text {eff }}$}

There were no recorded $\beta_{\text {eff }}$ measurements for this experiment. Other similar experiments ${ }^{\mathrm{d}}$ provide a $\beta_{\text {eff }}$ of 0.0067 , which is typical for the uranium enrichment used. The experimenter recommends using the value of $0.0067{ }^{\mathrm{e}}$ It is typical to assume a $5 \%$ uncertainty in $\beta_{\text {eff, }}$, according to related benchmarks HEU-MET-FAST-059 and HEU-MET-FAST-069. Therefore, the calculated $\beta_{\text {eff }}$ for this experiment is $0.0067 \pm 0.00034$.

\footnotetext{
a X-5 Monte Carlo Team, "MCNP - a General Monte Carlo n-Particle Transport Code, version 5," LA-UR-031987, Los Alamos National Laboratory (2003).

${ }^{b}$ M. B. Chadwick, et al., "ENDF/B-VII.0: Next Generation Evaluated Nuclear Data Library for Nuclear Science and Technology," Nucl. Data Sheets, 107: 2931-3060 (2006).

${ }^{c}$ D. Mennerdahl, "Statistical Noise for Nuclear Criticality Safety Specialists," Trans. Am. Nucl. Soc., 101: $465-466$ (2009).

d J. T. Mihalczo, "Critical Experiments and Calculations with Annular Cylinders of U(93.2) Metal," ORNL-3499, Oak Ridge National Laboratory (1963).

e Personal communication with John T. Mihalczo, August 2011.
} 
HEU-MET-FAST-081

\section{2 $\underline{\text { HEU Pieces }}$}

2.2.1 Unit Worths - The worth of each of the nine units was calculated by comparing the benchmark model in Section 3 with models in which each individual unit was removed. The worth was converted into reactivity, $\rho \$$, and plotted against unit mass (see Table 2.1 and Figure 2.1). As expected, the worth of the centerpiece (Unit 9) is the greatest. The worth of the other eight units does increase with increasing mass; however, there is no direct correlation between unit mass and worth. Because of the variation in unit worth for this configuration, all uncertainties are treated as $100 \%$ systematic with no correction for randomness in measurement.

Table 2.1. Calculated Worth of Each Unit.

\begin{tabular}{|c|c|c||}
\hline \hline Unit & Worth (p\$) & Mass (kg) \\
\hline \hline 1 & -5.32 & 38.5 \\
\hline 2 & -2.66 & 15.8 \\
\hline 3 & -3.34 & 23.2 \\
\hline 4 & -2.41 & 15.7 \\
\hline 5 & -2.05 & 21.4 \\
\hline 6 & -2.22 & 15.7 \\
\hline 7 & -3.12 & 23.2 \\
\hline 8 & -2.56 & 15.8 \\
\hline 9 & -11.89 & 31.3 \\
\hline
\end{tabular}

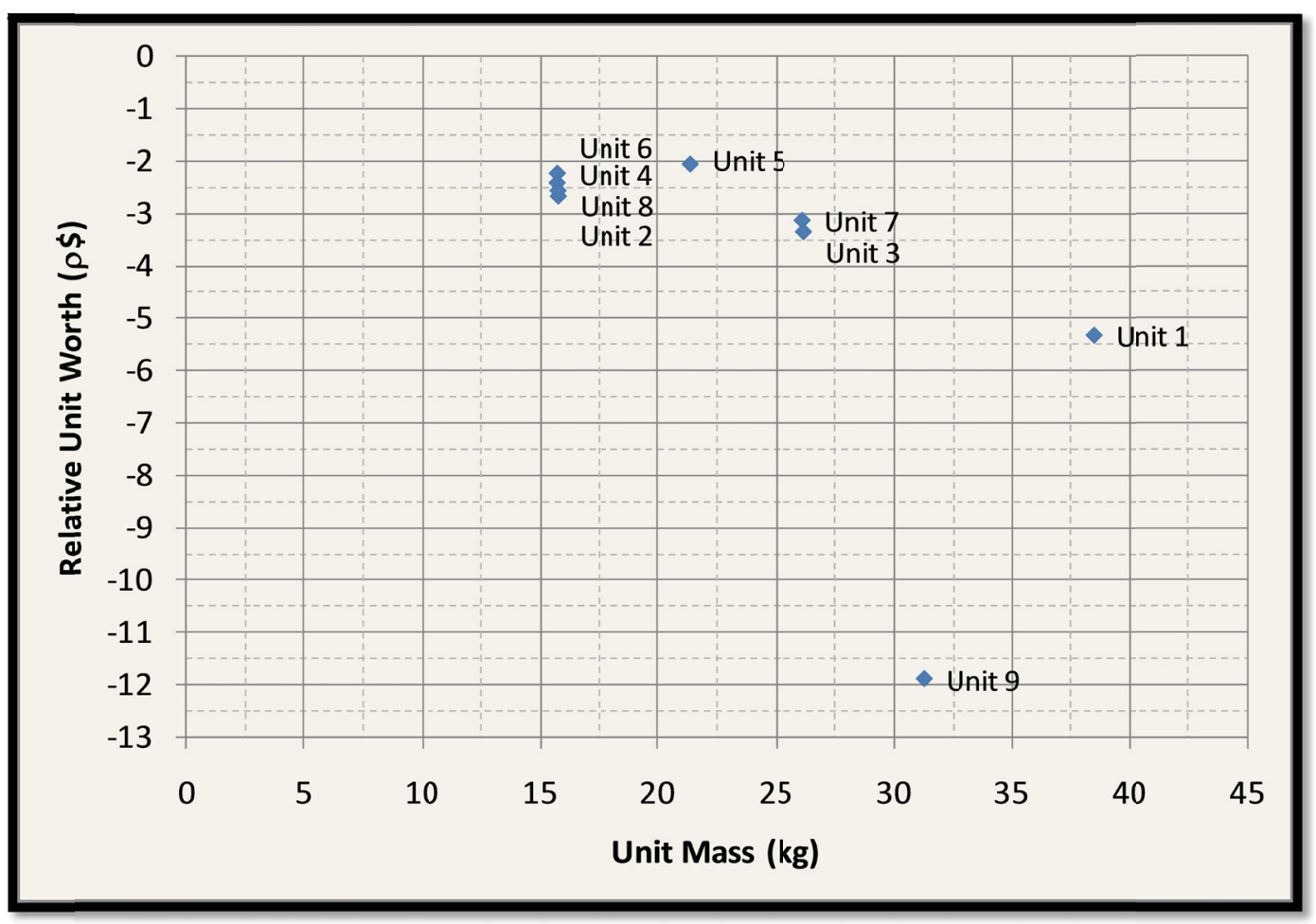

Figure 2.1. Relative Unit Worth. 
NEA/NSC/DOC/(95)03/II

Volume II

HEU-MET-FAST-081

2.2.2 Homogenization of Units - The nine major units are made up of individual pieces stacked together. There would have been small gaps between each piece that could allow for some streaming. Detailed dimensions of each individual part were not available. Units were considered homogenous for this evaluation, with the densities calculated in Section 2.2.4. The uncertainty in the homogenization of the GROTESQUE units is considered to be negligible since the effect for removing the gaps and overall dimensional uncertainty were determined to be negligible (Section 3.1.1.1 and Section 2.2.6). For units with multiple types of pieces (e.g., cylinders and slabs) the homogenization was assumed for each subunit region, single cylinder or rectangular parallelepiped, respectively.

The effect of homogenizing the holes in the cylindrical pieces into the unit was demonstrated to be small compared to the total simplification bias for the simple benchmark model (Section 3.1.2). Therefore, the uncertainty in the diameter, location, or orientation of the holes was also judged to be negligible.

2.2.3 Gaps between Pieces - No information was provided on gap size, so a reasonable approximation of twice the machining tolerance of \pm 0.002 in. $( \pm 0.00508 \mathrm{~cm})$ was used to estimate the effect of gaps between individual pieces of each unit. Actual gap thicknesses would be comparable to those found in HEU-MET-FAST-051, which are considerably smaller in size than the tolerance value used in this evaluation. ${ }^{\text {a }}$ No uncertainty was evaluated for the size of these gaps because removing them created a negligible bias, as discussed in Section 3.1.1.1. Therefore, the total macroscopic dimensions and mass are preserved for this analysis, and gaps and their associated uncertainties are ignored.

2.2.4 Density - The density of each unit was calculated using the reported masses and unit dimensions (see Figure 1.2 through 1.10 and Table 1.15). A summary of unit volumes, masses, and densities is reproduced in Table 2.2. The density of each unit was calculated using the reported masses and unit volumes (see Figures 1.2 through 1.10). A summary of unit volumes, masses, and densities is reproduced in Table 2.1. Units 5 and 9 are comprised of different geometry types. These subunit parts are separated into single table entries.

The small support holes were ignored in the simple model and homogenized into the units, giving a slightly higher unit volume and lower density. Using the given mass and calculated volumes, the homogenized density of each unit was calculated (Table 2.3).

An average mass density was determined (both with and without holes) by dividing the total mass of all units by the total volume (both with and without holes) of all units used in the GROTESQUE experiment. The average density of the HEU units with holes included in the cylindrical pieces is $18.72 \mathrm{~g} / \mathrm{cm}^{3}$; it is $18.66 \mathrm{~g} / \mathrm{cm}^{3}$ when the holes are neglected (i.e., homogenized into the units).

\footnotetext{
${ }^{a}$ Personal communication with John T. Mihalczo, August 2011.
} 
NEA/NSC/DOC/(95)03/II

Volume II

HEU-MET-FAST-081

Table 2.2. Evaluated Density Data (including holes).

\begin{tabular}{|c|c|c|c|}
\hline Unit & Mass $\mathbf{( g )}$ & Volume $\left.\mathbf{( c m}^{\mathbf{3}}\right)$ & Density $\left.\mathbf{( g / \mathbf { c m } ^ { 3 }}\right)^{\text {(a) }}$ \\
\hline 1 & 38497 & 2066.3039 & 18.63085 \\
\hline 2 & 15768 & 836.9674 & 18.83944 \\
\hline 3 & 26216 & 1399.5315 & 18.73198 \\
\hline 4 & 15720 & 839.1585 & 18.73305 \\
\hline 5-slabs & 16098 & 862.4600 & 18.66521 \\
\hline 5-cylinder & 5286 & 281.9990 & 18.74475 \\
\hline 6 & 15727 & 840.2244 & 18.71762 \\
\hline 7 & 26160 & 1393.9278 & 18.76711 \\
\hline 8 & 15755 & 839.6707 & 18.76331 \\
\hline 9-cylinder & 5247 & 279.2051 & 18.79264 \\
\hline 9-slabs & 17210 & 922.2562 & 18.66076 \\
\hline 9-hemisphere & 8838 & 471.1919 & 18.75669 \\
\hline
\end{tabular}

(a) The number of significant figures retained in the mass density does not represent the precision of the measurements but enables duplication of atom densities in the benchmark specifications.

Table 2.3. Evaluated Density Data (without holes).

\begin{tabular}{|c|c|c|c|}
\hline \hline Unit & Mass $\mathbf{( g )}$ & Volume $\left.\mathbf{( c m}^{\mathbf{3}}\right)$ & Density $\mathbf{( g / \mathbf { c m } ^ { 3 }} \mathbf{~}^{\mathbf{( a )}}$ \\
\hline \hline 1 & 38497 & 2066.3039 & 18.63085 \\
\hline 2 & 15768 & 842.2039 & 18.72231 \\
\hline 3 & 26216 & 1404.9938 & 18.65916 \\
\hline 4 & 15720 & 844.4156 & 18.61642 \\
\hline 5-slabs & 16098 & 862.4600 & 18.66521 \\
\hline 5-cylinder & 5286 & 283.7497 & 18.62909 \\
\hline 6 & 15727 & 845.4836 & 18.60119 \\
\hline 7 & 26160 & 1399.3901 & 18.69386 \\
\hline 8 & 15755 & 844.9218 & 18.64670 \\
\hline 9-cylinder & 5247 & 280.2963 & 18.71948 \\
\hline 9-slabs & 17210 & 922.2562 & 18.66076 \\
\hline 9-hemisphere & 8838 & 471.1919 & 18.75669 \\
\hline
\end{tabular}

(a) The number of significant figures retained in the mass density does not represent the precision of the measurements but enables duplication of atom densities in the benchmark specifications.

2.2.5 HEU Mass - Mass measurements for each component piece, as well as the major units, are provided in the logbook. ${ }^{\text {a }}$ The total masses of each unit are shown in Table 1.15.

The measurements are reported to the nearest gram, but no description of the measurement technique or accuracy is provided in the primary reference. Evaluations of several other experiments (HEU-MET-FAST-051, HEU-MET-FAST-059, HEU-MET-FAST-069, HEU-MET-FAST-071, and HEU-MET-FAST-076) performed at the same facility by the same experimenter with HEU material used a value of uncertainty in the mass of each HEU part of $\pm 0.5 \mathrm{~g}$. The mass uncertainty is based on calibration standards from the Bureau of Standards that were used to calibrate the scales for measuring uranium masses at the Y-12 Plant, which were accurate to less than $0.5 \mathrm{~g}$ for parts weighing up to $20 \mathrm{~kg}$. ${ }^{\mathrm{b}}$

\footnotetext{
a ORCEF Logbook 15r, p. 45.

b Personal communication with John T. Mihalczo, April 2011.
} 
HEU-MET-FAST-081

These previous experiments indicate that the measurements were also rounded to the nearest gram, which is consistent with the reporting format in the experimental logbook.

To find the effect of this uncertainty on the $\mathrm{k}_{\mathrm{eff}}$ value, the mass of each HEU piece from Tables $1.2-1.10$ were adjusted by a factor of 3 times the $1 \sigma$ uncertainty of $0.5 \mathrm{~g}$. In order to keep the total uranium volume of the experiment constant, the density of each of the uranium unit was adjusted accordingly. The combined total $1 \sigma$ uncertainty in mass was $28 \mathrm{~g}$, which is much greater than an estimated uncertainty of $\sim 5 \mathrm{~g}(0.5 \mathrm{~g} / 20 \mathrm{~kg} \times 206.5 \mathrm{~kg})$. Any additional mass uncertainty due to wearing of parts, oxidation, hydrating, and oil are negligible. The calculated uncertainty in $\mathrm{k}_{\text {eff }}$ due to the uncertainty in HEU mass is shown in Table 2.4.

Table 2.4. HEU Mass Uncertainty.

\begin{tabular}{||c|ccc|c|ccc||}
\hline \hline Deviation & $\Delta \mathbf{k}$ & \pm & $\sigma_{\Delta \mathbf{k}}$ & $\begin{array}{c}\text { Scaling } \\
\text { Factor }\end{array}$ & $\Delta \mathbf{k}_{\text {eff }}(\mathbf{1} \boldsymbol{\sigma})$ & \pm & $\sigma_{\Delta \mathbf{k e f f}}$ \\
\hline \hline $\pm 84 \mathrm{~g}$ & 0.00029 & \pm & 0.00001 & 3 & 0.00010 & \pm & $<0.00001$ \\
\hline
\end{tabular}

2.2.6 HEU Dimensions - The major uranium units were comprised of smaller component pieces that were used in other experiments at the ORCEF. No information was provided in the logbook regarding machining tolerances or measurement precision; however, these uranium pieces from the same facility that were used by the same experimenter in other projects near the same time period were described as being dimensionally accurate (i.e., having a manufacturing tolerance) to within 0.002 in. $(0.00508 \mathrm{~cm}){ }^{a}$ Reference 3 also states that the machining tolerances for the HEU slabs were 0.002 in. $(0.00508 \mathrm{~cm})$. Calculations were performed in which the dimensions of all HEU pieces were increased by $0.00508 \mathrm{~cm}$ and then subsequently decreased by $0.00508 \mathrm{~cm}$. Figures 1.1 through 1.10 and Tables 1.2 through 1.10 were used to approximate the number of pieces stacked in the experiment or placed side-by-side. A summary of the evaluated number of pieces in each dimension for each unit is provided in Table 2.5. Mass was conserved by adjusting the density of the units. The heights, diameters, lengths, widths, and thicknesses of every piece was simultaneously increased or decreased by the manufacturing tolerance assuming all uncertainties were $100 \%$ systematic. The uncertainty in $\mathrm{k}_{\mathrm{eff}}$ due to the uncertainty in the HEU dimensions was still determined to be negligible (see Table 2.6).

Actual gap thicknesses would be comparable to those found in HEU-MET-FAST-051, which are considerably smaller in size than the tolerance value used in this evaluation. ${ }^{\mathrm{b}}$ Even when using the manufacturing tolerance of \pm 0.002 in. provided above, which is much larger than the actual dimensional uncertainty, the calculated uncertainty in $\mathrm{k}_{\mathrm{eff}}$ is still negligible.

\footnotetext{
a J. T. Mihalczo, "Prompt-Neutron Lifetime in Critical Enriched-Uranium Metal Cylinders and Annuli," Nucl. Sci. Eng., 20, 60-65 (1965).

${ }^{\mathrm{b}}$ Personal communication with John T. Mihalczo, August 2011.
} 
NEA/NSC/DOC/(95)03/II

Volume II

HEU-MET-FAST-081

Table 2.5. Number of Pieces across Each Unit.

\begin{tabular}{|c|c|c|c|c|c|c|c|}
\hline Unit & Dimension & \# Pieces & Type & Unit & Dimension & \# Pieces & Type \\
\hline \multirow[t]{4}{*}{1} & Height & $\sim 12$ & Slabs & \multirow[t]{3}{*}{6} & Height & 3 & Cylinders \\
\hline & Width & 1 & Slabs & & Diameter & 1 & Cylinders \\
\hline & Length & $\sim 2$ & Slabs & & & 3 & Total \\
\hline & & 16 & Total & \multirow[t]{3}{*}{7} & Height & 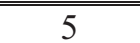 & Cylinders \\
\hline \multirow[t]{3}{*}{2} & Height & 3 & Cylinders & & Diameter & 1 & Cylinders \\
\hline & Diameter & 1 & Cylinders & & & 5 & Total \\
\hline & & 3 & Total & \multirow[t]{3}{*}{8} & Height & 3 & "Cylinders \\
\hline \multirow[t]{3}{*}{3} & Height & 5 & Cylinders & & Diameter & 1 & Cylinders \\
\hline & Diameter & 1 & Cylinders & & & 3 & Total \\
\hline & & 5 & Total & \multirow[t]{8}{*}{9} & Height & 1 & Cylinder \\
\hline \multirow[t]{3}{*}{ 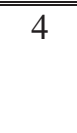 } & Height & 3 & Cylinders & & Height & 3 & Slabs \\
\hline & Diameter & 1 & Cylinders & & Height & 1 & Hemisphere \\
\hline & & 3 & Total & & Width & 1 & Slabs \\
\hline \multirow[t]{6}{*}{5} & Height & $\begin{array}{c}6 \\
\end{array}$ & Slabs & & Length & 1 & Slabs \\
\hline & Height & 1 & Cylinder & & Diameter & 1 & Cylinder \\
\hline & Width & $<3$ & Slabs & & Diameter & 1 & Hemisphere \\
\hline & Length & 1 & Slabs & & & 5 & Total \\
\hline & Diameter & 1 & Cylinder & & & & \\
\hline & & 13 & Total & & & & \\
\hline
\end{tabular}

Table 2.6. HEU Dimensional Uncertainty.

\begin{tabular}{||c|ccc|c|ccc||}
\hline \hline Deviation & $\Delta \mathbf{k}$ & \pm & $\sigma_{\Delta \mathbf{k}}$ & $\begin{array}{c}\text { Scaling } \\
\text { Factor }\end{array}$ & $\Delta \mathbf{k}_{\text {eff }}(\mathbf{1 \sigma})$ & \pm & $\boldsymbol{\sigma}_{\Delta \mathrm{keff}}$ \\
\hline \hline $\begin{array}{c}0.00508 \mathrm{~cm} \\
\text { per piece } \\
\text { per dimension }\end{array}$ & -0.00001 & \pm & 0.00001 & 1 & -0.00001 & \pm & 0.00001 \\
\hline
\end{tabular}

2.2.7 HEU Tilt Angle - The tilt angles can be calculated using trigonometric ratios of the distance from the center of the experiment, distance to the midpoint of each periphery unit, and the deflection of the given unit. The deflection ratio is the ratio of the vertical deflection over the radius (or distance) from the deflected position to a given point (in this case, the front face of the periphery unit). The arctangent of the deflection ratio provides the tilt angle. Thus a perturbation in either the measured distance from the center of the experiment or the vertical deflection would impact the calculated tilt angle. Uncertainty in the dimensions of the HEU units would have a negligible impact on the total uncertainty in the tilt angle.

The measurements for the tilt angle and coordinates of the HEU units were reported to 3 significant digits, which may not reflect the accuracy to which these measurements were performed. The uncertainty in the measured deflection of the diaphragm is 0.005 in. $(0.0127 \mathrm{~cm})$ and the uncertainty in the measure of the bottom center coordinates of the fissile material is $0.010 \mathrm{in} .(0.0254 \mathrm{~cm}){ }^{a}{ }^{\mathrm{a}}$ This method maximizes the uncertainty in the angle.

The uncertainty in the tilt angle of the HEU units was determined by adjusting the unit positions by \pm 0.010 in. $(0.0254 \mathrm{~cm})$ from the center of the diaphragm and simultaneously moving the parts \pm 0.005 inches $(0.0127 \mathrm{~cm})$ up or down in deflection. These changes were used to calculate the uncertainty in the

${ }^{\text {a }}$ Personal communication with John Mihalczo, April 2011. 
HEU-MET-FAST-081

tilt angle for each unit. The changes in the angle due to the uncertainty in axial deflection and radial placement are shown in Table 2.7.

Table 2.7. HEU Tilt Angle Uncertainty.

\begin{tabular}{|c|c|c|c|c|c|c||}
\hline Unit & $\begin{array}{c}\text { Center Bottom } \\
\mathbf{X}, \mathbf{Y} \text { Coordinates } \\
\mathbf{( c m )}\end{array}$ & $\begin{array}{c}\text { Bottom } \\
\mathbf{Z} \text { Coordinate } \\
\mathbf{( c m )}\end{array}$ & $\begin{array}{c}\text { Center Middle } \\
\mathbf{X , Y} \text { Coordinates } \\
\mathbf{( c m )}\end{array}$ & $\begin{array}{c}\text { Deflection } \\
\text { Ratio }\end{array}$ & $\begin{array}{c}\text { Reported } \\
\text { Angle } \\
\left({ }^{\circ}\right)\end{array}$ & $\begin{array}{c}\text { Angle } \\
\text { Uncertainty } \\
\left({ }^{\circ}\right)\end{array}$ \\
\hline \hline 1 & $0.000,-17.464$ & 0.150 & $0.000,-17.306$ & 0.0236 & 1.350 & 0.066 \\
\hline 2 & $-12.176,-9.343$ & 0.111 & $-12.051,-9.247$ & 0.0244 & 1.400 & 0.068 \\
\hline 3 & $-16.333,1.861$ & 0.174 & $-16.196,1.845$ & 0.0205 & 1.173 & 0.068 \\
\hline 4 & $-9.539,11.168$ & 0.156 & $-9.394,10.999$ & 0.0344 & 1.970 & 0.072 \\
\hline 5 & $0.0,15.698$ & 0.290 & $0.000,15.400$ & 0.0451 & 2.580 & 0.066 \\
\hline 6 & $9.854,10.944$ & 0.134 & $9.727,10.803$ & 0.0293 & 1.680 & 0.072 \\
\hline 7 & $16.388,1.434$ & 0.140 & $16.224,1.419$ & 0.0244 & 1.400 & 0.068 \\
\hline 8 & $12.029,-9.398$ & 0.087 & $11.931,-9.322$ & 0.0192 & 1.100 & 0.068 \\
\hline-- & -- & -- & -- & -- & average & 0.068 \\
\hline
\end{tabular}

The change in $k_{\text {eff }}$ due to the uncertainty in the deflection of the HEU units was calculated by using the average of the calculated changes in the angles from Table 2.7. To determine the effects of uncertainty, the tilt angle was increased and decreased by $0.068^{\circ}$. This is a $1 \sigma$ uncertainty and is not corrected by the number of perturbed units because correlation effects between the units would not be equal due to the difference in their individual worth (see Section 2.2.1.) The effective uncertainty in $\mathrm{k}_{\text {eff }}$ due to the uncertainty in the tilt angle is reported in Table 2.8. Because the maximum tilt angle was calculated by perturbing the $1 \sigma$ uncertainties in the deflection and radial position, the calculated uncertainty in $\mathrm{k}_{\text {eff }}$ is divided by $\sqrt{ } 2$.

Table 2.8. HEU Tilt Uncertainty.

\begin{tabular}{||c|ccc|c|ccc||}
\hline Deviation & $\Delta \mathbf{k}$ & \pm & $\boldsymbol{\sigma}_{\Delta \mathbf{k}}$ & $\begin{array}{c}\text { Scaling } \\
\text { Factor }\end{array}$ & $\Delta \mathbf{k}_{\text {eff }}(\mathbf{1} \boldsymbol{)})$ & \pm & $\boldsymbol{\sigma}_{\Delta \mathrm{keff}}$ \\
\hline \hline $\pm 0.068^{\circ}$ & 0.00024 & \pm & 0.00001 & $\sqrt{ } 2$ & 0.00017 & \pm & 0.00001 \\
\hline
\end{tabular}

2.2.8 HEU Isotopic Content - The isotopic data for the GROTESQUE experiment is provided in Table 1.14; these values are reproduced in Table 2.9 for comparison with the mass-weighted average isotopic composition (assuming all HEU material had the same isotopic content). The isotopic values for the cylinders were initially assumed to best represent those for the hemisphere used in the central unit. ${ }^{\text {a }}$ However, an average of the isotopic compositions could also be used. The effective bias and uncertainty in selecting the isotopic composition of the hemisphere is negligible compared to the overall benchmark experiment uncertainty.

\footnotetext{
a Personal communication with John T. Mihalczo, April 2011.
} 
NEA/NSC/DOC/(95)03/II

Volume II

HEU-MET-FAST-081

Table 2.9. Uranium Isotopic Content.

\begin{tabular}{||c|c|c|c|}
\hline Isotope & $\begin{array}{c}\text { Cylinder and } \\
\text { Hemisphere } \\
\text { Content } \\
\text { (wt.\%) }\end{array}$ & $\begin{array}{c}\text { Slab Content } \\
\text { (wt.\%) }\end{array}$ & $\begin{array}{c}\text { Mass-Weighted } \\
\text { Average Content } \\
\text { (wt.\%) }\end{array}$ \\
\hline \hline${ }^{234} \mathrm{U}$ & 0.97 & 1.07 & 1.00 \\
\hline${ }^{235} \mathrm{U}$ & 93.15 & 93.15 & 93.15 \\
\hline${ }^{236} \mathrm{U}$ & 0.24 & 0.68 & 0.39 \\
\hline${ }^{238} \mathrm{U}$ & 5.64 & 5.10 & 5.46 \\
\hline
\end{tabular}

Based on these data, and similar treatment of isotopic uncertainties for HEU parts used in HEU-MET-FAST-059 and HEU-MET-FAST-069, a reasonable estimate of the uncertainty in the average isotopic measurements for the cylinders is $\pm 0.005 \mathrm{wt} . \%$. Each isotope's weight percent was adjusted by $\pm 0.15 \mathrm{wt} . \%$ (thirty times the $1 \sigma$ uncertainty of $\pm 0.005 \mathrm{wt} . \%$ ), and the ${ }^{238} \mathrm{U}$ content was adjusted to maintain a total isotopic sum of $100 \%$. The uncertainty in the isotopic composition of the slabs and cylinders were perturbed simultaneously since there was not a significant difference in their contents. The effect of the total uranium isotopic uncertainty is presented in Table 2.10.

The uncertainty in the isotopic composition of the hemisphere is greater than the perturbations evaluated as the exact composition was unknown. It is known that the HEU metal used in the hemisphere would be very close in composition to the cylinder and slab compositions. Perturbation of the hemisphere isotopic compositions within the range of values provided in Table 2.9 provides negligible additional uncertainty to the benchmark experiment.

Table 2.10. Uranium Isotopic Uncertainty.

\begin{tabular}{|c|c|c|c|c|c|c|c|}
\hline Deviation & $\Delta \mathbf{k}$ & \pm & $\sigma_{\Delta \mathrm{k}}$ & $\begin{array}{l}\text { Scaling } \\
\text { Factor }\end{array}$ & $\Delta \mathbf{k}_{\text {eff }}(1 \sigma)$ & \pm & $\sigma_{\Delta \mathrm{keff}}$ \\
\hline \pm 0.15 wt. $\%{ }^{234} \mathrm{U}$ & 0.00053 & \pm & 0.00001 & 30 & 0.00002 & \pm & $<0.00001$ \\
\hline \pm 0.15 wt. $\%{ }^{235} \mathrm{U}$ & 0.00076 & \pm & 0.00001 & 30 & 0.00003 & \pm & $<0.00001$ \\
\hline \pm 0.15 wt. $\%{ }^{236} U$ & 0.00017 & \pm & 0.00001 & 30 & 0.00001 & \pm & $<0.00001$ \\
\hline
\end{tabular}

2.2.9 HEU Impurities - No impurity data were provided for the HEU units used in the GROTESQUE experiment. However, these parts were produced at the same time as those for which isotopic data was available. Data from HEU-MET-FAST-059, HEU-MET-FAST-069, HEU-MET-FAST-071, and HEU-MET-FAST-076 were used as a good to approximation of the effect of impurities in the uranium units used in this experiment.

The above mentioned benchmark evaluations contain a table of impurities typical for HEU parts from Y12 that were carefully cast and machined in a similar manner to those used in the GROTESQUE experiments. HEU-MET-FAST-069 indicates that impurity measurements are the average of 11 different spectrographic analyses of randomly sampled components for each impurity. These values are consistent with the nominal impurity content of highly enriched uranium metal at the Oak Ridge Y-12 Plant at the time the units were produced (i.e., the Y-12 enrichment and fabrication process typically produced 99.95 $\mathrm{g}$ of $\mathrm{U}$ per $100 \mathrm{~g}$ of metal). Oxygen and nitrogen content was assumed by the experimentalist to be 20 and $30 \mathrm{ppm}$, respectively, consistent with highly enriched uranium produced at the time of these experiments. The impurity data were taken from HEU-MET-FAST-069 and are shown in Table 2.11. 
NEA/NSC/DOC/(95)03/II

Volume II

HEU-MET-FAST-081

Those impurities listed as less than a minimum value are considered less than the detection limit, and the actual content is selected as half the detection limit and the other half representing the $1 \sigma$ uncertainty.

Table 2.11. Typical HEU Impurities. ${ }^{(a)}$

\begin{tabular}{|c|c|c|c|}
\hline Element $^{(a)}$ & $\begin{array}{c}\text { PPM } \\
\text { by } \text { Weight }^{(b)}\end{array}$ & $\begin{array}{l}\text { Variation } \\
(\text { ppm) }\end{array}$ & $\begin{array}{c}\text { Standard Deviation } \\
(\text { ppm) }\end{array}$ \\
\hline$\overline{\mathrm{Ag}}$ & 8 & $3-25$ & 3.2 \\
\hline $\mathrm{Ba}$ & $<0.01^{(d)}$ & - & 0.005 \\
\hline $\mathrm{Bi}$ & 164 & $81-311$ & 52.9 \\
\hline $\mathrm{C}$ & $<10$ & - & 2.4 \\
\hline $\mathrm{Ca}$ & 0.1 & - & 0.05 \\
\hline $\mathrm{Cd}$ & $<1$ & - & 0.5 \\
\hline Co & 5 & $2-15$ & 1.9 \\
\hline $\mathrm{Cr}$ & 7 & $4-12$ & 1.9 \\
\hline $\mathrm{Cu}$ & 25 & $10-40$ & 8 \\
\hline $\mathrm{K}$ & $<0.2$ & $0.2-0.8$ & 0.1 \\
\hline $\mathrm{Li}$ & $<2$ & - & 1 \\
\hline $\mathrm{Mg}$ & 3 & $2-3$ & 1.7 \\
\hline $\mathrm{Mn}$ & 56 & $25-89$ & 17.1 \\
\hline Mo & $<1$ & $<1-1$ & 0.5 \\
\hline $\mathrm{Na}$ & 27 & $15-50$ & 7.7 \\
\hline $\mathrm{Ni}$ & 100 & - & 10 \\
\hline $\mathrm{Sb}$ & 38 & $10-80$ & 17.4 \\
\hline $\mathrm{Ti}$ & 1 & - & 0.5 \\
\hline
\end{tabular}

(a) Mass spectrographic analysis, except for oxygen and nitrogen, were taken from: J. T. Mihalczo, "Graphite and Polyethylene Reflected Uranium-Metal Cylinders and Annuli," Union Carbide Corporation Nuclear Division, Oak Ridge Y-12 Plant, Y-DR-81 (April 28, 1972). Oxygen and nitrogen content were assumed by the principal experimentalist to be 20 and $30 \mathrm{ppm}$, respectively. Minor differences in the impurities exist between values listed in Table 5 and the impurity values provided in HEU-MET-FAST-051.

(b) Except for the values shown as less than the detection limit, impurity data are average values from 11 randomly sampled uranium parts.

(c) Personal communication, J. A. Mullens to John Mihalczo in HEU-MET-FAST-076, June 2004.

(d) Less than $(<)$ indicates lower detection limit and not that the impurity is not present.

The average impurity content was increased by $3 \sigma$ to find an upper perturbed $\mathrm{k}_{\text {eff }}$ value and subsequently decreased to find a lower perturbed $k_{\text {eff }}$ value, although impurity content was not reduced below zero. Half the difference between the upper and lower perturbation $k_{\text {eff }}$ values was used to represent the $3 \sigma$ uncertainty variation in $\mathrm{k}_{\mathrm{eff}}$ due to impurities in the HEU. Additionally, the weight fraction of the uranium metal was adjusted, as appropriate, to compensate for the adjustments in impurity content. A $1 \sigma$ uncertainty of $\pm 5 \mathrm{ppm}$ was assumed for the oxygen and nitrogen content. Results are shown in Table 2.12 . 
NEA/NSC/DOC/(95)03/II

Volume II

HEU-MET-FAST-081

Table 2.12. Uranium Impurities Uncertainty.

\begin{tabular}{|c|ccc|c|ccc||}
\hline Deviation & $\Delta \mathbf{k}$ & \pm & $\boldsymbol{\sigma}_{\Delta \mathbf{k}}$ & $\begin{array}{c}\text { Scaling } \\
\text { Factor }\end{array}$ & $\Delta \mathbf{k}_{\text {eff }}(\mathbf{1} \boldsymbol{\sigma})$ & \pm & $\boldsymbol{\sigma}_{\Delta \mathrm{keff}}$ \\
\hline \hline $\pm 3 \sigma$ & -0.00014 & \pm & 0.00001 & 3 & -0.00005 & \pm & $<0.00001$ \\
\hline
\end{tabular}

2.2.10 HEU Spatial Variation - The radial placement of the 8 units of uranium on the diaphragm was measured to within 0.010 in. $(0.0254 \mathrm{~cm})^{\mathrm{a}}$ and the deflection of each unit was measured to within 0.005 in. $(0.0127 \mathrm{~cm})$. The centerpiece was moved separately from the other 8 units because it is physically realistic to assume that the placement of the centerpiece was not dependent on the positioning of the other HEU units. Calculations were performed for five different variations in the spatial positioning of the nine metal units. Calculations were deemed unnecessary for three additional variations in the spatial positioning of the HEU units. Results are tabulated in Table 2.13. All uncertainties in the spatial placement and orientation of the HEU units were considered to represent $1 \sigma$ uncertainties.

Radial Position: Using the benchmark model to simulate the experiment, the 8 outer units were moved away from the centerpiece by 0.010 in. $(0.0254 \mathrm{~cm})$ to create an upper perturbation limit, and then moved the same distance closer to create a lower perturbation limit; the difference between the two limits was divided by two. As discussed in Section 2.2.1, due to the unique worths of each component, there is no reduction in the calculated uncertainty for correlated effects. Thus this uncertainty is treated as $100 \%$ systematic.

Angular Placement: No uncertainty is assessed for the angular placement of the eight units surrounding the centerpiece (as shown in Figure 1.13). The uncertainty is judged to be negligible compared to the uncertainty in $\mathrm{k}_{\mathrm{eff}}$ due to the uncertainty in the radial distance of the units from the experiment center.

Vertical Deflection: The eight outer units were raised and then lowered by \pm 0.005 in. $(0.0127 \mathrm{~cm})$ to determine an upper and lower perturbation limit for the uncertainty in their deflection. The difference between these two perturbations were divided by two.

Alternating Vertical Deflection: The 8 outer units were arranged in an alternating pattern of increased and decreased deflection height of \pm 0.005 in. $(0.0127 \mathrm{~cm})$. The effect was negligible.

Centerpiece Vertical Deflection: To evaluate the vertical spatial variation of the centerpiece, it was raised and lowered by 0.005 in $(0.0127 \mathrm{~cm})$, creating an upper and lower perturbation limit, respectively, and the difference between the upper and lower perturbation $\mathrm{k}_{\mathrm{eff}}$ values was divided by two.

Centerpiece Position: The radial placement was evaluated by moving the centerpiece 0.005 in. $(0.0127$ $\mathrm{cm})$, which is half the radial position uncertainty of $0.010 \mathrm{in} .(0.0254 \mathrm{~cm})$, in positive and negative directions along the $\mathrm{x}$ - and $\mathrm{y}$-axis. The largest change occurred when moving the centerpiece towards Unit 5. This value was selected to represent the uncertainty in the centerpiece placement.

Stack Order: The exact location of every individual piece in all nine HEU units is unknown. Any uncertainty due to the order of piece placement is considered negligible as most of the pieces have similar densities and isotopic abundances. Furthermore, the units are homogenized as the effective bias in neglecting gaps between parts is negligible. The simplification biases of using a single HEU density, a single uranium isotopic composition, and removing the holes in the cylinders are also small (Section 3.1).

Stack Alignment: Careful precision was typically used in ORCEF experiments performed with the vertical lift assembly, where the uncertainty in piece alignment within a stack was limited to within the

\footnotetext{
${ }^{\text {a }}$ Personal communication with John T. Mihalzco, April 2011.
} 
manufacturing tolerances of the pieces (see HEU-MET-FAST-069). Therefore, it is concluded that additional uncertainty due to the alignment of pieces stacked within a unit would be negligible and already included in the evaluation of uncertainty in the HEU dimensions.

Table 2.13. HEU Spatial Variation.

\begin{tabular}{||c|c|ccc|c|ccc||}
\hline $\begin{array}{c}\text { Parameter } \\
\text { Variation }\end{array}$ & Deviation & $\Delta \mathbf{k}$ & \pm & $\sigma_{\Delta \mathbf{k}}$ & $\begin{array}{c}\text { Scaling } \\
\text { Factor }\end{array}$ & $\Delta \mathbf{k}_{\text {eff }}(\mathbf{1 \sigma})$ & \pm & $\sigma_{\Delta \mathbf{k e f f}}$ \\
\hline \hline $\begin{array}{c}\text { Radial } \\
\text { Coordinates }\end{array}$ & $\pm 0.0254 \mathrm{~cm}$ & -0.00080 & \pm & 0.00001 & 1 & -0.00080 & \pm & 0.00001 \\
\hline $\begin{array}{c}\text { Vertical } \\
\text { Deflection }\end{array}$ & $\pm 0.0127 \mathrm{~cm}$ & -0.00003 & \pm & 0.00001 & 1 & -0.00003 & \pm & 0.00001 \\
\hline $\begin{array}{c}\text { Alternating } \\
\text { Vertical Heights }\end{array}$ & $\pm 0.0127 \mathrm{~cm}$ & 0.00004 & \pm & 0.00001 & 1 & 0.00004 & \pm & 0.00001 \\
\hline $\begin{array}{c}\text { Centerpiece } \\
\text { Vertical Deflection }\end{array}$ & $\pm 0.0127 \mathrm{~cm}$ & $<0.00001$ & \pm & 0.00001 & 1 & $<0.00001$ & \pm & 0.00001 \\
\hline $\begin{array}{c}\text { Centerpiece } \\
\text { Position }\end{array}$ & $\pm 0.0254 \mathrm{~cm}$ & -0.00008 & \pm & 0.00001 & 1 & -0.00008 & \pm & 0.00001 \\
\hline \hline
\end{tabular}

\subsection{Support Structure Worth}

The measurements in the logbook detail the method used to determine the worth of the support structure for the experiment. The combined worth of the support plate, diaphragm, support ring, and support stand was determined to be $+10.2 \phi^{\mathrm{a}}$ using positive stable reactor period measurements.

Using the MCNP-calculated $\beta_{\text {eff }}$ for this experiment of 0.0067 , the equivalent $k_{\text {eff }}$ value for the $10.2 \phi$ worth of the support structures is $(0.0067 \times 0.102 \$)=+0.00068 \Delta \mathrm{k}_{\mathrm{eff}}$. There was an additional measurement using two 10 mil steel diaphragms, which has a worth of $19.29 \phi$, demonstrating that the majority of the worth came from the diaphragm and not the other support structure components. Therefore the effect of neglecting the additional support structure would result in a negligible bias with no additional uncertainty.

It is typical to assume a $10 \%$ uncertainty in the worth measurements of the structure and diaphragm for this type of experiment performed at ORCEF, according to similar benchmark experiments performed by the same experimenter, HEU-MET-FAST-059 and HEU-MET-FAST-069. An uncertainty of $10 \%$ is typically larger than the uncertainty demonstrated when repeated worth measurements were performed for similar experiments. The uncertainty in the measurement of the support structure and $\beta_{\mathrm{eff}}$ is quantified in Table 2.14 .

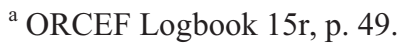


NEA/NSC/DOC/(95)03/II

Volume II

HEU-MET-FAST-081

Table 2.14. Support Structure Worth Uncertainty.

\begin{tabular}{||c|c|c||}
\hline Parameter & Value & Uncertainty \\
\hline $\begin{array}{c}\text { Support Structure } \\
\text { Worth }(\phi)\end{array}$ & +10.2 & $\pm 10 \%$ \\
\hline$\beta_{\text {eff }}$ & 0.0067 & $\pm 5 \%$ \\
\hline Reactivity $\left(\Delta \mathrm{k}_{\mathrm{eff}}\right)$ & +0.00068 & \pm 0.00008 \\
\hline
\end{tabular}

\subsection{Room Return}

Unreflected systems tend to be more sensitive to room return than those with reflection, so it was necessary to develop a simplified model of the ORCEF to estimate the effects of the surroundings on the experiment. The dimensions of the East Cell of the ORCEF are documented in other benchmarks, such as HEU-MET-FAST-076. The uncertainty in the measurements of this facility was not available. Since the effect of room return is small, the uncertainty due to the room return itself is assumed to be negligible. The bias and bias uncertainty for removing the room from the model is evaluated further in Section 3.1.

\subsection{Temperature}

As indicated in Section 1.4, heating effects in the experiment components were negligible. A $1 \sigma$ temperature variation of $\pm 2{ }^{\circ} \mathrm{C}$ sufficiently represents the temperature uncertainty in this experiment. Using a $\beta_{\text {eff }}$ of 0.0067 and a temperature reactivity coefficient of $-0.3 \phi /{ }^{\circ} \mathrm{C},{ }^{\mathrm{a}}$ the resulting $\Delta \mathrm{k}_{\text {eff }}$ is negligible (Table 2.15).

Table 2.15. Temperature Effect Uncertainty.

\begin{tabular}{|c|c|}
\hline Deviation & $\Delta \mathbf{k}_{\text {eff }}(\mathbf{1 \sigma})$ \\
\hline \hline $\pm 2{ }^{\circ} \mathrm{C}$ & -0.00004 \\
\hline
\end{tabular}

\subsection{Measurement of $\mathbf{k}_{\text {eff }}$}

2.6.1 Initial Measurements - The experimental $\mathrm{k}_{\text {eff }}$ value was reported in the experimental logbook. ${ }^{\mathrm{b}}$ This value was determined through stable reactor period measurements, and was reported in the reactivity unit of cents $(\phi)$. As with the worth measurement of the support structure, a $10 \%$ uncertainty in the measured $\mathrm{k}_{\text {eff }}$ and a $5 \%$ uncertainty in $\beta_{\text {eff }}$ is assumed. Table 2.16 contains the measured $\mathrm{k}_{\text {eff }}$ value in cents, and the reactivity value was converted into units of $\Delta \mathrm{k}$ using a calculated $\beta_{\text {eff }}$ of 0.0067 to obtain the measured $\mathrm{k}_{\text {eff }}$ value.

\footnotetext{
${ }^{a}$ Personal communication with John T. Mihalczo, March 2010.

${ }^{\mathrm{b}}$ ORCEF Logbook 15r, pp.47-48.
} 
NEA/NSC/DOC/(95)03/II

Volume II

HEU-MET-FAST-081

Table 2.16. Measured Reactivity Data. ${ }^{(a)}$

\begin{tabular}{|c|c|c|ccc||}
\hline $\begin{array}{c}\text { Measurement } \\
\text { Number }\end{array}$ & $\begin{array}{c}\text { Measured } \\
\text { Reactivity }(\boldsymbol{\ell})\end{array}$ & $\begin{array}{c}\text { Measured } \\
\text { Reactivity }(\mathbf{\Delta k})\end{array}$ & \multicolumn{2}{|c|}{$\mathbf{k}_{\text {eff }} \pm \mathbf{1 \sigma}$} \\
\hline \hline 1 & -9.20 & -0.00062 & 0.99938 & \pm & 0.00007 \\
\hline 2 & -9.05 & -0.00061 & 0.99939 & \pm & 0.00007 \\
\hline Average & -9.125 & -0.00061 & 0.99939 & \pm & 0.00007 \\
\hline
\end{tabular}

(a) Oak Ridge National Laboratory Critical Experiments Logbook 15r, p. 47.

2.6.2 Repeated Measurements - Repeatability measurements were also performed. The repeatability measurements are shown in Table 2.17. A $10 \%$ uncertainty in the measured $\mathrm{k}_{\text {eff }}$ and a $5 \%$ uncertainty in $\beta_{\text {eff }}$ is assumed.

Table 2.17. Measured Repeatability Data. ${ }^{\text {(a) }}$

\begin{tabular}{|c|c|c|c|}
\hline $\begin{array}{c}\text { Measurement } \\
\text { Number }\end{array}$ & $\begin{array}{c}\text { Measured } \\
\text { Reactivity (d) }\end{array}$ & $\begin{array}{c}\text { Measured } \\
\text { Reactivity }(\Delta \mathrm{k})\end{array}$ & $k_{\text {eff }} \pm 1 \sigma$ \\
\hline 1 & -7.87 & -0.00053 & $0.99947 \pm 0.00006$ \\
\hline 2 & -8.47 & -0.00057 & $0.99943 \pm 0.00006$ \\
\hline Average & -8.17 & -0.00055 & $0.99945 \pm 0.00006$ \\
\hline
\end{tabular}

(a) Oak Ridge National Laboratory Critical Experiments Logbook 15r, p. 48. Labeled as "repeat of Experiment 4" from 6-15-64.

2.6.3 Experiment $\mathbf{k}_{\text {eff }}-$ The average of the four experimental measurements of $k_{\text {eff }}$ are used to obtain the experiment $\mathrm{k}_{\text {eff }}$ value shown in Table 2.18 .

Table 2.18. Experiment $\mathrm{k}_{\mathrm{eff}}$.

\begin{tabular}{|c|c|}
\hline \hline Average $\mathbf{k}_{\text {eff }}{ }^{(\mathbf{a})}$ & Uncertainty $\boldsymbol{\sigma}_{\Delta \mathrm{keff}}$ \\
\hline \hline 0.99942 & 0.00003 \\
\hline
\end{tabular}

\subsection{Total Experimental Uncertainty}

The total uncertainty for the experiment was calculated by taking the square root of the sum of the squares of all the individual uncertainties discussed in this section. The summarized total uncertainties for each case are presented in Table 2.19. 
NEA/NSC/DOC/(95)03/II

Volume II

HEU-MET-FAST-081

Table 2.19. Total Experimental Uncertainty, $\Delta \mathrm{k}_{\text {eff. }}$.

\begin{tabular}{|c|c|c|c|}
\hline Perturbed Parameter & $\begin{array}{c}\text { Parameter } \\
\text { Value }\end{array}$ & $\begin{array}{c}1 \sigma \\
\text { Uncertainty } \\
\end{array}$ & $\pm \Delta \mathrm{k}_{\text {eff }}(1 \sigma)^{(\mathrm{a})}$ \\
\hline Homogenization of Units & -- & -- & Negligible \\
\hline Holes in Cylindrical Pieces & -- & -- & Negligible \\
\hline Gaps between Pieces & -- & -- & Negligible \\
\hline Total HEU Mass (g) & 206522 & 28 & Negligible \\
\hline HEU Dimensions (cm) & $\begin{array}{c}\text { Figures } \\
1.2-1.10\end{array}$ & Section 2.2.6 & Negligible \\
\hline Tilt Angle $\left(^{\circ}\right)$ & Table 2.7 & $0.068 / \sqrt{ } 2$ & 0.00017 \\
\hline${ }^{234} \mathrm{U}$ Content (wt.\%) & Table 2.9 & 0.05 & Negligible \\
\hline${ }^{235} \mathrm{U}$ Content (wt.\%) & Table 2.9 & 0.05 & Negligible \\
\hline${ }^{236} \mathrm{U}$ Content (wt.\%) & Table 2.9 & 0.05 & Negligible \\
\hline Impurity Content (wt.\%) & \multicolumn{2}{|c|}{ Table 2.11} & Negligible \\
\hline Radial Position $(\mathrm{cm})$ & Table 1.12 & 0.0254 & 0.00080 \\
\hline Angular Placement $\left({ }^{\circ}\right)$ & -- & -- & Negligible \\
\hline Vertical Deflection $(\mathrm{cm})$ & Table 2.7 & 0.0127 & Negligible \\
\hline Alternating Vertical Deflection $(\mathrm{cm})$ & Table 2.7 & 0.0127 & Negligible \\
\hline Centerpiece Vertical Deflection $(\mathrm{cm})$ & -1.755 & 0.0127 & Negligible \\
\hline Centerpiece (x, y) Position (cm) & $(0,0)$ & 0.0127 & Negligible \\
\hline Stack Order & -- & -- & Negligible \\
\hline Stack Alignment & -- & -- & Negligible \\
\hline Support Structure Worth $(\not)^{(\mathrm{b})}$ & -10.2 & 1.14 & Negligible \\
\hline Room Return & -- & -- & Negligible \\
\hline Temperature (K) & 293 & 2 & Negligible \\
\hline Measurement of $k_{\mathrm{eff}}(\not)^{(\mathrm{b})}$ & -9.13 & 0.72 & Negligible \\
\hline Experiment Repeatability $(\phi)^{(\mathrm{b})}$ & -8.17 & 0.65 & Negligible \\
\hline Total Uncertainty & -- & -- & 0.00082 \\
\hline
\end{tabular}

(a) Uncertainties $\leq 0.00010$ are considered negligible.

(b) Includes a $5 \%$ uncertainty in the $\beta_{\text {eff }}$ value of 0.0067 . 
HEU-MET-FAST-081

\subsection{BENCHMARK SPECIFICATIONS}

\subsection{Description of the Model}

The GROTESQUE experiment consisted of nine units comprised of smaller HEU pieces, eight of which were arranged in a circular manner on a steel diaphragm. The diaphragm had a hole cut in the center through which a ninth unit, the centerpiece, was raised to add reactivity. The weight of the eight units caused the diaphragm to sag, causing each unit to tilt slightly inward. The diaphragm, with its support structure, is not included in the benchmark model.

The original experiment was designed to test geometric capabilities when modeling complex arrangements. For this reason, including a detailed model in this evaluation is considered a preservation of the original intention of the work. However, there are several simplifications that can be applied to the model to create a simple version for other applications. For this reason, both simple and detailed models are developed in this section, with sample inputs for both models included in Appendix A. The simplifications used to create the models are described below and the corresponding biases are quantified. Please note that some simplifications were made to both models.

MCNP5 with ENDF/B-VII.0 cross section library data were used to evaluate biases in the benchmark models. A bias is considered negligible if $\Delta \mathrm{k}$ is $\leq 0.00010$.

\subsubsection{Detailed Model -}

3.1.1.1 HEU Simplifications - The pieces of each of the units have been homogenized into their respective basic units: rectangular parallelepipeds, cylinders, and a hemisphere. Small holes (support holes remnant from prior experimentation) in the cylindrical units were retained in the detailed model. The total mass of each unit was divided by the total unit volume to obtain unit densities (see Section 2.2.4). The effective bias in ignoring the gaps between pieces within a given unit was evaluated by approximating gaps between the pieces by twice the manufacturing tolerance of \pm 0.002 in. $( \pm 0.00508$ $\mathrm{cm}$ ). Actual gap thicknesses would be comparable to those found in HEU-MET-FAST-051, which are considerably smaller in size than the tolerance value used in this evaluation. ${ }^{a}$ The number of pieces within a given unit is summarized in Table 2.5. Total unit mass was conserved. The effective bias was determined to be negligible. Uncertainty perturbations in mass and geometry of the HEU units was also negligible (Sections 2.2.5 and 2.2.6, respectively), supporting the negligibility of streaming effects due to minuscule gaps between individual pieces within each unit.

3.1.1.2 Support Structure Simplification - The experimenter measured the worth of removing the steel diaphragm and the other support structures as $10.2 \phi$. The major support worth contribution came from the steel diaphragm. The experimentally measured model correction is $-0.00065 \pm 0.00007 \Delta \mathrm{k}$ as discussed in Section 2.3. This correction applies to both simple and detailed models.

3.1.1.3 Room Return - The properties and dimensions of the room in which the experiment was performed were not provided in the references, but they are available in many other East Cell ORCEF experiment reports. The dimensions used in this evaluation were obtained from a similar benchmark report: HEU-MET-FAST-076. The east cell is a $35 \times 35 \times 30 \mathrm{ft}$. high room, and the assemblies of uranium were located approximately $11.7 \mathrm{ft}$. from the five-foot-thick concrete west wall, $12.7 \mathrm{ft}$. from the twofoot-thick concrete north wall, and $9.2 \mathrm{ft}$. above the concrete floor. It was assumed that the unreported concrete wall, floor, and ceiling thicknesses are $5 \mathrm{ft}$. $^{\mathrm{b}}$ The concrete was modeled as Oak Ridge Concrete with a density of $2.3 \mathrm{~g} / \mathrm{cm}^{3}$ and the room density of the air was assumed to be $1.2 \mathrm{~kg} / \mathrm{m}^{3}$. The use of other types of concrete would provide similar results, as shown in HEU-MET-FAST-076. Both

\footnotetext{
${ }^{\text {a }}$ Personal communication with John T. Mihalczo, August 2011.

${ }^{\mathrm{b}}$ Personal communication with John T. Mihalczo, April 2011.
} 
concretes were prepared using crushed limestone instead of sand due to the unavailability of sand at the time. ${ }^{\mathrm{a}}$

The consequences of neglecting the room return effects were estimated to be $-0.00099 \pm 0.00001 \Delta \mathrm{k}_{\text {eff }}$. This worth is approximately equivalent to $-15.54 \pm 0.44 \not$, including an assumed $5 \%$ uncertainty in $\beta_{\text {eff. }}$. This simplification was used in both the simple and detailed models.

3.1.1.4 Impurities - The exact impurity content of the GROTESQUE uranium was unknown. Impurity data were not provided, but similar experiments provided some insight into possible impurities and their contents (see Table 2.11). The average impurity content, as discussed in Section 2.2.9, was added to the model, and the uranium mass appropriately decreased, to evaluate the effective bias in neglecting impurities in the benchmark models. Modeling the experiment without the inclusion of possible impurities created a bias of $-0.00022 \pm 0.00003 \Delta \mathrm{k}$. This simplification was used in both the simple and detailed models.

3.1.1.5 Bias Summary for the Detailed Model - Table 3.1 summarizes each individual bias discussed in Section 3.1.1. The total bias for the detailed benchmark model is the difference between the calculated $\mathrm{k}_{\text {eff }}$ value from a detailed model with impurities (excluding support structure and room return effects) and one incorporating the simplifications discussed in this section. This difference is added to the individual biases obtained for the experimentally determined removal of the support structure and estimated room return effects.

Table 3.1. Summary of Evaluated Biases for Detailed Model.

\begin{tabular}{|l|lll||}
\hline Bias Description & \multicolumn{2}{|c|}{ Bias \pm 16 } \\
\hline \hline Intra-Unit Gaps and Unit Mass Density & \multicolumn{2}{|c|}{ Negligible } \\
\hline Removal of Support Structures & -0.00068 & \pm & 0.00008 \\
\hline Room Return & -0.00099 & \pm & 0.00003 \\
\hline Removal of Impurities & -0.00022 & \pm & 0.00003 \\
\hline Total Bias $^{(\mathbf{a})}$ & $\mathbf{- 0 . 0 0 1 8 9}$ & \pm & $\mathbf{0 . 0 0 0 0 9}$ \\
\hline
\end{tabular}

(a) The total bias for the detailed model was obtained by comparing the calculated eigenvalues of a model with and without impurities and adding the difference to the experimentally measured simplification of support structure removal and the estimated correction for room return effects.

\subsubsection{Simple Model -}

The geometrically detailed model from Section 3.1.1 was further simplified in order to make a simple benchmark model. The following simplifications have been incorporated into the simple model, in addition to the simplifications already included in the detailed model, as described above in Section 3.1.1.

3.1.2.1 Additional HEU Simplifications - The $0.254 \mathrm{~cm}$ radius holes in the HEU cylinders were removed from the model and the density was appropriately reduced (see Section 2.2.4). This created a bias of $-0.00018 \pm 0.00003 \Delta \mathrm{k}$.

An average uranium density was calculated by dividing the total mass of the HEU components (206522 $\mathrm{g}$ ) by the total volume. The effective bias in modeling all units with the same average density is 0.00053 $\pm 0.00003 \Delta \mathrm{k}$.

\footnotetext{
a Personal communication with John T. Mihalczo, February 2010. 
NEA/NSC/DOC/(95)03/II

Volume II

HEU-MET-FAST-081

A mass-weighted average uranium content was calculated for this experiment (see Table 2.9). The effective bias in modeling all units with the same uranium content is $-0.00016 \pm 0.00003 \Delta \mathrm{k}$.

The bottoms of all nine HEU units were modeled as if placed on a single planar surface. This necessitated raising the outer eight units between 0.087 and $0.290 \mathrm{~cm}$. The centerpiece was raised by $1.755 \mathrm{~cm}$. This created a bias of $0.00028 \pm 0.00003 \Delta \mathrm{k}$.

The slight inward tilt of the eight outer units was removed. This caused a bias of $-0.00560 \pm 0.00003 \Delta \mathrm{k}$. Due to the large, dominating, bias for removing the tilt of the units, the calculation was repeated for this bias using KENO-VI ${ }^{\mathrm{a}}$ with ENDF/B-VII.0 (238-group) cross section data. The calculated bias for removing the unit tilt using KENO-VI was $-0.00623 \pm 0.00011 \Delta \mathrm{k}$. Additional calculations using a developmental version of the MONK9 $9^{\mathrm{b}}$ Monte Carlo Program were performed. A calculation with MONK9(DEV) and ENDF/B-VII.0 obtained a result of $-0.00550 \pm 0.00014 \Delta \mathrm{k}^{\mathrm{c}}{ }^{\mathrm{c}}$ The standard deviation of these three values was used to obtain an estimated $1 \sigma$ bias uncertainty of $\pm 0.00040 \Delta \mathrm{k}$. Calculations using MONK9 also demonstrated that the bias was approximately the same, within statistical uncertainty, regardless of which neutron cross section library was used. Furthermore, the effective cumulative bias determined by removing the tilt from each individual unit and summing the results is approximately the same as the bias obtained when the tilt was simultaneously removed from all units.

3.1.2.2 Bias Summary for the Simple Model - Table 3.2 summarizes each individual bias discussed in Section 3.1.2, where the total bias for the simple benchmark model is the sum the difference between the calculated $\mathrm{k}_{\text {eff }}$ value from a detailed model with impurities (excluding support structure and room return effects) and one incorporating the simplifications discussed in this section and Section 3.1.1. This difference is added to the individual biases obtained for the experimentally determined removal of the support structure and estimated room return effects.

Correlating effects in bias analysis simplifications may also contribute to the difference between the summation of the individual biases and the bias calculated for the benchmark model when all simplifications are performed simultaneously. This difference, however, is within the estimated $3 \sigma$ bias uncertainty. The bias computed with all simplifications included together is the best representative of the true bias. The uncertainty in that bias is obtained from the individual analysis of each simplification.

\footnotetext{
${ }^{a}$ D. F. Hollenbach, L. M. Petrie, S. Goluoglu, N. F. Landers, and M. E. Dunn, "KENO-VI: A General Quadratic Version of the KENO Program," ORNL/TM-2005/39 Version 6 Vol. II, Sect. F17, Oak Ridge National Laboratory (January 2009).

${ }^{\mathrm{b}}$ M. J. Armishaw and A. J. Cooper, "Current Status and Future Direction of the MONK Software Package," ICNC 2007, St. Petersburg, Russia, May 28 - June 1 (2007).

${ }^{\mathrm{c}}$ Personal Communication with Dave Hanlon, July 2011.
} 
Table 3.2. Summary of Evaluated Biases for Simplified Model.

\begin{tabular}{||l|ccc||}
\hline Bias Description & \multicolumn{2}{|c||}{ Bias $\pm \mathbf{1 \sigma}$} \\
\hline \hline Intra-Unit Gaps and Unit Mass Density & \multicolumn{2}{|c||}{ Negligible } \\
\hline Removal of Support Structures & -0.00068 & \pm & 0.00008 \\
\hline Room Return & -0.00099 & \pm 0.00003 \\
\hline Removal of Impurities & -0.00022 & \pm & 0.00003 \\
\hline Removal of Holes in Cylinders & -0.00018 & \pm & 0.00003 \\
\hline Average Fuel Density & +0.00053 & \pm & 0.00003 \\
\hline Average Uranium Isotopic Composition & -0.00016 & \pm & 0.00003 \\
\hline Placement of All Units on a Level Surface & +0.00028 & \pm & 0.00003 \\
\hline Removal of Unit Tilt & -0.00560 & \pm & 0.00040 \\
\hline Sum of Individual Biases & -0.00702 & \pm & 0.00041 \\
\hline \hline Total Bias ${ }^{(a)}$ & $\mathbf{- 0 . 0 0 7 6 8}$ & \pm & $\mathbf{0 . 0 0 0 4 1}$ \\
\hline
\end{tabular}

(a) The total bias for the simple model was obtained by comparing the calculated eigenvalues of a model with and without the model simplifications discussed above and adding the difference to the experimentally measured simplification of support structure removal and the estimated bias for room return effect.

The total bias for both of the detailed and simple benchmark models is compared in Table 3.3.

Table 3.3. Total Model Bias $(\Delta \mathrm{k})$.

\begin{tabular}{|c|c|}
\hline Detailed Model & Simple Model \\
\hline \hline$-0.00189 \pm 0.00009$ & $-0.00768 \pm 0.00041$ \\
\hline
\end{tabular}

\subsection{Model Dimensions}

Both the detailed and simple benchmark models are described in this section.

3.2.1 Individual HEU Units - The following figures are not to scale with respect to each other. However, each individual figure shows the components of each unit to scale with respect to the other components of that unit.

The first major unit (Unit 1) is located on the south side of the experiment, along the y-axis. It is a complex parallelepiped, as shown in Figure 3.1. The height at the highest point is $13.377 \mathrm{~cm}(11.155 \mathrm{~cm}$ $+2.222 \mathrm{~cm}$ ). The base parallelepiped is $12.703 \mathrm{~cm}$ along the $\mathrm{x}$-axis, and 12.703 in the y direction. The smallest height is $11.155 \mathrm{~cm}$. The dimensions of Unit 1 are identical for both the detailed and simple models. 
NEA/NSC/DOC/(95)03/II

Volume II

HEU-MET-FAST-081

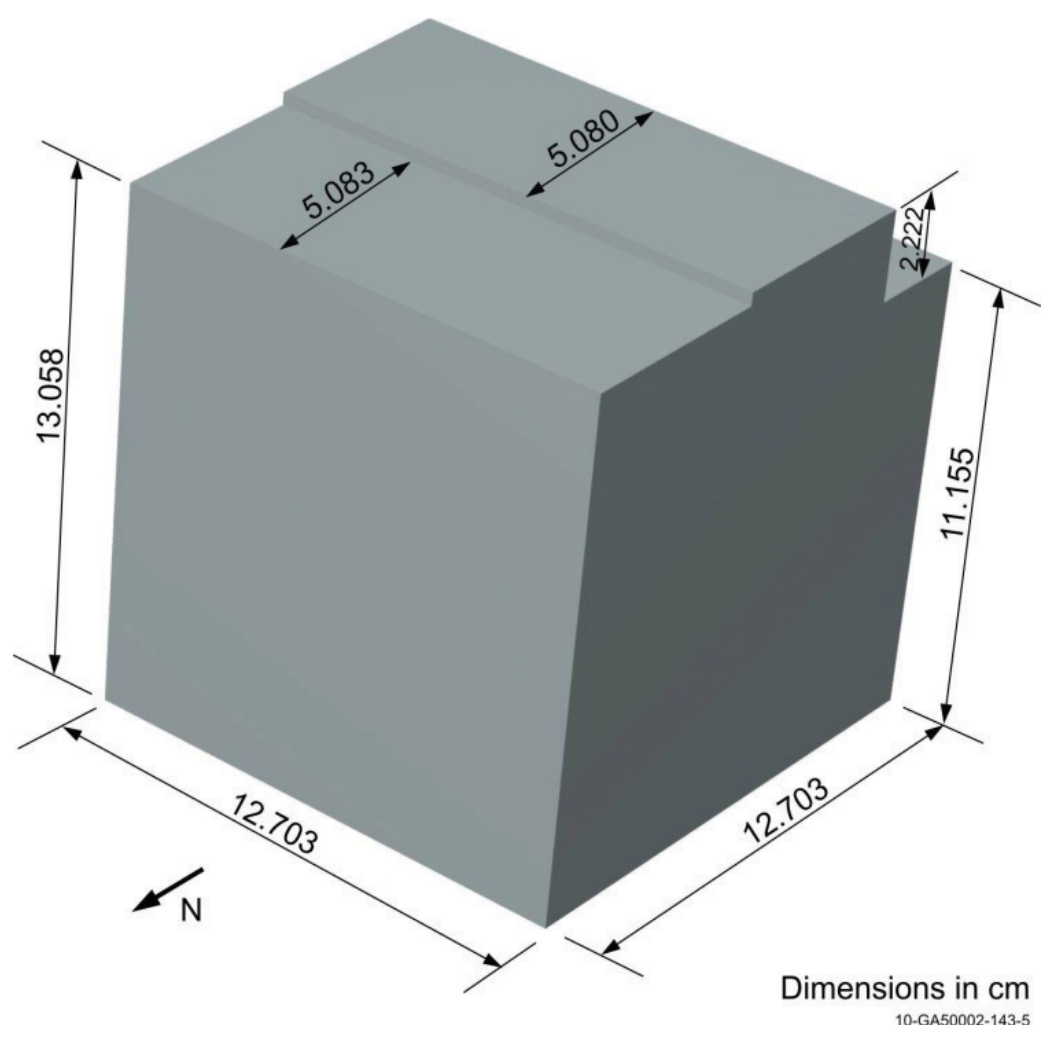

Figure 3.1. Unit 1 (detailed and simple model). 
Unit 2 is the next unit to the west of Unit 1; subsequent units will continue to be described in a clockwise direction from Unit 1 . Unit 2 is a cylinder with a diameter of $9.111 \mathrm{~cm}$ and a height of $12.918 \mathrm{~cm}$. Figure 3.2 shows the cylinder used in the detailed model in the upper portion of the figure (top) and the simple model in the lower portion (bottom).
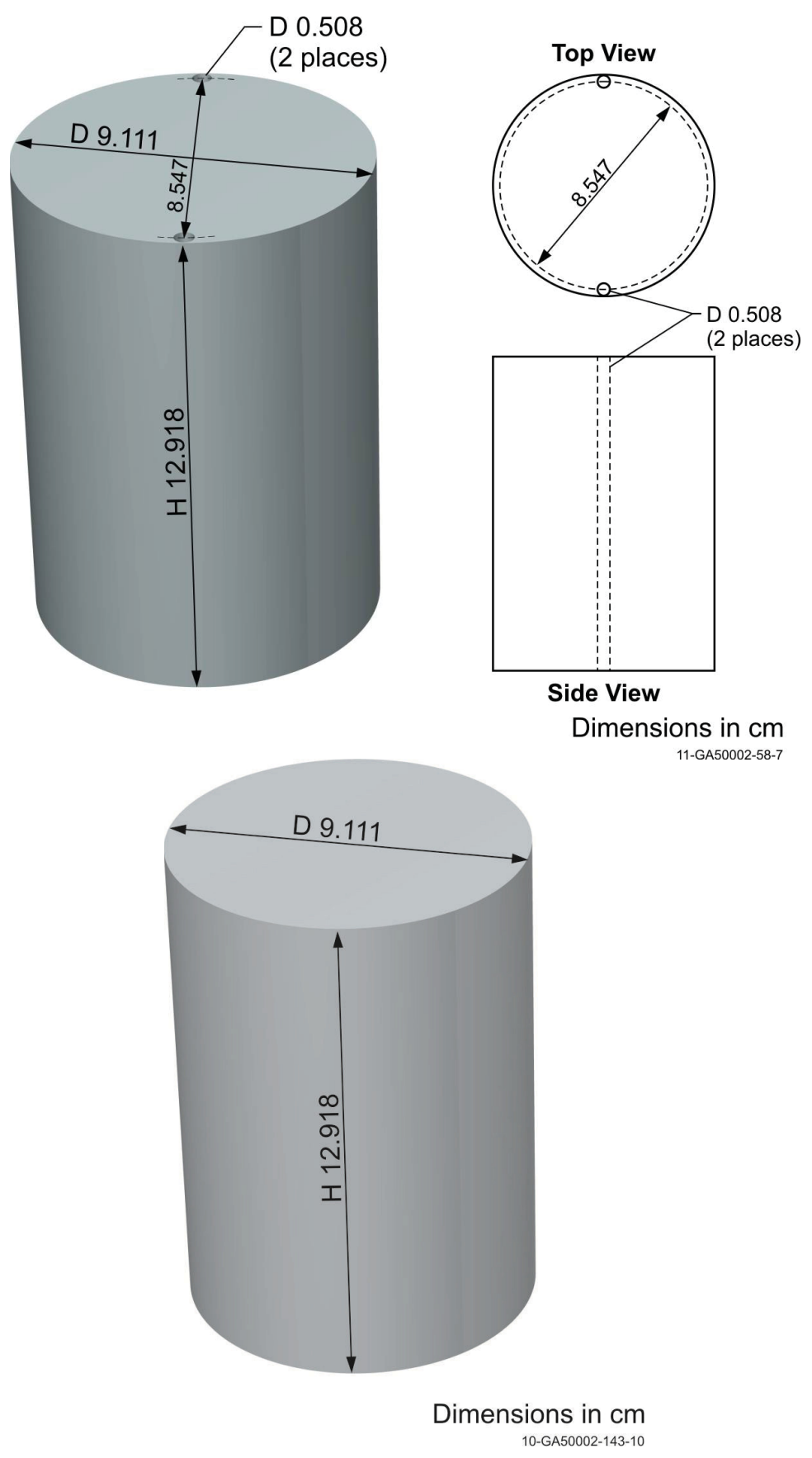

11-GA50002-58-7

Figure 3.2. Unit 2 (top=detailed, bottom=simple). 


\section{HEU-MET-FAST-081}

Unit 3 is close to being aligned with the $\mathrm{x}$-axis of the model, though not exactly centered on the axis. It is a cylinder with a diameter of $11.522 \mathrm{~cm}$ and a height of $13.475 \mathrm{~cm}$. Figure 3.3 shows the cylinder used in the detailed model on the top and the simple model on the bottom.

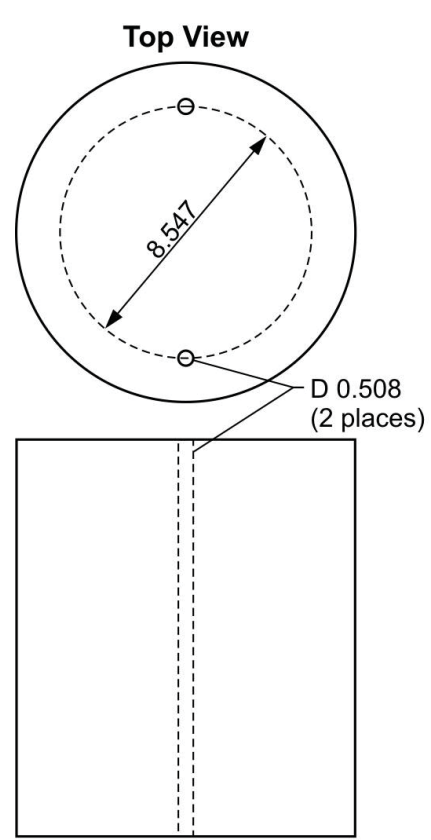

Side View

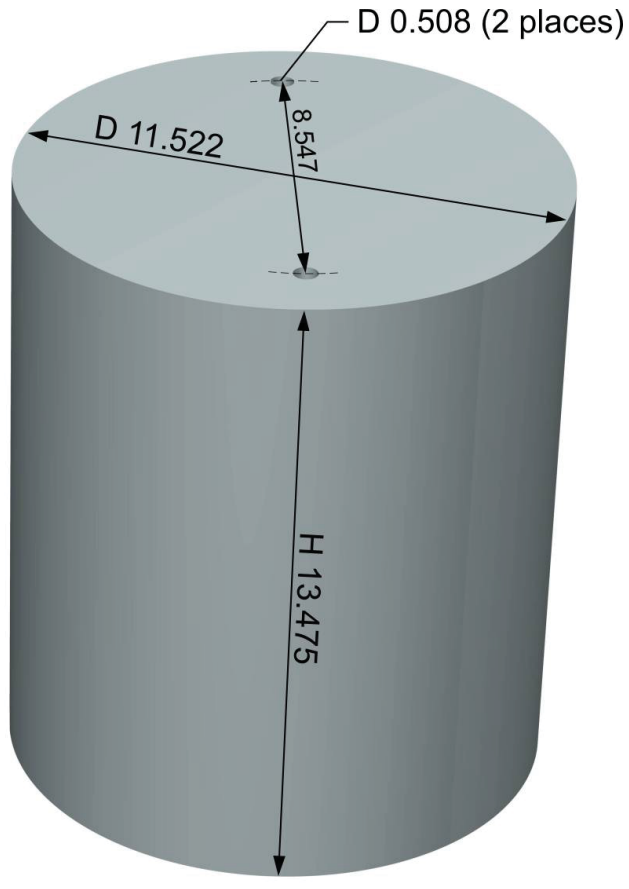

Dimensions in $\mathrm{cm}$ 11-GA50002-58-8

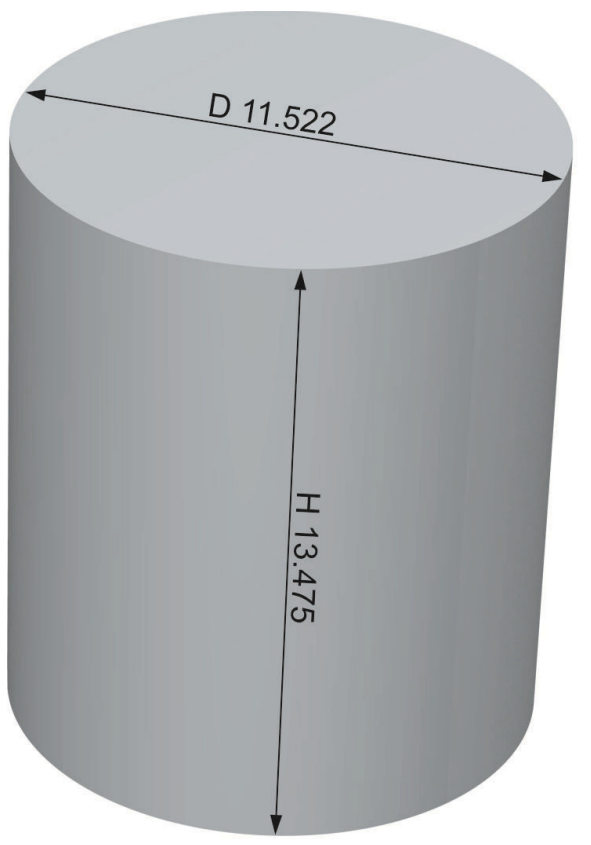

Dimensions in $\mathrm{cm}$ 10-GA50002-143-1C

Figure 3.3. Unit 3 (top=detailed, bottom=simple). 
Unit 4 is the last cylinder on the west side of the experiment. It is $9.105 \mathrm{~cm}$ in diameter and $12.969 \mathrm{~cm}$ high. Figure 3.4 shows the cylinder used in the detailed model on the top and the simple model on the bottom.
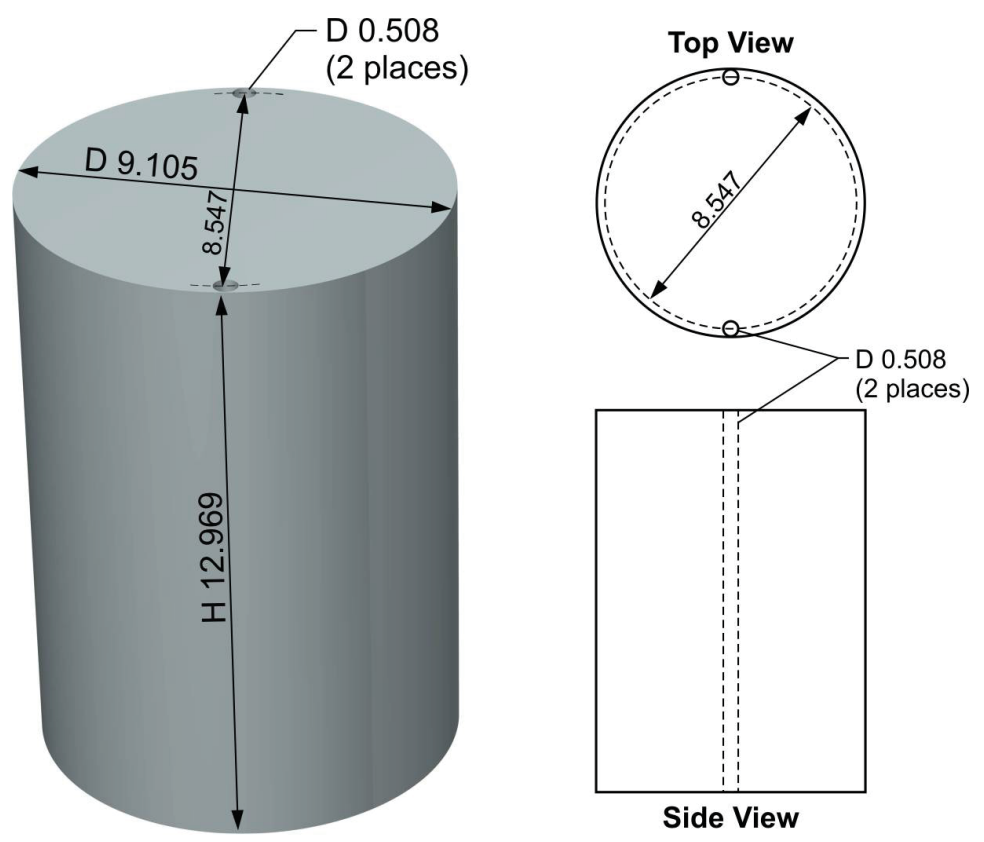

\section{Dimensions in $\mathrm{cm}$}

11-GA50002-58-7

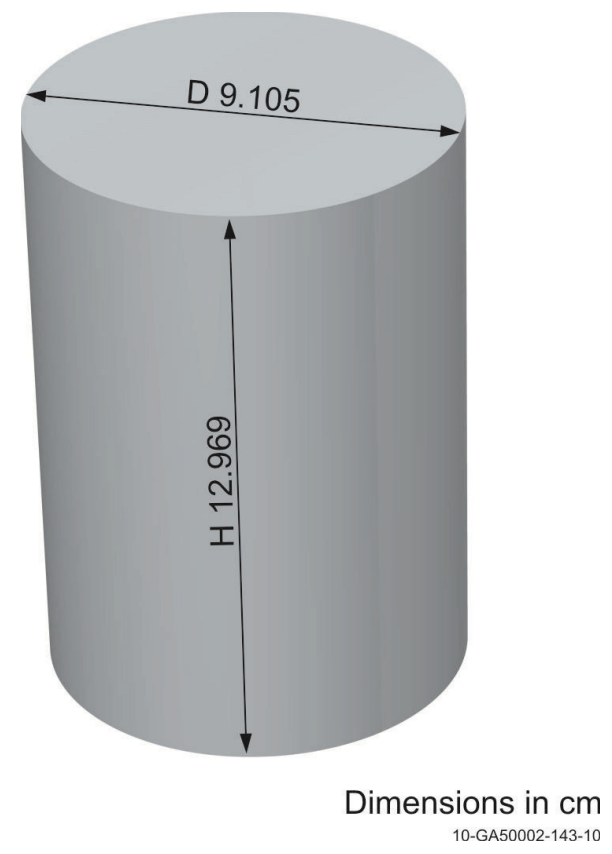

Figure 3.4. Unit 4 (top=detailed, bottom=simple). 
Unit 5 is on the north side of the experiment and opposite Unit 1. It is composed of a rectangular parallelepiped with a cylinder placed on top. The cylinder is positioned on the half of the parallelepiped closest to the center of the experiment. The parallelepiped is $12.703 \times 7.620 \times 8.910 \mathrm{~cm}$ and aligned with the longest side parallel to the y-axis. The cylinder on top is $9.146 \mathrm{~cm}$ in diameter and $4.319 \mathrm{~cm}$ in height. Figure 3.5 shows the unit used in the detailed model on the top and the simple model on the bottom.
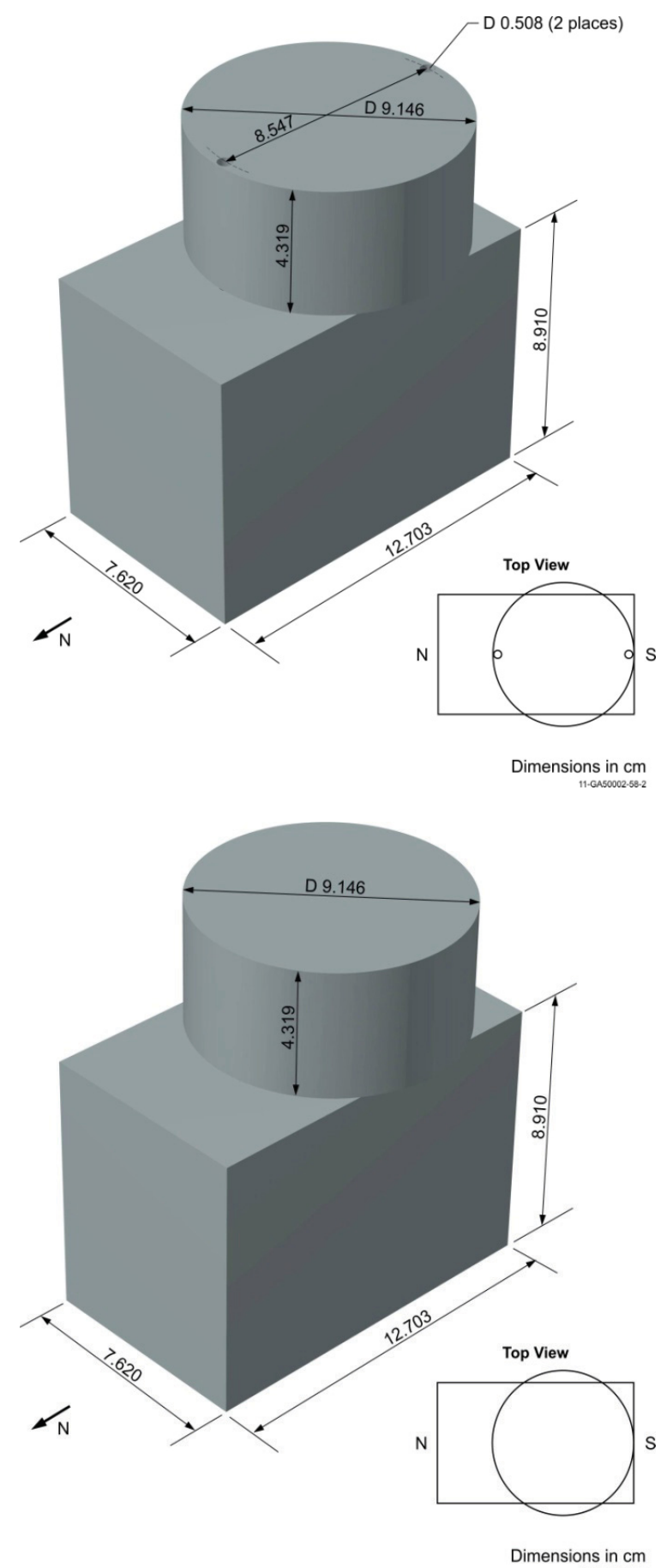

Figure 3.5. Unit 5 (top $=$ detailed, bottom $=$ simple). 
Units 6,7 , and 8 are positioned on the east side of the circular experiment. They are all cylinders of differing dimensions. Unit 6 (Figure 3.6) has a diameter of 9.109 and a height of 12.974. Unit 7 (Figure 3.7 ) is very nearly aligned with the x-axis of the experiment, but not completely centered on the axis. It is $11.499 \mathrm{~cm}$ in diameter and the height is $13.475 \mathrm{~cm}$. Unit 8 (Figure 3.8) is the last cylinder in the experiment, counting clockwise from Unit 1 . It is $9.113 \mathrm{~cm}$ in diameter and the height is $12.954 \mathrm{~cm}$. In each of Figures 3.6 through 3.8, the cylinder used in the detailed model is shown on the top and the simple model on the bottom.
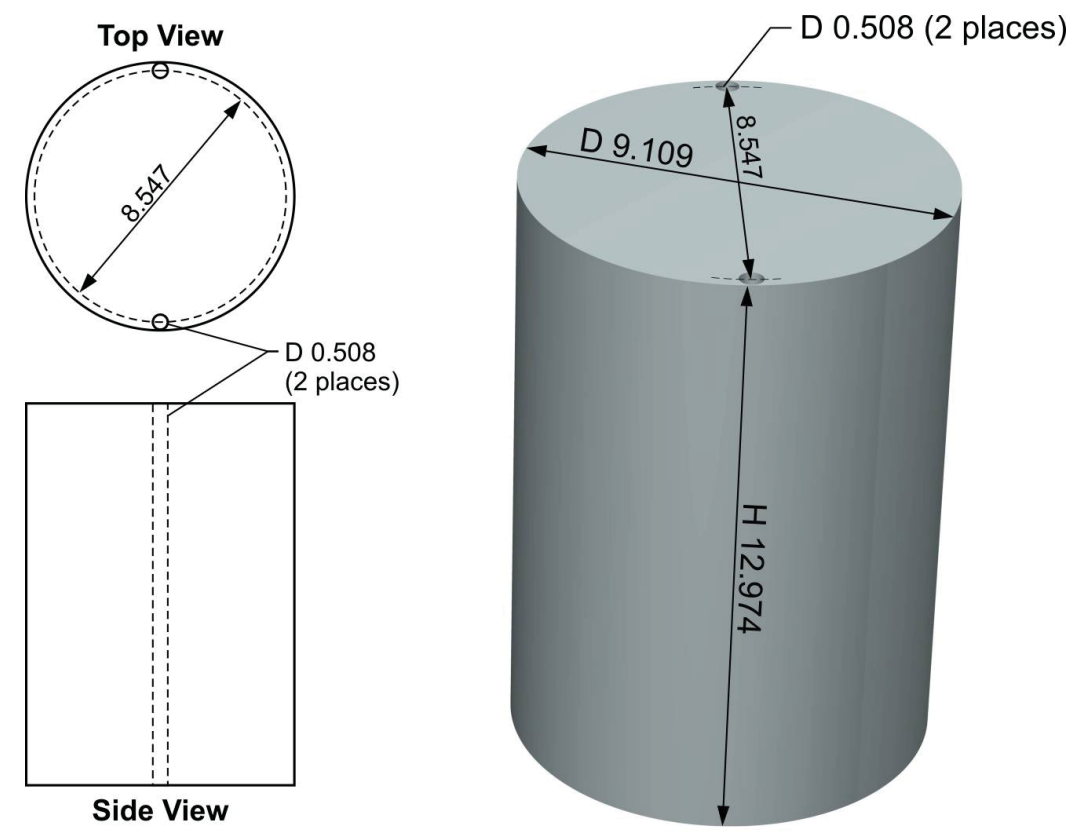

Side View

Dimensions in $\mathrm{cm}$

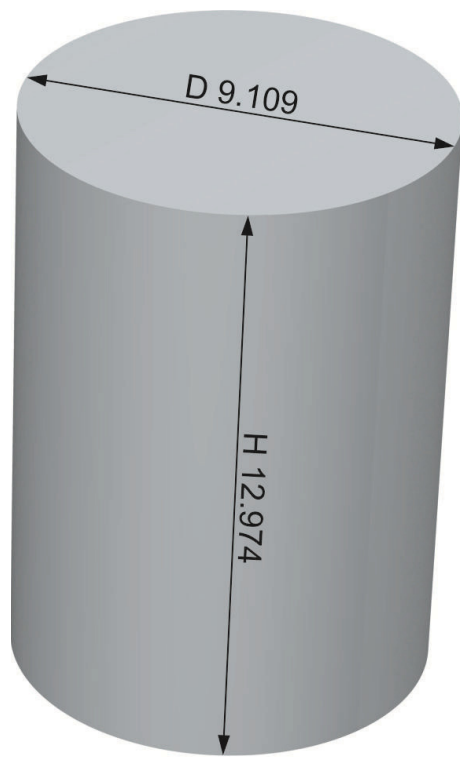

11-GA50002-58-8

\section{Dimensions in $\mathrm{cm}$}

Figure 3.6. Unit 6 (top=detailed, bottom=simple). 
NEA/NSC/DOC/(95)03/II

Volume II

HEU-MET-FAST-081
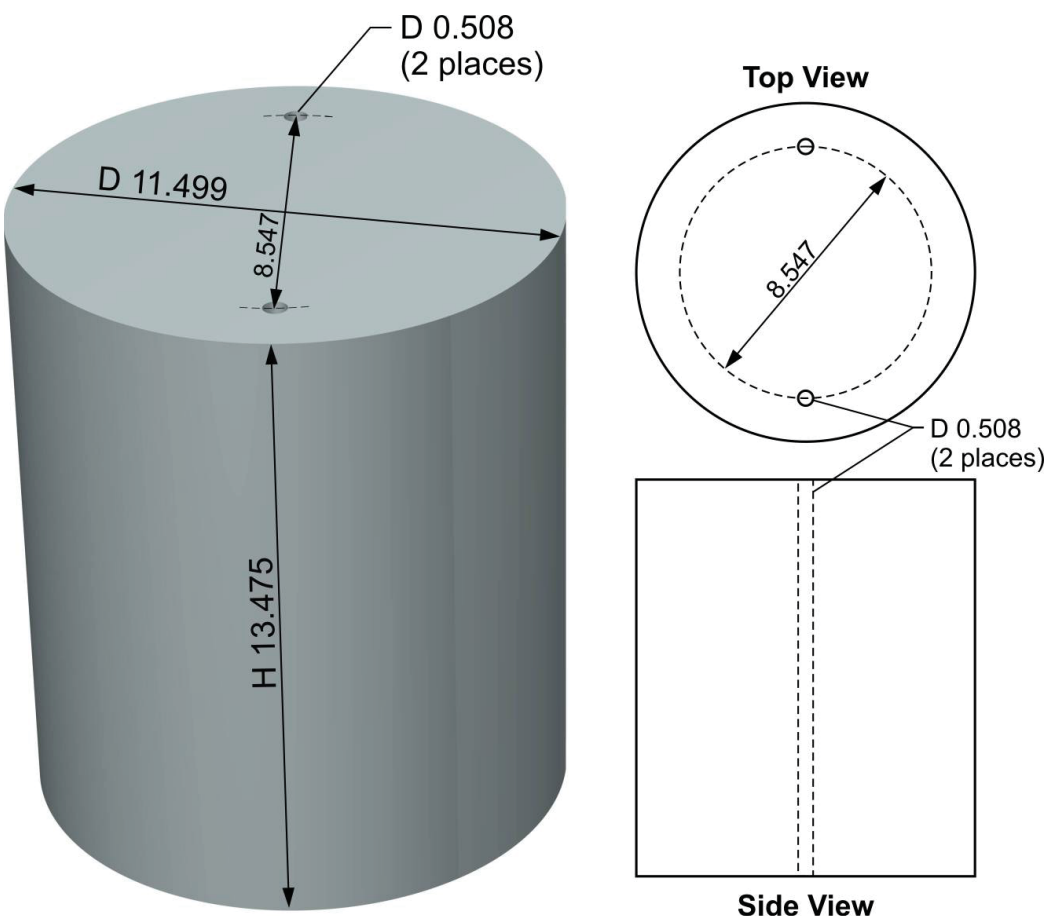

Side View

Dimensions in $\mathrm{cm}$

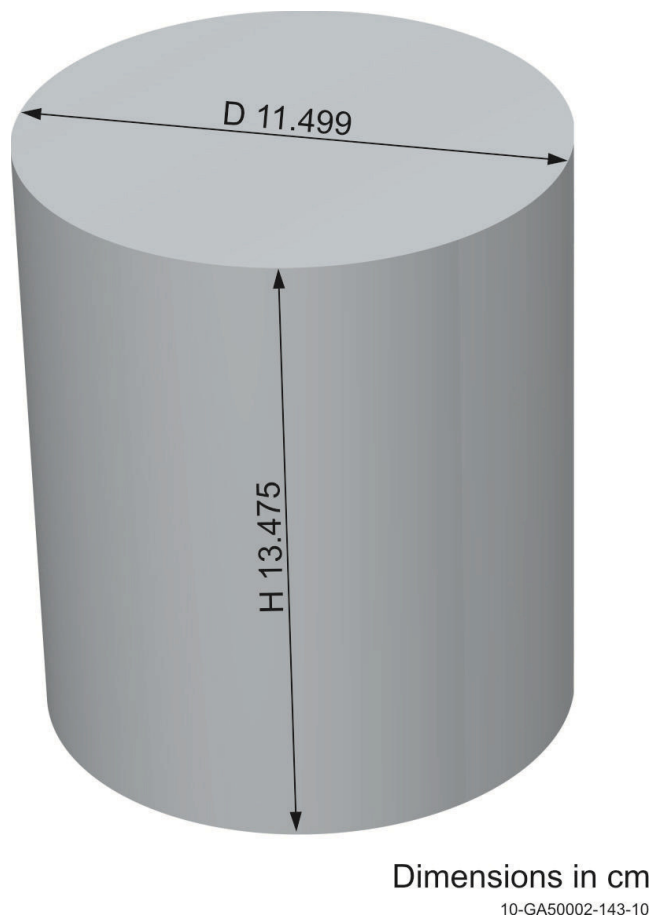

Figure 3.7. Unit 7 (top=detailed, bottom $=$ simple). 
NEA/NSC/DOC/(95)03/II

Volume II

\section{HEU-MET-FAST-081}
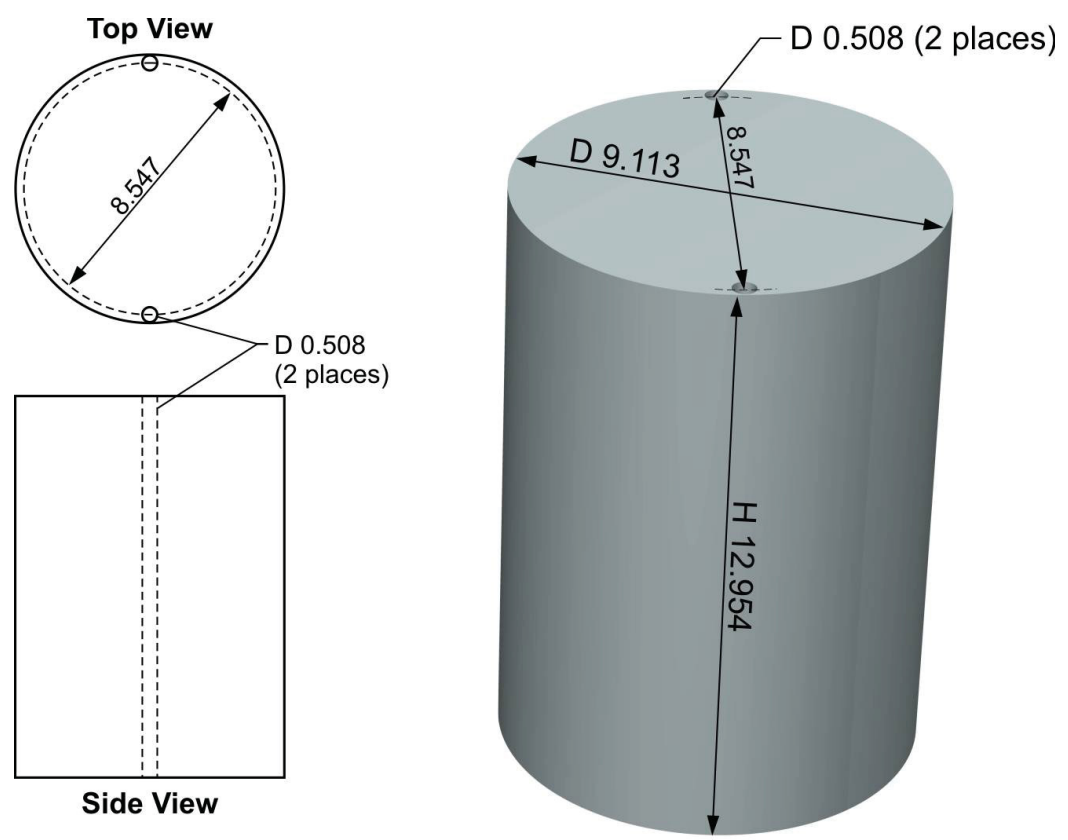

Side View

Dimensions in $\mathrm{cm}$

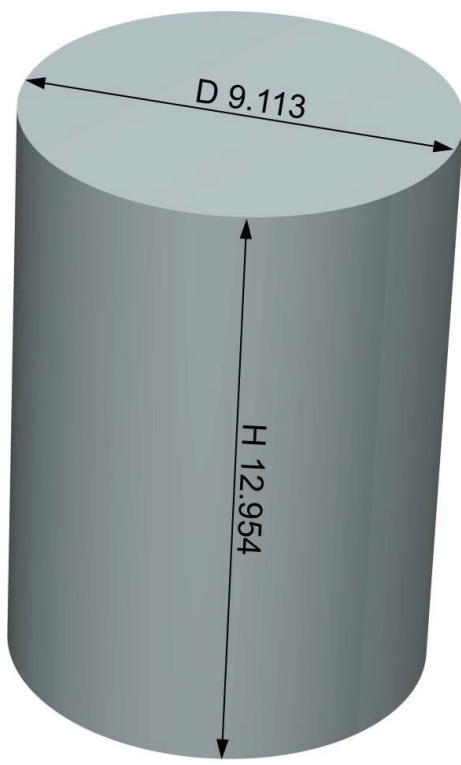

11-GA50002-58-8

\section{Dimensions in $\mathrm{cm}$}

Figure 3.8. Unit 8 (top=detailed, bottom $=$ simple). 
Unit 9 is the centerpiece of the experiment. It is composed of a hemisphere, a cylinder, and a rectangular parallelepiped. The cylinder is the bottommost piece, with a diameter of $11.514 \mathrm{~cm}$ and a height of 2.692 $\mathrm{cm}$. The rectangular parallelepiped was placed on top of the cylinder, with the west and south edges flush with the outer most point of the cylinder on the west and south sides. This created an un-centered effect, with the overhangs in the east and north directions of the experiment. The parallelepiped was $12.700 \mathrm{~cm}$ $\times 12.700 \mathrm{~cm}$ and $5.718 \mathrm{~cm}$ in height. The hemisphere is the uppermost part, with the outer most point of its west edge flush with the west edge of the other two pieces but with the north edge flush with the north side of the parallelepiped. It is $12.164 \mathrm{~cm}$ in diameter, and so does not extend fully to the opposite side of the parallelepiped. This unit is illustrated in detail in Figure 3.9, the unit used in the detailed model is on the top and the simple model on the bottom.
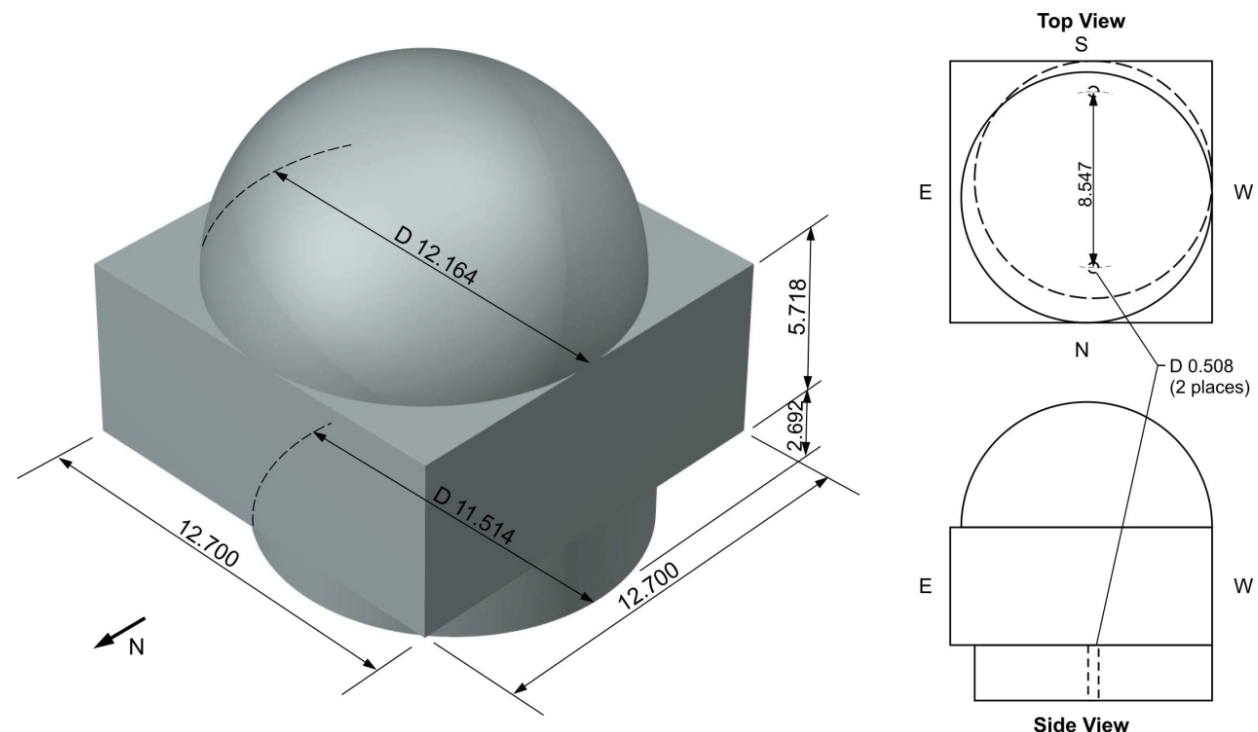

Dimensions in $\mathrm{cm}$
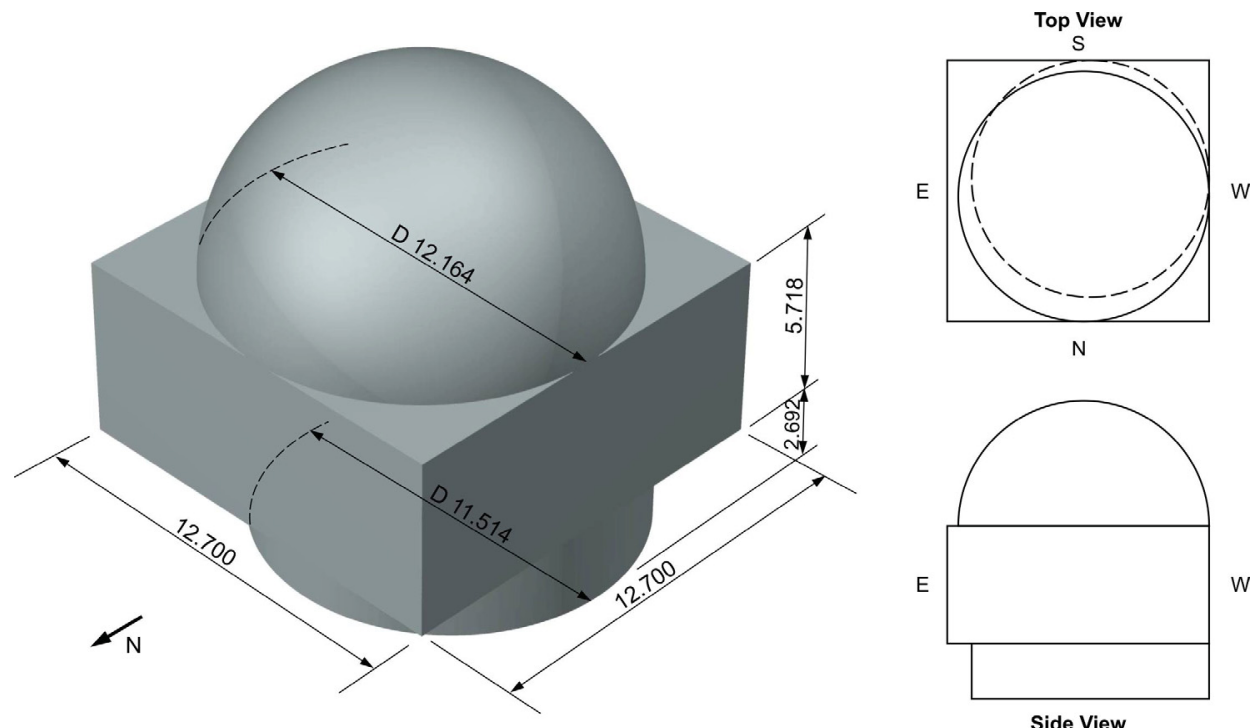

Side View

Dimensions in $\mathrm{cm}$

Figure 3.9. Unit 9, Centerpiece(top=detailed, bottom=simple). 
HEU-MET-FAST-081

3.2.2 Assembly Description - The exact position of the center of the bottom of each major unit in relation to the center of the experimental configuration is described in Table 3.4. This information is used for both the simple and detailed models. Additional information regarding the vertical positioning of the pieces and their tilt angle towards the center of the experiment, necessary for describing the detailed model, are provided in Table 3.5. The simple model does not have tilting and all pieces are modeled as if supported on a level planar surface. Figures 3.10 and 3.11 show an isometric and schematic view of the simple model, respectively, to demonstrate placement of units within the simple and detailed models. Only the simple model is shown because the overall placement of the units is the same in both models. The tilt, bottom $\mathrm{z}$ coordinate, and holes in the cylinders removed from the simple model (See Section 3.1.2) are not shown because they do not affect the overall macroscopic dimensions being presented in the following tables and figures.

Table 3.4. Assembly Geometry Positioning.

\begin{tabular}{|c|c|c|c|}
\hline $\begin{array}{c}\text { Unit } \\
\text { Number }\end{array}$ & $\begin{array}{c}\text { Angular } \\
\text { Spacing } \\
\left(\mathbf{(}^{\mathbf{0}}\right.\end{array}$ & $\begin{array}{c}\text { Center } \\
\text { Bottom } \\
\text { X Coordinate } \\
\text { (cm) }\end{array}$ & $\begin{array}{c}\text { Center } \\
\text { Bottom } \\
\text { Y Coordinate } \\
\text { (cm) }\end{array}$ \\
\hline \hline 1 & 270.0 & 0.0 & -17.464 \\
\hline 2 & 217.5 & -12.176 & -9.343 \\
\hline 3 & 173.5 & -16.333 & 1.861 \\
\hline 4 & 130.5 & -9.539 & 11.168 \\
\hline $5^{(\mathrm{a})}$ & 90.0 & 0.0 & 17.477 \\
\hline $5^{(\mathrm{b})}$ & 90.0 & 0.0 & 15.698 \\
\hline 6 & 48.0 & 9.854 & 10.944 \\
\hline 7 & 5.0 & 16.388 & 1.434 \\
\hline 8 & 322.0 & 12.029 & -9.398 \\
\hline $9^{(\mathrm{b})}$ & - & -0.593 & -0.593 \\
\hline $9^{(\mathrm{a})}$ & - & 0.0 & 0.0 \\
\hline $9^{(\mathrm{c})}$ & - & -0.268 & 0.268 \\
\hline
\end{tabular}

(a) Rectangular parallelepiped component piece.

(b) Cylinder component piece.

(c) Hemisphere component piece. 
NEA/NSC/DOC/(95)03/II

Volume II

HEU-MET-FAST-081

Table 3.5. Vertical Positioning and Tilt Angle for HEU Units (detailed model only).

\begin{tabular}{|c|c|c|}
\hline $\begin{array}{c}\text { Unit } \\
\text { Number }\end{array}$ & $\begin{array}{c}\text { Bottom } \\
\text { Z Coordinate } \\
(\mathbf{c m})\end{array}$ & Tilt Angle $\mathbf{(}^{\mathbf{}}$ ) \\
\hline \hline 1 & 0.150 & 1.350 \\
\hline 2 & 0.111 & 1.400 \\
\hline 3 & 0.174 & 1.173 \\
\hline 4 & 0.156 & 1.970 \\
\hline $5^{(\text {a) }}$ & 0.290 & 2.580 \\
\hline $5^{(\text {b) }}$ & 9.2 & 2.580 \\
\hline 6 & 0.134 & 1.680 \\
\hline 7 & 0.140 & 1.400 \\
\hline 8 & 0.087 & 1.100 \\
\hline $9^{(\text {b) }}$ & -1.755 & 0.000 \\
\hline $9^{(\text {a) }}$ & 0.937 & 0.000 \\
\hline $9^{(\mathrm{c})}$ & 6.655 & 0.000 \\
\hline
\end{tabular}

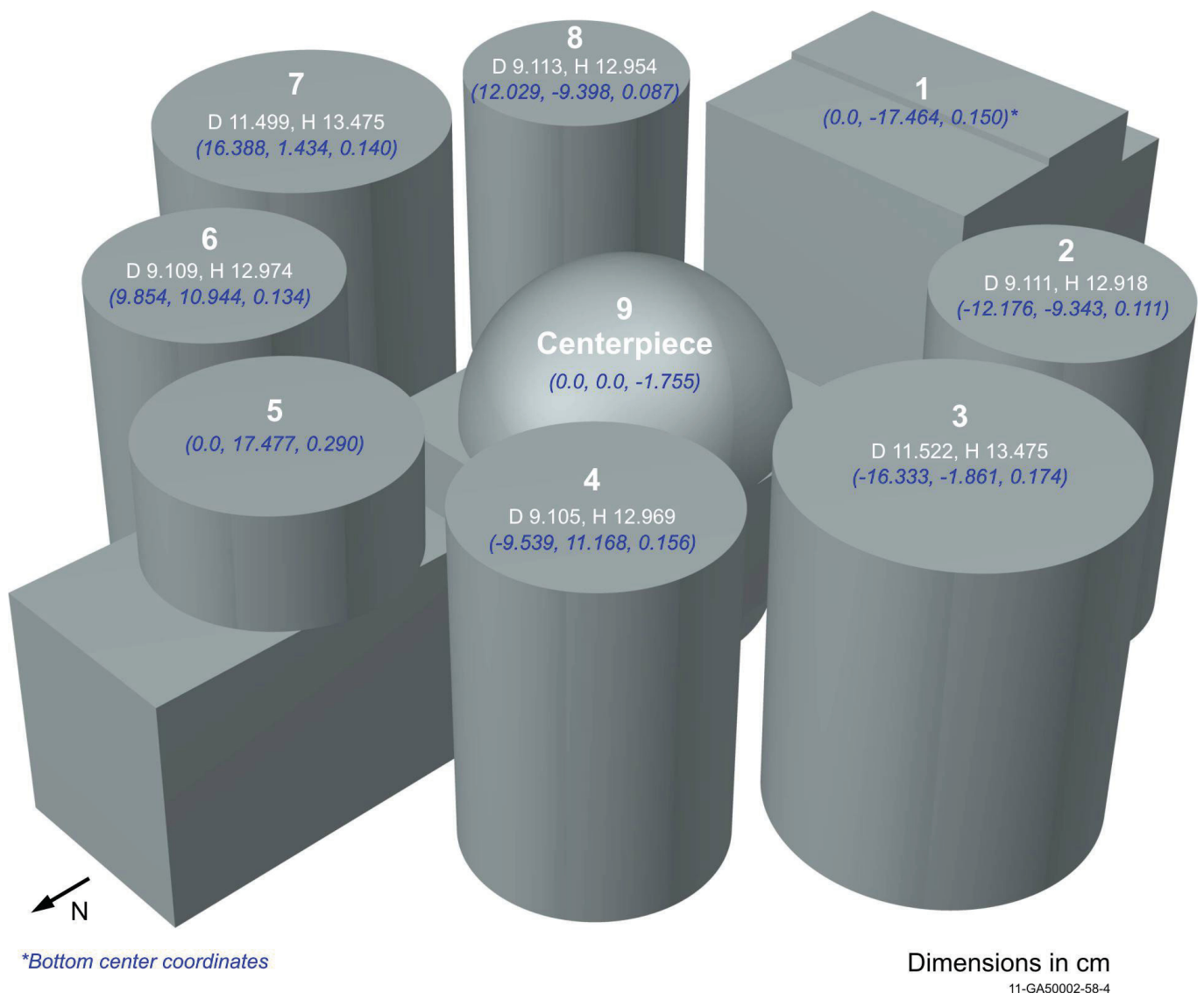

Figure 3.10. Isometric View of the GROTESQUE Models. (Holes in cylindrical pieces not shown). 
NEA/NSC/DOC/(95)03/II

Volume II

HEU-MET-FAST-081

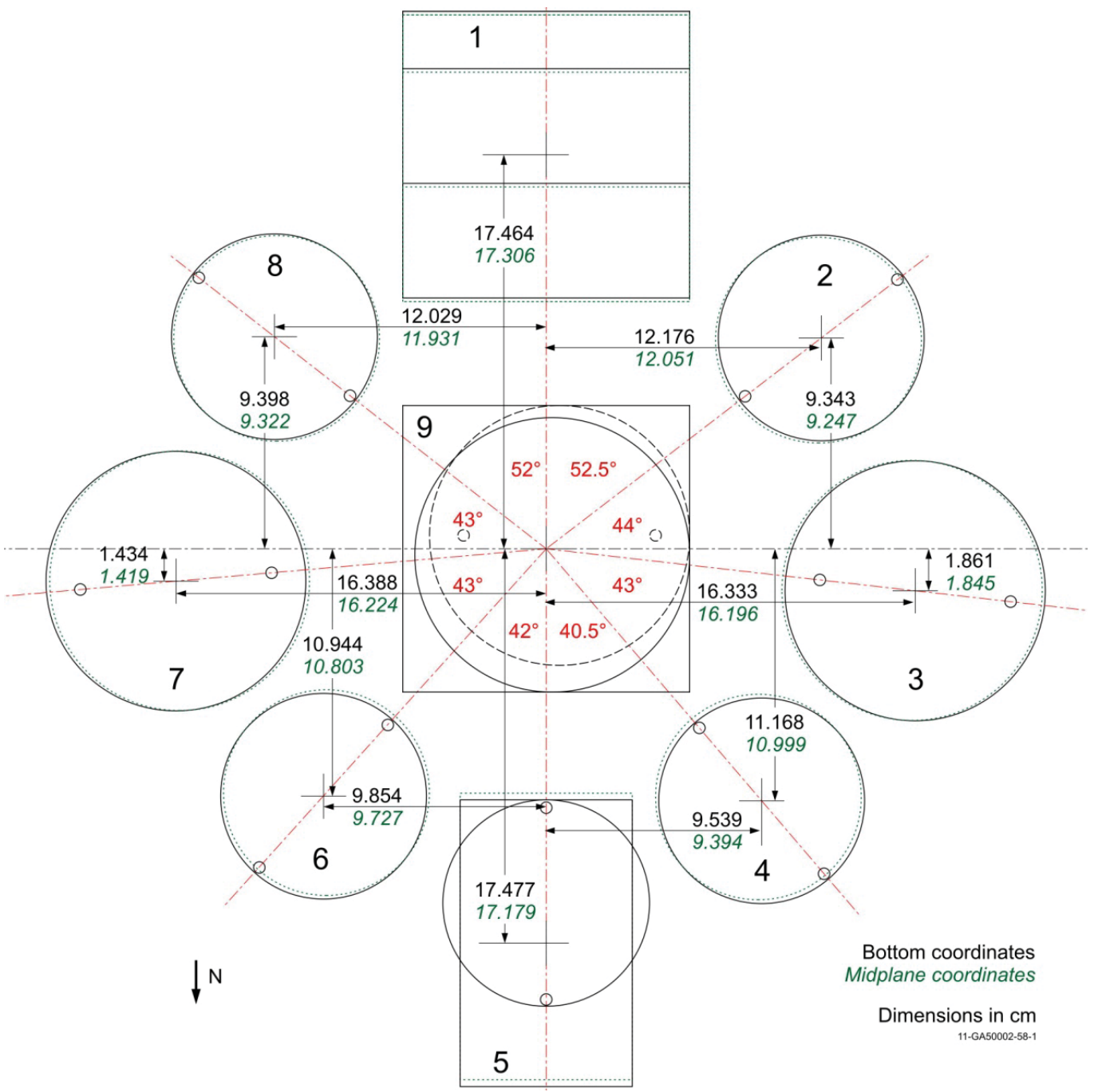

Figure 3.11. Schematic View of the GROTESQUE Models (Top View). 
NEA/NSC/DOC/(95)03/II

Volume II

HEU-MET-FAST-081

\subsection{Description of Material Data}

3.3.1 HEU Metal - The atomic densities of uranium isotopes are provided in Table 3.6 and Table 3.7 for the detailed and simple models, respectively. Each unit (or subunit in the case of Units 5 and 9) have unique compositions and densities in the detailed model. All units have the same density and isotopic composition in the simple model. The atom densities for both models have been adjusted for the removal of impurities; the effective uranium content fraction is 0.99951 . 
NEA/NSC/DOC/(95)03/II

Volume II

HEU-MET-FAST-081

Table 3.6. Detailed Model Uranium Composition.

\begin{tabular}{|c|c|c|c|}
\hline Unit & Isotope & $\begin{array}{c}\text { Composition } \\
\text { (wt.\%) }\end{array}$ & $\begin{array}{l}\text { Atom Density } \\
\text { (atoms/b- cm) }\end{array}$ \\
\hline \multirow{4}{*}{1} & ${ }^{234} \mathrm{U}$ & 1.07 & $5.1270 \mathrm{E}-04$ \\
\hline & ${ }^{235} \mathrm{U}$ & 93.15 & $4.4443 \mathrm{E}-02$ \\
\hline & ${ }^{236} \mathrm{U}$ & 0.68 & $3.2306 \mathrm{E}-04$ \\
\hline & ${ }^{238} \mathrm{U}$ & 5.10 & $2.4025 \mathrm{E}-03$ \\
\hline \multirow{4}{*}{2} & ${ }^{234} \mathrm{U}$ & 0.97 & 4.6998E-04 \\
\hline & ${ }^{235} \mathrm{U}$ & 93.15 & $4.4940 \mathrm{E}-02$ \\
\hline & ${ }^{236} \mathrm{U}$ & 0.24 & $1.1530 \mathrm{E}-04$ \\
\hline & ${ }^{238} \mathrm{U}$ & 5.64 & $2.6867 \mathrm{E}-03$ \\
\hline \multirow{4}{*}{3} & ${ }^{234} \mathrm{U}$ & 0.97 & $4.6730 \mathrm{E}-04$ \\
\hline & ${ }^{235} \mathrm{U}$ & 93.15 & $4.4684 \mathrm{E}-02$ \\
\hline & ${ }^{236} \mathrm{U}$ & 0.24 & $1.1464 \mathrm{E}-04$ \\
\hline & ${ }^{238} \mathrm{U}$ & 5.64 & $2.6713 \mathrm{E}-03$ \\
\hline \multirow{4}{*}{4} & ${ }^{234} \mathrm{U}$ & 0.97 & $4.6733 \mathrm{E}-04$ \\
\hline & ${ }^{235} \mathrm{U}$ & 93.15 & $4.4687 \mathrm{E}-02$ \\
\hline & ${ }^{236} \mathrm{U}$ & 0.24 & $1.1465 \mathrm{E}-04$ \\
\hline & ${ }^{238} \mathrm{U}$ & 5.64 & $2.6715 \mathrm{E}-03$ \\
\hline \multirow{4}{*}{$5-$ box } & ${ }^{234} \mathrm{U}$ & 1.07 & 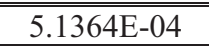 \\
\hline & ${ }^{235} \mathrm{U}$ & 93.15 & $4.4525 \mathrm{E}-02$ \\
\hline & ${ }^{236} \mathrm{U}$ & 0.68 & $3.2365 \mathrm{E}-04$ \\
\hline & ${ }^{238} \mathrm{U}$ & 5.10 & $2.4070 \mathrm{E}-03$ \\
\hline \multirow{4}{*}{5 - cylinder } & ${ }^{234} \mathrm{U}$ & 0.97 & $4.6762 \mathrm{E}-04$ \\
\hline & ${ }^{235} \mathrm{U}$ & 93.15 & $4.4714 \mathrm{E}-02$ \\
\hline & ${ }^{236} \mathrm{U}$ & 0.24 & $1.1472 \mathrm{E}-04$ \\
\hline & ${ }^{238} \mathrm{U}$ & 5.64 & $2.6731 \mathrm{E}-03$ \\
\hline \multirow{4}{*}{6} & ${ }^{234} \mathrm{U}$ & 0.97 & 4.6694E-04 \\
\hline & ${ }^{235} \mathrm{U}$ & 93.15 & $4.4650 \mathrm{E}-02$ \\
\hline & ${ }^{236} \mathrm{U}$ & 0.24 & $1.1455 \mathrm{E}-04$ \\
\hline & ${ }^{238} \mathrm{U}$ & 5.64 & $2.6693 \mathrm{E}-03$ \\
\hline \multirow{4}{*}{7} & ${ }^{234} \mathrm{U}$ & 0.97 & 4.6818E-04 \\
\hline & ${ }^{235} \mathrm{U}$ & 93.15 & $4.4768 \mathrm{E}-02$ \\
\hline & ${ }^{236} \mathrm{U}$ & 0.24 & $1.1485 \mathrm{E}-04$ \\
\hline & ${ }^{238} \mathrm{U}$ & 5.64 & $2.6763 \mathrm{E}-03$ \\
\hline \multirow{4}{*}{8} & ${ }^{234} \mathrm{U}$ & 0.97 & (4.6808E-04 \\
\hline & ${ }^{235} \mathrm{U}$ & 93.15 & $4.4759 \mathrm{E}-02$ \\
\hline & ${ }^{236} \mathrm{U}$ & 0.24 & $1.1483 \mathrm{E}-04$ \\
\hline & ${ }^{238} \mathrm{U}$ & 5.64 & $2.6758 \mathrm{E}-03$ \\
\hline \multirow{4}{*}{9 - cylinder } & ${ }^{234} \mathrm{U}$ & 0.97 & 4.6881E-04 \\
\hline & ${ }^{235} \mathrm{U}$ & 93.15 & $4.4829 \mathrm{E}-02$ \\
\hline & ${ }^{236} \mathrm{U}$ & 0.24 & $1.1501 \mathrm{E}-04$ \\
\hline & ${ }^{238} \mathrm{U}$ & 5.64 & $2.6800 \mathrm{E}-03$ \\
\hline \multirow{4}{*}{$9-$ box } & ${ }^{234} \mathrm{U}$ & 1.07 & 5.1352E-04 \\
\hline & ${ }^{235} \mathrm{U}$ & 93.15 & 4.4514E-02 \\
\hline & ${ }^{236} \mathrm{U}$ & 0.68 & $3.2358 \mathrm{E}-04$ \\
\hline & ${ }^{238} \mathrm{U}$ & 5.10 & $2.4064 \mathrm{E}-03$ \\
\hline \multirow{4}{*}{9 - hemisphere } & ${ }^{234} \mathrm{U}$ & 0.97 & 4.6792E-04 \\
\hline & ${ }^{235} \mathrm{U}$ & 93.15 & $4.4743 \mathrm{E}-02$ \\
\hline & ${ }^{236} \mathrm{U}$ & 0.24 & $1.1479 \mathrm{E}-04$ \\
\hline & ${ }^{238} \mathrm{U}$ & 5.64 & $2.6749 \mathrm{E}-03$ \\
\hline
\end{tabular}


$\mathrm{NEA} / \mathrm{NSC} / \mathrm{DOC} /(95) 03 / \mathrm{II}$

Volume II

HEU-MET-FAST-081

Table 3.7. Simple Model Uranium Composition.

\begin{tabular}{|c|c|c||}
\hline Isotope & $\begin{array}{c}\text { Composition } \\
\text { (wt.\%) }\end{array}$ & $\begin{array}{c}\text { Atom Density } \\
\text { (atoms/b- cm) }\end{array}$ \\
\hline \hline${ }^{234} \mathrm{U}$ & 1.00 & $4.7990 \mathrm{E}-04$ \\
\hline${ }^{235} \mathrm{U}$ & 93.15 & $4.4512 \mathrm{E}-02$ \\
\hline${ }^{236} \mathrm{U}$ & 0.39 & $1.8557 \mathrm{E}-04$ \\
\hline${ }^{238} \mathrm{U}$ & 5.46 & $2.5761 \mathrm{E}-03$ \\
\hline
\end{tabular}

\subsection{Temperature Data}

The benchmark model is evaluated at room temperature $(293 \mathrm{~K})$ for both the simple and detailed models.

\subsection{Experimental and Benchmark Model $\mathbf{k}_{\text {eff }}$}

The experimental and benchmark $\mathrm{k}_{\text {eff }}$ values for GROTESQUE are presented in Table 3.8 with their associated uncertainties. The reactivity effects of the support structure, room return effects, and biases discussed in Section 3.1 have been added to the experimental $k_{\text {eff }}$ to obtain the benchmark $\mathrm{k}_{\text {eff }}$ values for both the detailed and simplified benchmark models. The experimental uncertainty was evaluated in Section 2 and summarized in Table 2.19. The experimental uncertainty is combined in quadrature with the bias uncertainty to obtain the total benchmark model uncertainty.

Table 3.8. Experimental and Benchmark $\mathrm{k}_{\mathrm{eff}}$ Values $(1 \sigma)$.

\begin{tabular}{|c|c|c|c|}
\hline Model & Experimental $\mathbf{k}_{\text {eff }}$ & $\Delta$ k Bias & Benchmark $\mathbf{k}_{\text {eff }}$ \\
\hline \hline Detailed & \multirow{2}{*}{$0.9994 \pm 0.0008$} & $-0.0019 \pm 0.0001$ & $0.9975 \pm 0.0008$ \\
\cline { 1 - 3 } \cline { 3 - 4 } Simple & & $-0.0077 \pm 0.0004$ & $0.9917 \pm 0.0009$ \\
\hline
\end{tabular}


NEA/NSC/DOC/(95)03/II

Volume II

HEU-MET-FAST-081

\subsection{RESULTS OF SAMPLE CALCULATIONS}

Results were calculated using MCNP5-1.51 with ENDF/B-VII.0, ENDF/B-VI.8, ${ }^{\mathrm{a}}$ ENDF/B-V.2, ${ }^{\mathrm{b}}$ and JENDL-3.3 $3^{\mathrm{C}}$ neutron cross-section libraries (see Tables 4.1 and 4.2 for the detailed and simple models, respectively) with example input listings and specifications provided in Appendix A. The MCNP5 calculations were performed with 1,050 generations that included 1,000,000 neutrons per generation. The $\mathrm{k}_{\text {eff }}$ estimates did not include the first 50 generations. The statistical uncertainty in $\mathrm{k}_{\mathrm{eff}}$ is \pm 0.00002 $(1 \sigma)$ in all cases. Eigenvalues calculated with MCNP5 are over $3 \sigma$ lower than the benchmark values; the reason for this computational bias is unknown.

Calculations were also performed using KENO-VI (SCALE 6.0) with ENDF/B-VII.0, ENDF/B-VI.8, and ENDF/B-V.2 neutron cross-section libraries. The KENO-VI calculations were performed with 1,050 generations that included 100,000 neutrons per generation. The $\mathrm{k}_{\text {eff }}$ estimates did not include the first 50 generations. The statistical uncertainty in $\mathrm{k}_{\text {eff }}$ is approximately $\pm 0.00008(1 \sigma)$. These results are also provided in Tables 4.1 and 4.2 for the detailed and simple models, respectively. Eigenvalues calculated with KENO-VI are approximately $3 \sigma$ greater than the benchmark values; the reason for the large difference between the MCNP5 and KENO-VI calculated results, using the same cross section data, is unknown.

Calculations were provided by Serco using a developmental version of MONK ${ }^{\mathrm{d}}$ with JEF2.2, ${ }^{\mathrm{e}} \mathrm{JEFF} 3.1{ }^{\mathrm{f}}$ ENDF/B-VII.0, or CENDL-3. $1^{\mathrm{g}}$ based BINGO continuous energy cross section libraries. The MONK9(DEV) calculations employed 5,000 superhistories per stage with up to 10 neutron generations tracked per superhistory, and was run for 10 settling stages followed by approximately 70 stages, to achieve a prevision of 0.0005 . The calculations were repeated twenty-five times each to achieve a prevision of \pm 0.0001 . The MONK calculations with ENDF/B-VII.0 are in good agreement with the MCNP results. Calculations with MONK and CENDL-3.1 provide calculated $\mathrm{k}_{\mathrm{eff}}$ values closest to the benchmark values.

\footnotetext{
${ }^{\text {a }}$ H. D. Lemmel, P. K. McLaughlin, and V. G. Pronyaev, "ENDF/B-VI Release 8 (Last Release of ENDF/B-VI) the U.S. Evaluated Nuclear Data Library for Neutron Reaction Data," IAEA-NDS-100 Rev. 11, International Atomic Energy Agency, Vienna (November 2001).

${ }^{b}$ B. A. Magurno and P. G. Young, "ENDF-201 Supplement I, ENDF/B-V.2 Summary Documentation," BNL-NCS17541, Brookhaven National Laboratory (January 1985).

' K. Shibata, et al., "Japanese Evaluated Nuclear Data Library Version 3 Revision3: JENDL-3.3," J. Nucl. Sci. Tech., 39: 1125-1136 (November 2002).

d Personal Communication with Dave Hanlon, July 2011.

e “The JEF-2.2 Nuclear Data Library,” JEFF Report 17, Organisation for Economic Co-operation and Development, Paris, France (2000).

${ }^{f}$ A. Koning, R. Forrest, M. Kellett, R. Mills, H. Henriksson, and Y. Rugama, "The JEFF-3.1 Nuclear Data Library," JEFF Report 21, Organisation for Economic Co-operation and Development, Paris, France (2006).

${ }^{\mathrm{g}}$ Z. G. Ge, et al., "The Updated Version of Chinese Evaluated Nuclear Data Library (CENDL-3.1)," Proc. Int. Conf. Nucl. Data for Sci. Tech., Jeju Island, Korea, April 26-30 (2010).
} 
NEA/NSC/DOC/(95)03/II

Volume II

HEU-MET-FAST-081

Table 4.1. Sample Calculation Results for the Detailed Benchmark Model.

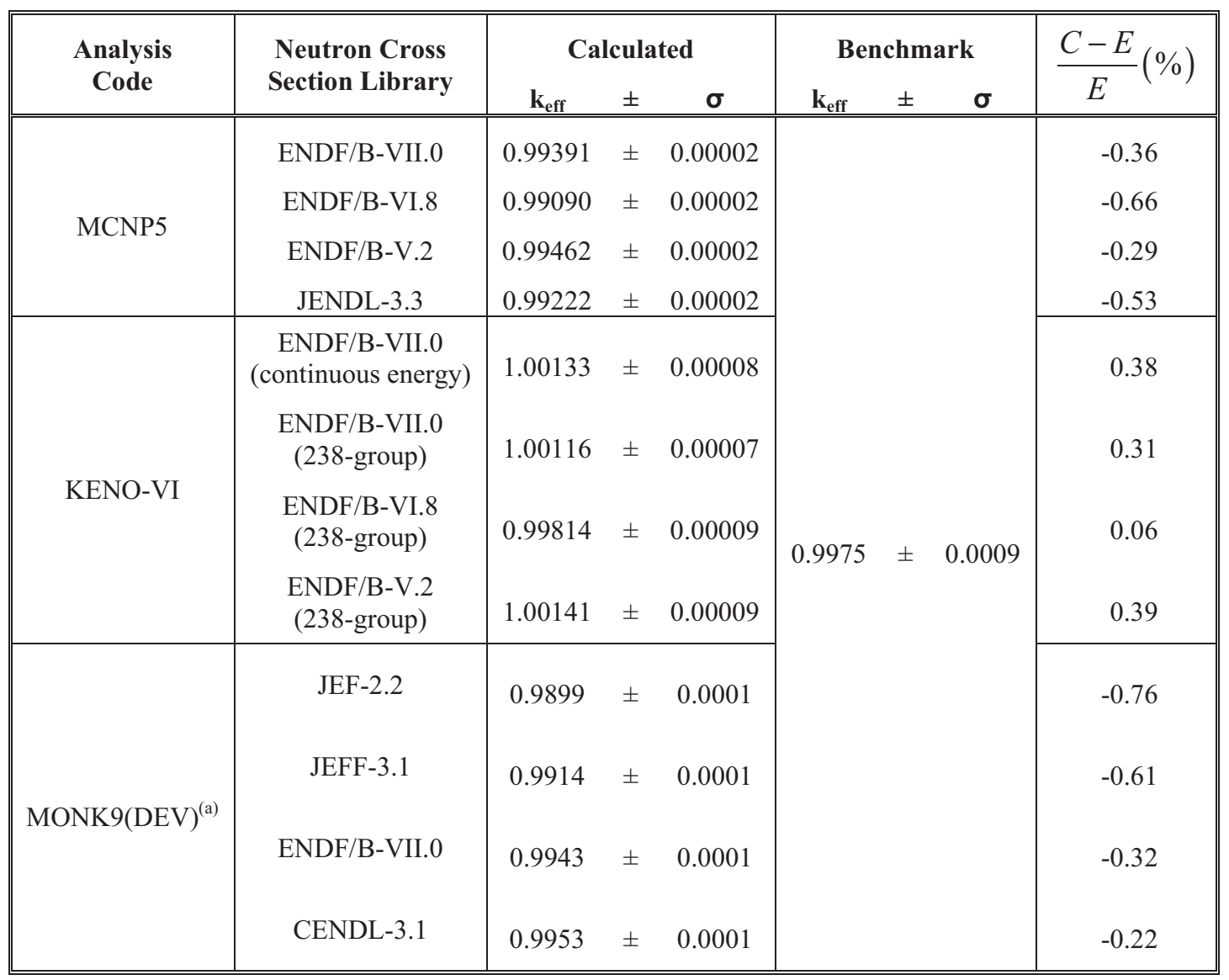

(a) Results provided by Dave Hanlon from Serco in the United Kingdom. 
NEA/NSC/DOC/(95)03/II

Volume II

HEU-MET-FAST-081

Table 4.2. Sample Calculation Results for the Simple Benchmark Model.

\begin{tabular}{|c|c|c|c|c|c|c|c|c|}
\hline \multirow{2}{*}{$\begin{array}{c}\text { Analysis } \\
\text { Code }\end{array}$} & \multirow{2}{*}{$\begin{array}{l}\text { Neutron Cross } \\
\text { Section Library }\end{array}$} & \multicolumn{3}{|c|}{ Calculated } & \multicolumn{3}{|c|}{ Benchmark } & \multirow{2}{*}{$\frac{C-E}{E}(\%)$} \\
\hline & & $\mathbf{k}_{\mathrm{eff}}$ & \pm & $\sigma$ & $\mathbf{k}_{\text {eff }}$ & \pm & $\sigma$ & \\
\hline \multirow{4}{*}{ MCNP5 } & ENDF/B-VII.0 & 0.98810 & \pm & 0.00002 & \multirow{12}{*}{\multicolumn{3}{|c|}{$0.9917 \pm 0.0010$}} & -0.37 \\
\hline & ENDF/B-VI.8 & 0.98507 & \pm & 0.00002 & & & & -0.67 \\
\hline & ENDF/B-V.2 & 0.98877 & \pm & 0.00002 & & & & -0.30 \\
\hline & JENDL-3.3 & 0.98644 & \pm & 0.00002 & & & & -0.53 \\
\hline \multirow{4}{*}{ KENO-VI } & $\begin{array}{c}\text { ENDF/B-VII.0 } \\
\text { (continuous energy) }\end{array}$ & 0.99489 & \pm & 0.00009 & & & & 0.32 \\
\hline & $\begin{array}{l}\text { ENDF/B-VII.0 } \\
\text { (238-group) }\end{array}$ & 0.99461 & \pm & 0.00008 & & & & 0.29 \\
\hline & $\begin{array}{l}\text { ENDF/B-VI.8 } \\
\text { (238-group) }\end{array}$ & 0.99160 & \pm & 0.00010 & & & & -0.01 \\
\hline & $\begin{array}{l}\text { ENDF/B-V.2 } \\
\text { (238-group) }\end{array}$ & 0.99471 & \pm & 0.00008 & & & & 0.30 \\
\hline \multirow{4}{*}{ MONK9(DEV) $)^{(a)}$} & JEF-2.2 & 0.9842 & \pm & 0.0001 & & & & -0.75 \\
\hline & JEFF-3.1 & 0.9854 & \pm & 0.0001 & & & & -0.63 \\
\hline & ENDF/B-VII.0 & 0.9885 & \pm & 0.0001 & & & & -0.31 \\
\hline & CENDL-3.1 & 0.9895 & \pm & 0.0001 & & & & -0.21 \\
\hline
\end{tabular}

(a) Results provided by Dave Hanlon from Serco in the United Kingdom. 
NEA/NSC/DOC/(95)03/II

Volume II

HEU-MET-FAST-081

\subsection{REFERENCES}

1. J. T. Mihalczo, and D. C. Irving, "Monte Carlo Calculations for Enriched Uranium Metal Assemblies," Trans. Am. Nucl. Soc., \# 287 (1964).

2. J. T. Mihalczo, "Multiplication Factor of Uranium Metal by One-Velocity Monte Carlo Calculations," Nucl. Sci. Eng., 27, 557-563 (1967).

3. J. T. Mihalczo and J. J. Lynn, "Neutron Multiplication Experiments with Enriched Uranium Metal in Slab Geometry," ORNL-CF-61-4-33, Oak Ridge National Laboratory (1961). 
$\mathrm{NEA} / \mathrm{NSC} / \mathrm{DOC} /(95) 03 / \mathrm{II}$

Volume II

HEU-MET-FAST-081

\section{APPENDIX A: TYPICAL INPUT LISTINGS}

\section{A.1 MCNP Input Listings}

Monte Carlo N-Particle (MCNP) version 5-1.51 calculations were used to calculate results in this evaluation. The Evaluated Neutron Data File library ENDF/B-VII.0 was utilized in the analysis of the experiment and benchmark model biases and uncertainties. The MCNP5 calculations were performed with 1,050 generations that included $1,000,000$ neutrons per generation. The $\mathrm{k}_{\mathrm{eff}}$ estimates did not include the first 50 generations. The statistical uncertainty in $\mathrm{k}_{\mathrm{eff}}$ is $\pm 0.00002(1 \sigma)$ in all cases.

\section{MCNP Input Listing, Simple Benchmark Model, Table 4.2}

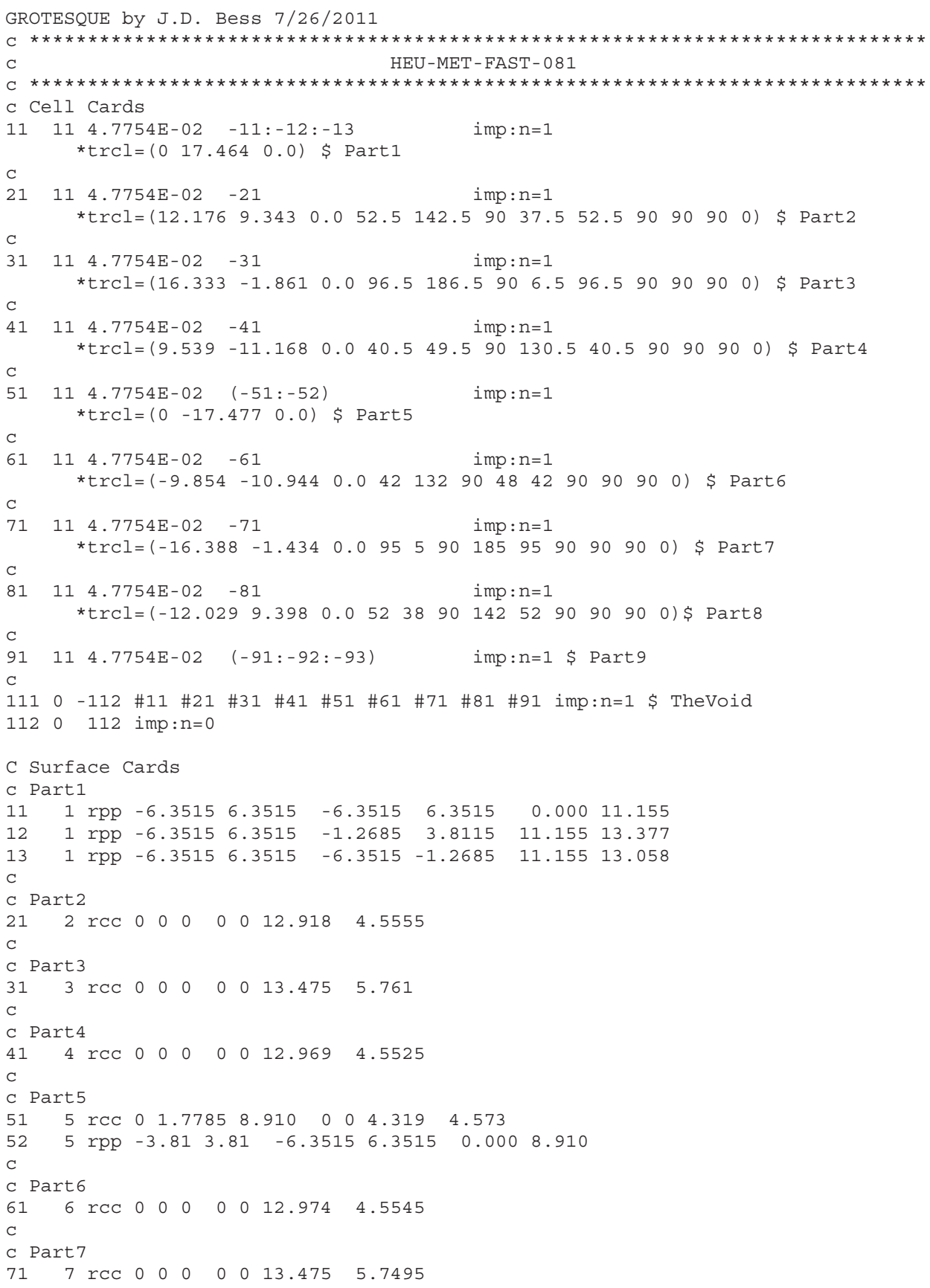


NEA/NSC/DOC/(95)03/II

Volume II

HEU-MET-FAST-081

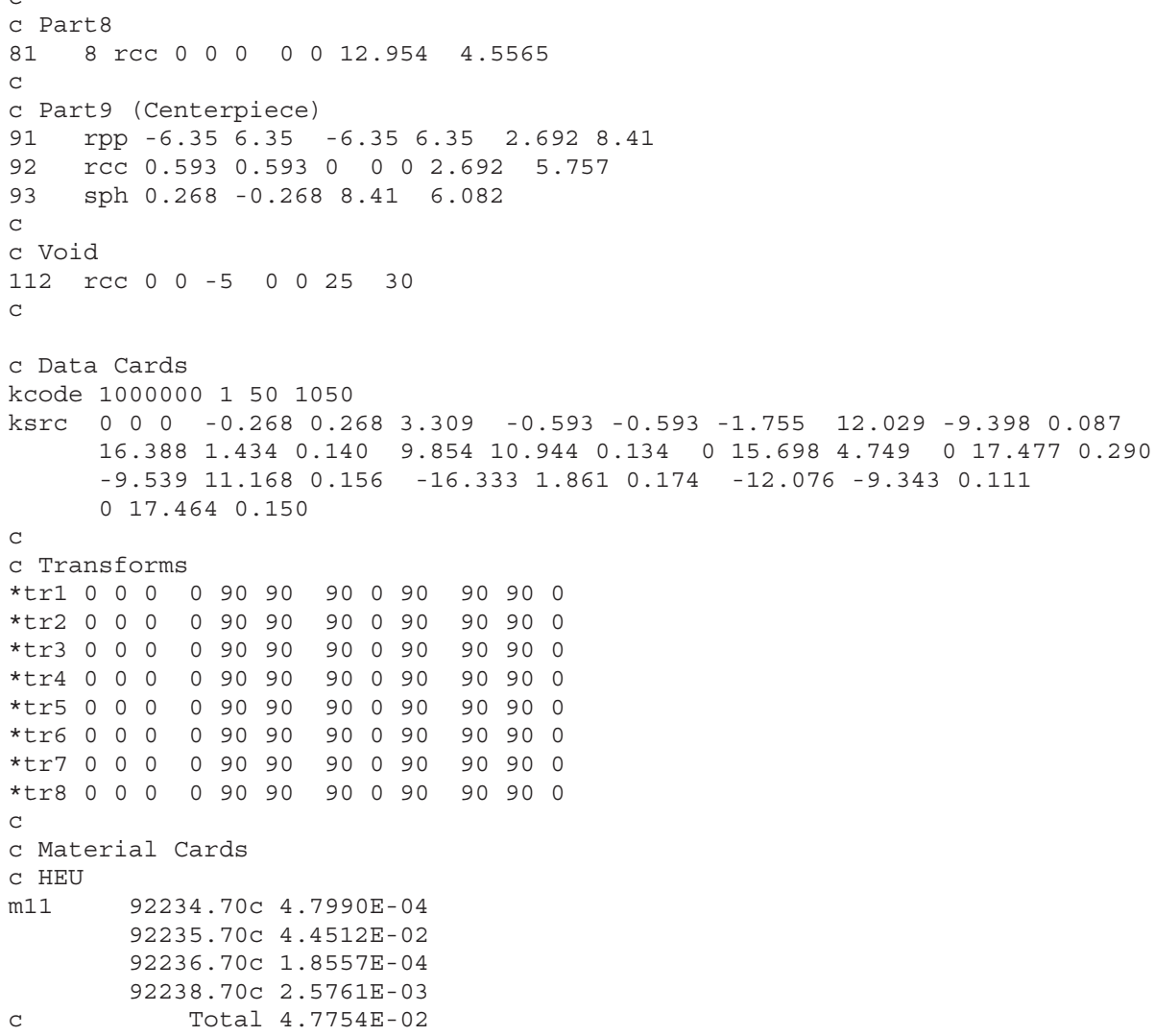

\section{MCNP Input Listing, Detailed Benchmark Model, Table 4.1.}

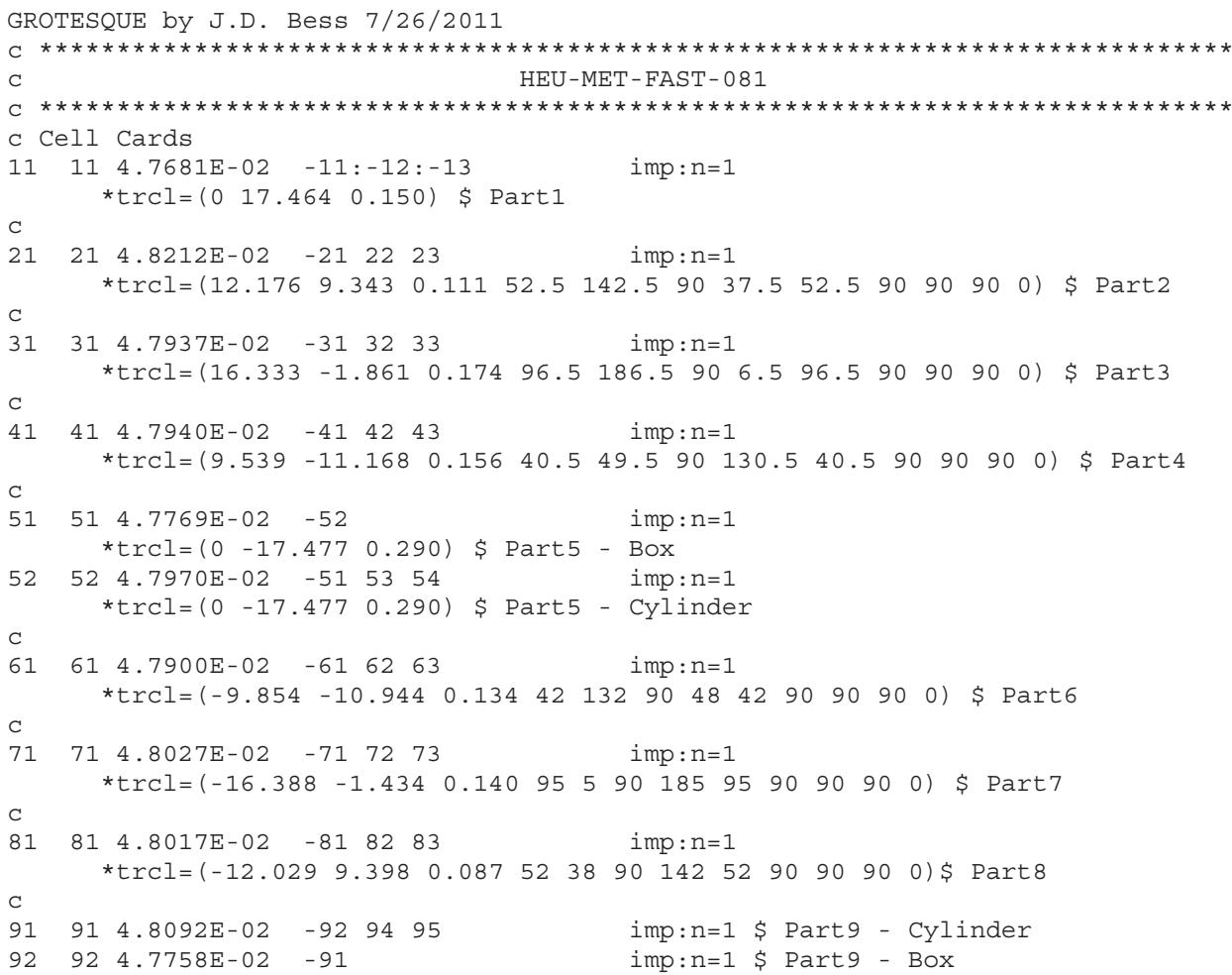




\section{NEA/NSC/DOC/(95)03/II \\ Volume II}

\section{HEU-MET-FAST-081}

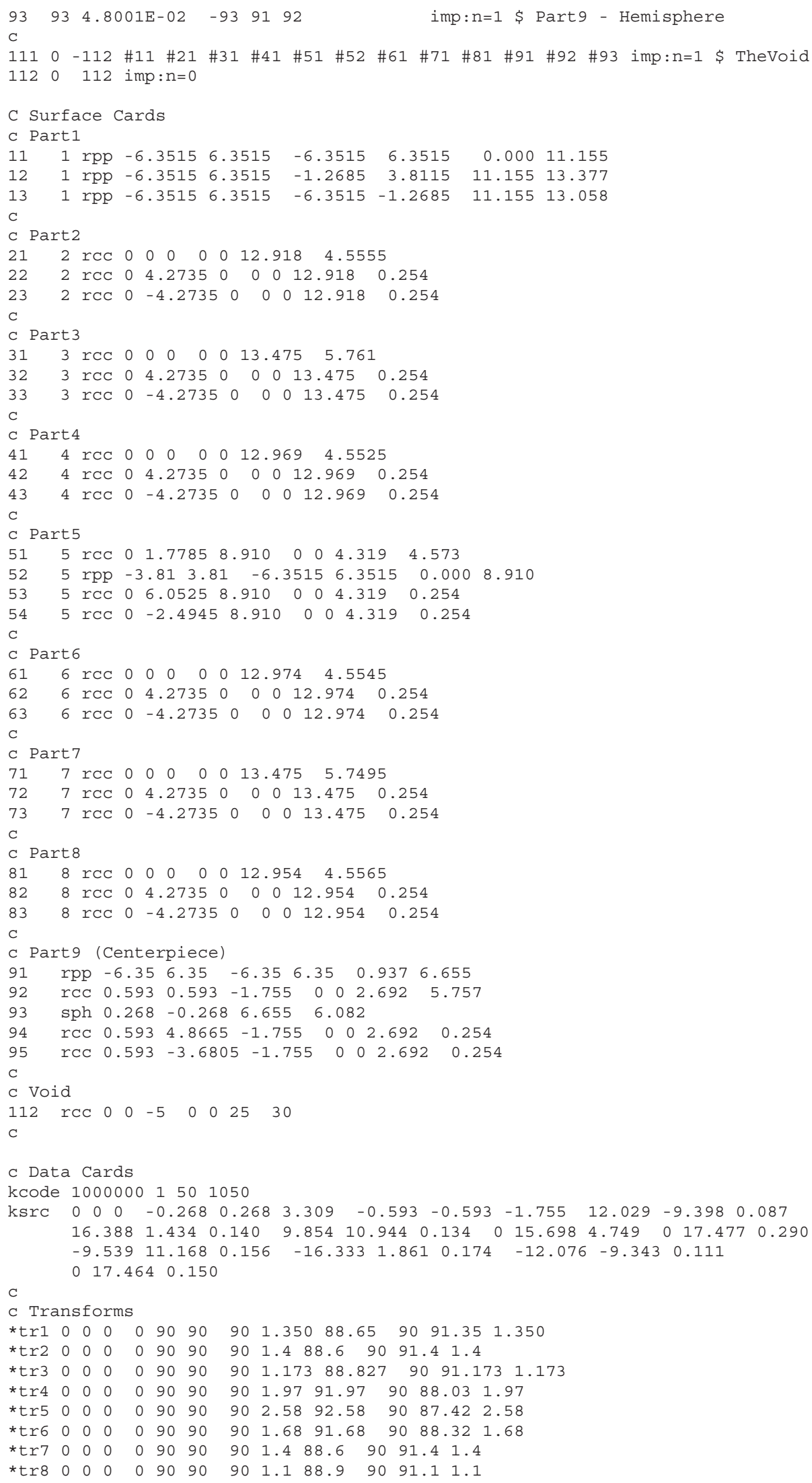


NEA/NSC/DOC/(95)03/II

Volume II

HEU-MET-FAST-081

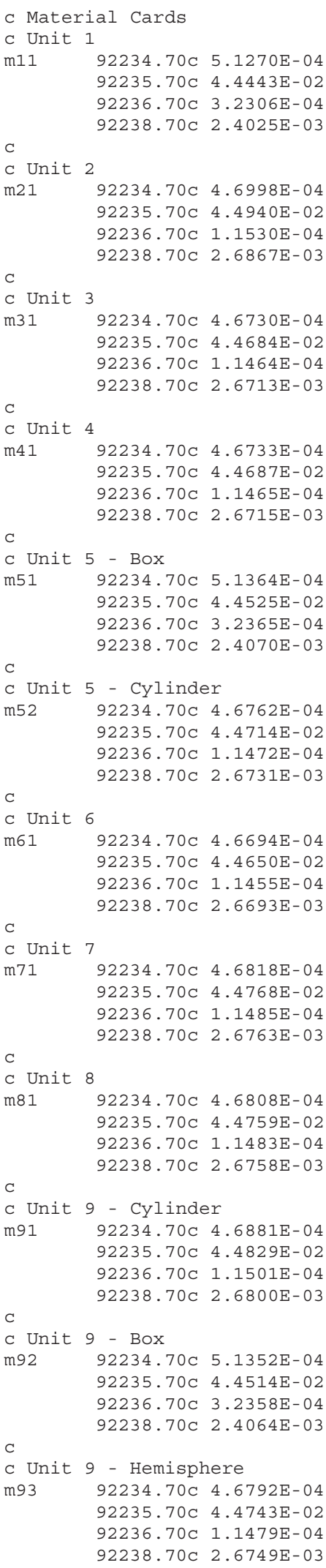

Revision: 0

Date: September 30, 2011 
NEA/NSC/DOC/(95)03/II

Volume II

HEU-MET-FAST-081

\section{A.2 KENO-VI Input Listings}

KENO-VI calculations (distributed in the SCALE 6.0 software suite) were used to calculate comparison results in this evaluation. The Evaluated Neutron Data File library ENDF/B-VII.0 was utilized in the analysis of the benchmark model bias for removing the tilt of the units and for sample calculations. The KENO-VI calculations were performed with 1,050 generations that included 100,000 neutrons per generation. The $\mathrm{k}_{\text {eff }}$ estimates did not include the first 50 generations. The statistical uncertainty in $\mathrm{k}_{\mathrm{eff}}$ is approximately $\pm 0.00008(1 \sigma)$.

\section{KENO Input Listing, Simple Benchmark Model, 4.2}

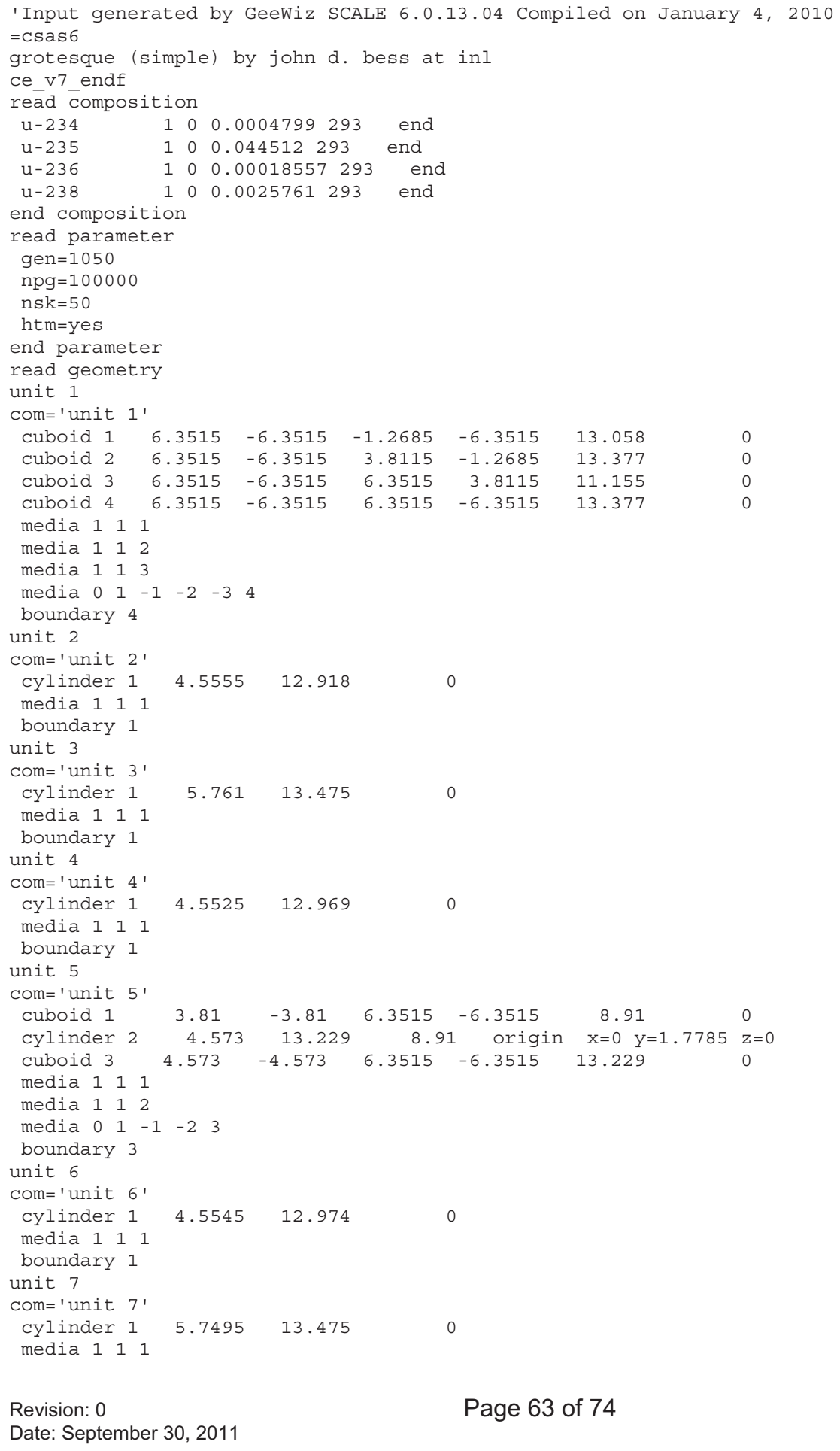


NEA/NSC/DOC/(95)03/II

Volume II

HEU-MET-FAST-081

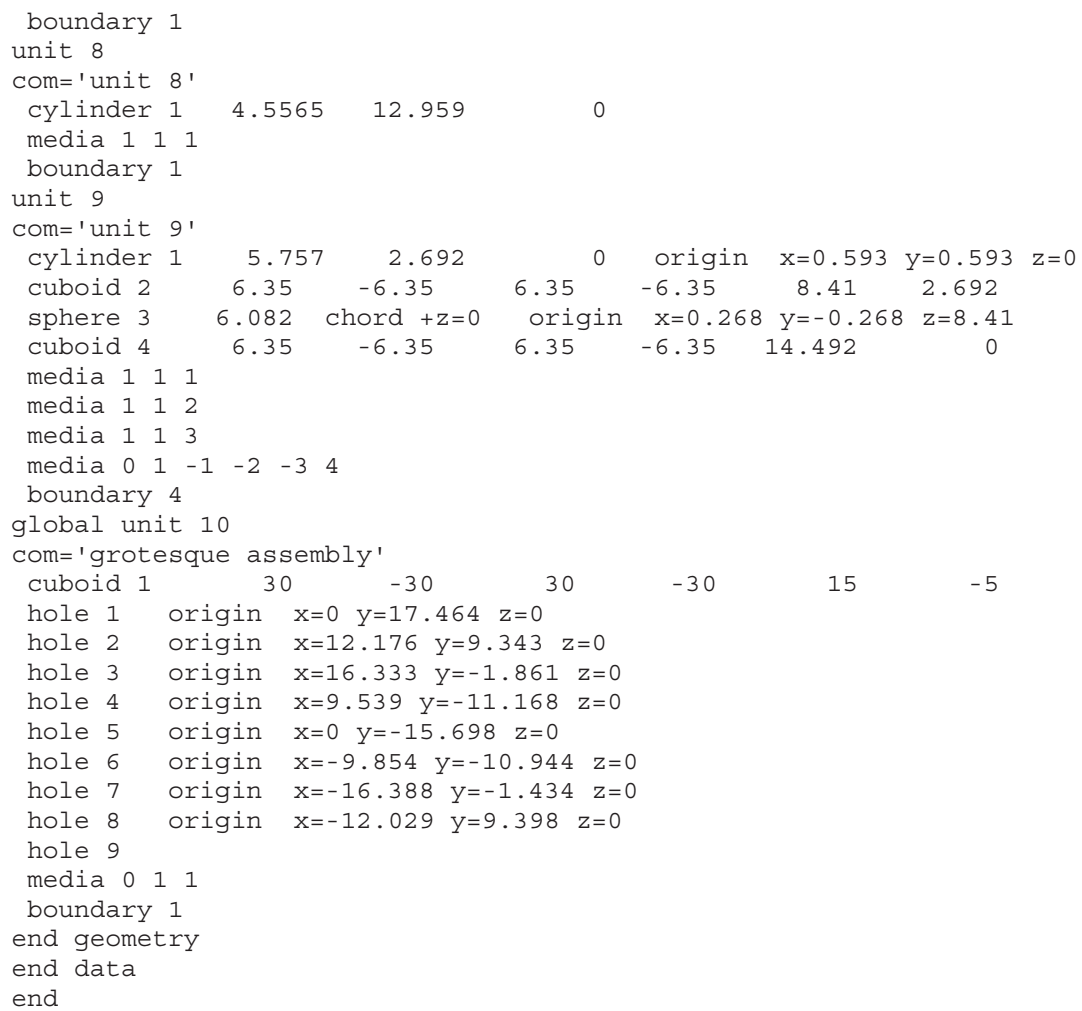

\section{KENO Input Listing, Detailed Benchmark Model, Table 4.1}

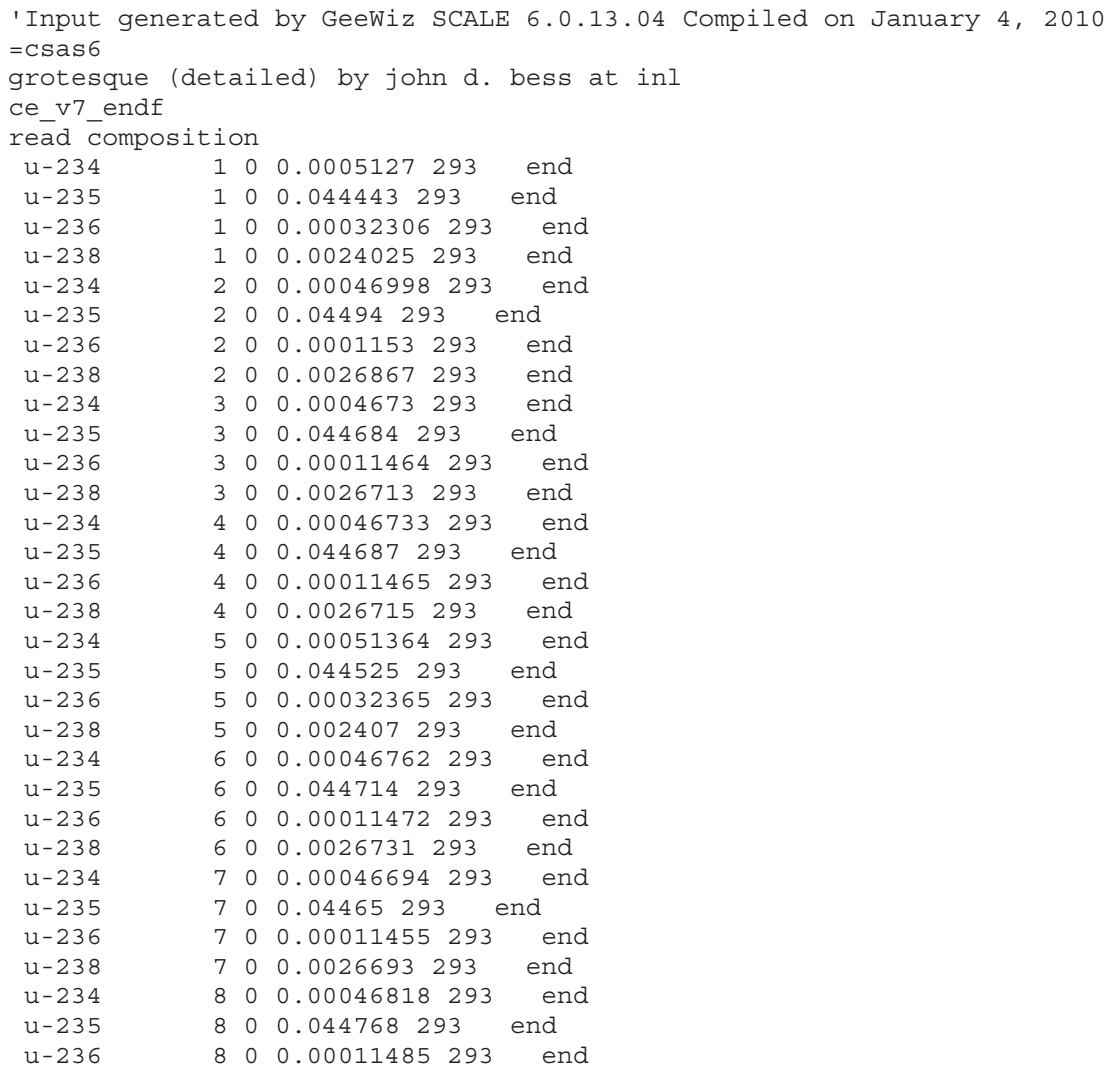


NEA/NSC/DOC/(95)03/II

Volume II

HEU-MET-FAST-081

$\begin{array}{llllll}u-238 & 8 & 0 & 0.0026763 & 293 & \text { end } \\ u-234 & 9 & 0 & 0.00046808 & 293 & \text { end } \\ u-235 & 9 & 0 & 0.044759 & 293 & \text { end } \\ u-236 & 9 & 0 & 0.00011483 & 293 & \text { end } \\ u-238 & 9 & 0 & 0.0026758 & 293 & \text { end } \\ u-234 & 10 & 0 & 0.00046881 & 293 & \text { end } \\ u-235 & 10 & 0 & 0.044829 & 293 & \text { end } \\ u-236 & 10 & 0 & 0.00011501 & 293 & \text { end } \\ u-238 & 10 & 0 & 0.00268 & 293 & \text { end } \\ u-234 & 11 & 0 & 0.00051352 & 293 & \text { end } \\ u-235 & 11 & 0 & 0.044514 & 293 & \text { end } \\ u-236 & 11 & 0 & 0.00032358 & 293 & \text { end } \\ u-238 & 11 & 0 & 0.0024064 & 293 & \text { end } \\ u-234 & 12 & 0 & 0.00046792 & 293 & \text { end } \\ u-235 & 12 & 0 & 0.044743 & 293 & \text { end } \\ u-236 & 12 & 0 & 0.00011479 & 293 & \text { end } \\ u-238 & 12 & 0 & 0.0026749 & 293 & \text { end }\end{array}$

end composition

read parameter

gen $=1050$

npg $=100000$

$\mathrm{nsk}=50$

htm=yes

end parameter

read geometry

unit 1

com=' unit 1 '

cuboid 1

$6.3515-6.3515$

$\begin{array}{llllll}\text { cuboid } 3 & 6.3515 & -6.3515 & 6.3515 & 3.8115 & 11.155\end{array}$

$\begin{array}{llllll}\text { cuboid } 4 & 6.3515 & -6.3515 & 6.3515 & -6.3515 & 13.377\end{array}$

media $1 \quad 1 \quad 1$

media $1 \begin{array}{lll}1 & 2\end{array}$

media 1 1 3

$\begin{array}{lllllll}\text { media } & 0 & 1 & -1 & -2 & -3 & 4\end{array}$

boundary 4

unit 2

com=' unit 2 '

cylinder 1

cylinder 2

$4.5555 \quad 12.918$

$0.254 \quad 12.918$

cylinder $3 \quad 0.254 \quad 12.918$

$\begin{array}{llllll}\text { media } & 2 & 1 & 1 & -2 & -3\end{array}$

media 012

media $0 \begin{array}{lll} & 3\end{array}$

boundary 1

unit 3

$\mathrm{com}=$ ' unit 3 '

cylinder 1

cylinder 2

cylinder 3

media $3 \quad 1 \quad 1$

media $0 \begin{array}{lll}0 & 2\end{array}$

media 013

boundary 1

unit 4

$\mathrm{com}=$ ' unit 4 '

cylinder 1

cylinder 2

cylinder 3

$4.5525 \quad 12.969$

$5.761 \quad 13.475$

$0.254 \quad 13.475$

$0.254 \quad 13.475$

$\begin{array}{rrr}6.3515 & 3.8115 & 11.155 \\ 6.3515 & -6.3515 & 13.377\end{array}$

0

0

0

media $4 \quad 1$

$0.254 \quad 12.969$

12.969

origin $\mathrm{x}=0 \quad \mathrm{y}=4.2735 \quad \mathrm{z}=0$

origin $\mathrm{x}=0 \quad \mathrm{y}=-4.2735 \mathrm{z}=0$

media $0 \begin{array}{lll} & 1 & 2\end{array}$

media $0 \begin{array}{lll} & 3\end{array}$

boundary 1

unit 5

com $=$ ' unit 5 '

cuboid 1

cylinder 2

cuboid 3

$\begin{array}{lll}6.3515 & -6.3515 \quad 8.91\end{array}$

origin $\mathrm{x}=0 \quad \mathrm{y}=4.2735 \quad \mathrm{z}=0$

origin $\mathrm{x}=0 \quad \mathrm{y}=-4.2735 \mathrm{z}=0$

cylinder 4

$4.573 \quad 13.229$

8.91 origin

origin $\mathrm{x}=0 \quad \mathrm{y}=4.2735 \mathrm{z}=0$

origin $\mathrm{x}=0 \mathrm{y}=-4.2735 \mathrm{z}=0$

cylinder 5

$4.573-4.573$

$\begin{array}{lll}515 & -6.3515 \quad 13.229\end{array}$

$z=0$

media $5 \quad 1 \quad 1$

$0.254 \quad 13.229$

$\begin{array}{llllll}\text { media } & 6 & 1 & 2 & -4 & -5\end{array}$

$\begin{array}{llllll}\text { media } & 0 & 1 & -1 & -2 & 3\end{array}$

media $0 \begin{array}{ll} & 1\end{array}$

media 015

Revision: 0

Page 65 of 74

Date: September 30, 2011 
NEA/NSC/DOC/(95)03/II

Volume II

HEU-MET-FAST-081

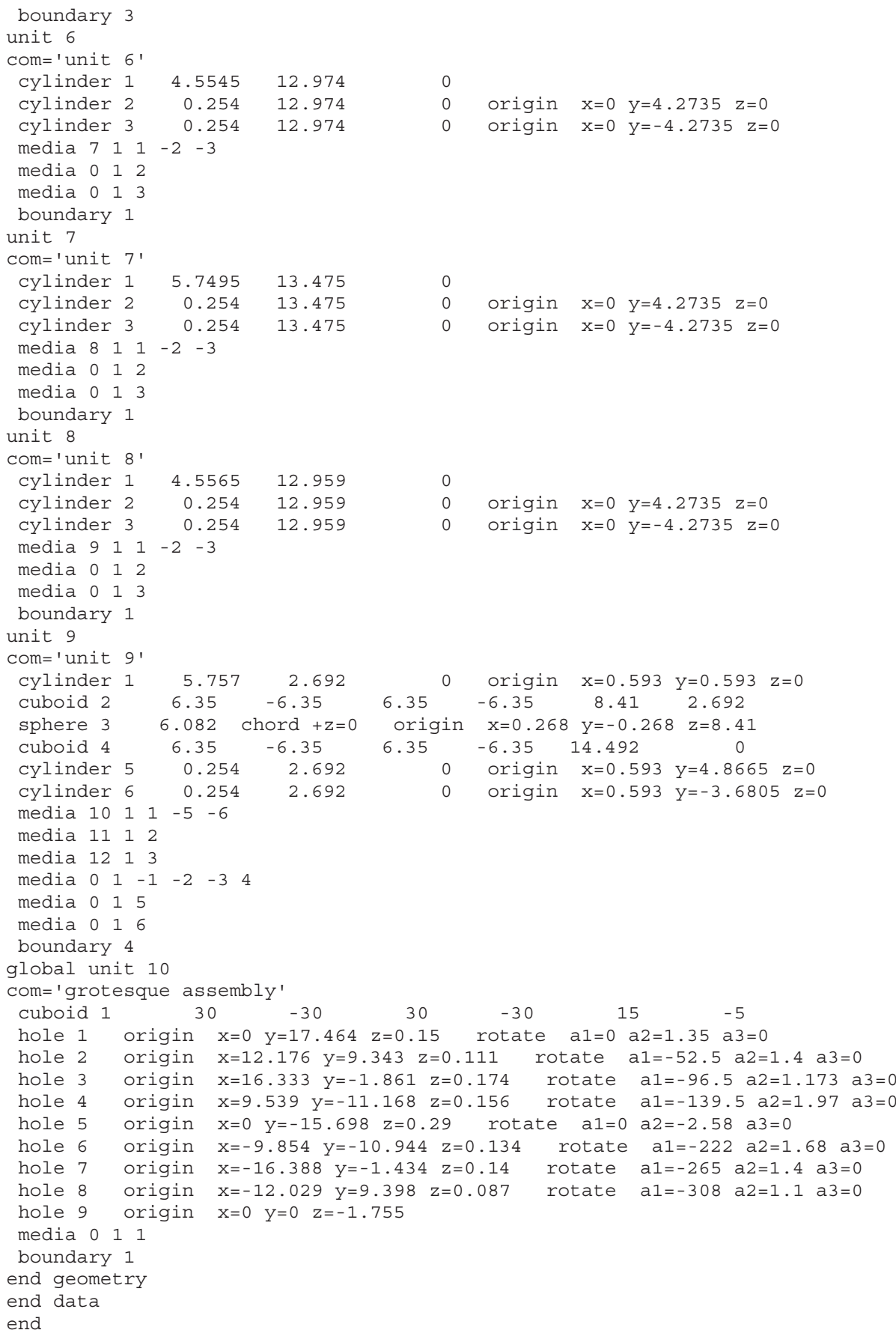


$\mathrm{NEA} / \mathrm{NSC} / \mathrm{DOC} /(95) 03 / \mathrm{II}$

Volume II

HEU-MET-FAST-081

\section{A.3 MONK Input Listings}

Each MONK9DEV calculation, using either JEF2.2, JEFF3.1, ENDFB/VII.0 or CENDL3.1-based BINGO continuous energy cross section libraries, employed 5000 superhistories per stage, with up to 10 neutron generations tracked per superhistory, and was run for 10 settling stages followed by approximately 70 stages, to achieve a precision of 0.0005 . The calculations were repeated twenty five times each to achieve a precision of \pm 0.0001 .

\section{MONK Input Listing, Simple Benchmark Model, Table 4.2}

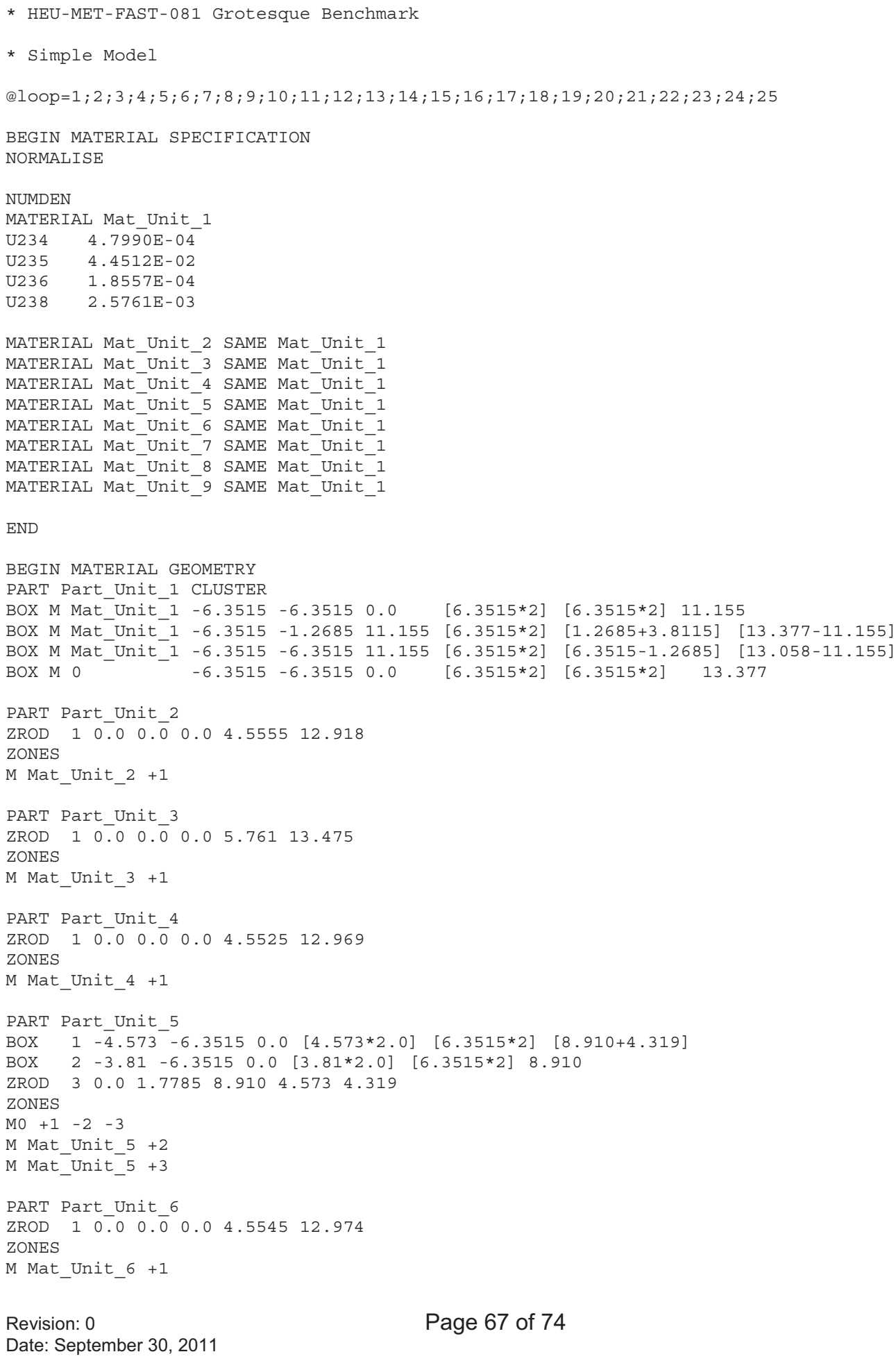


NEA/NSC/DOC/(95)03/II

Volume II

HEU-MET-FAST-081

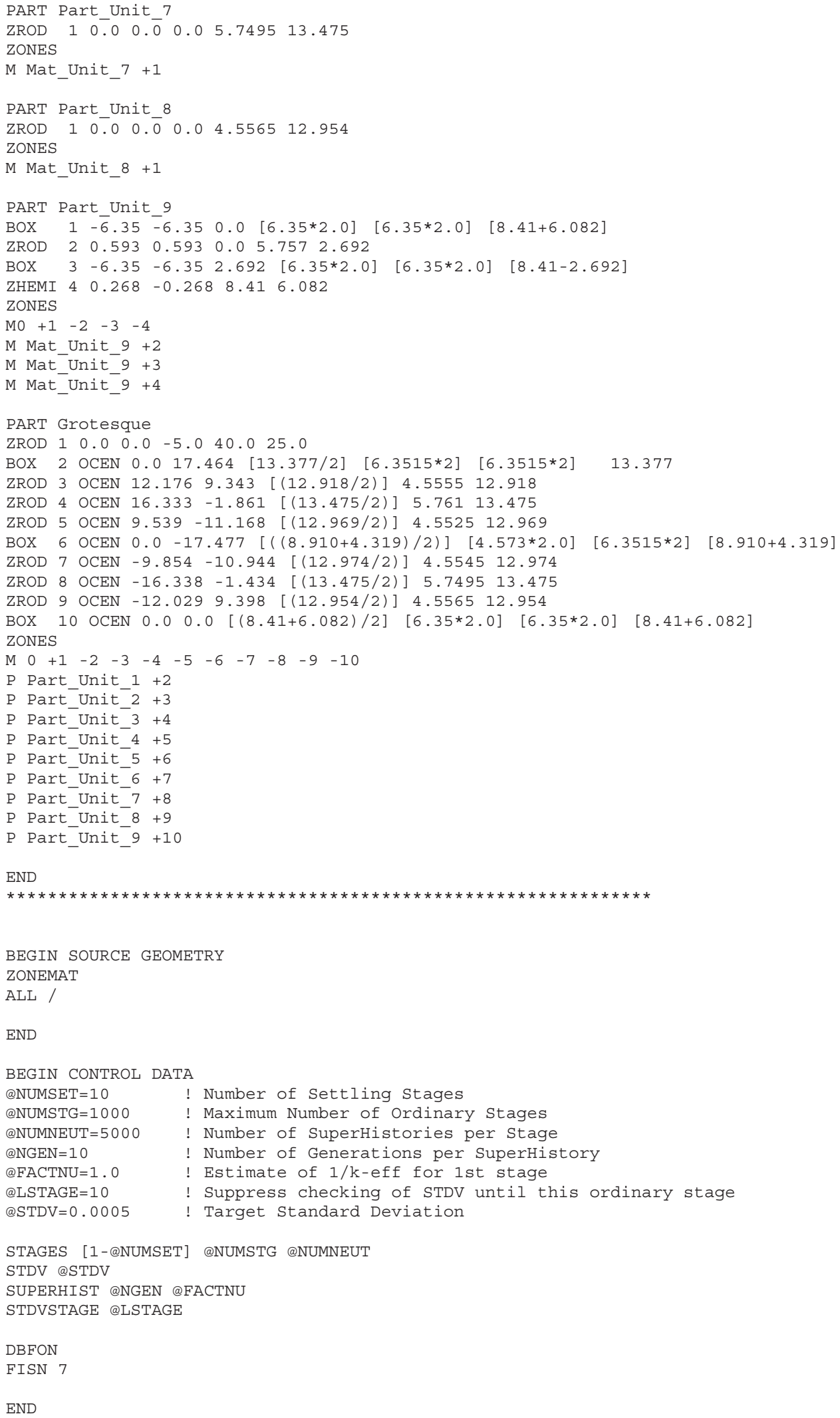


NEA/NSC/DOC/(95)03/II

Volume II

HEU-MET-FAST-081

\section{MONK Input Listing, Detailed Benchmark Model, Table 4.1}

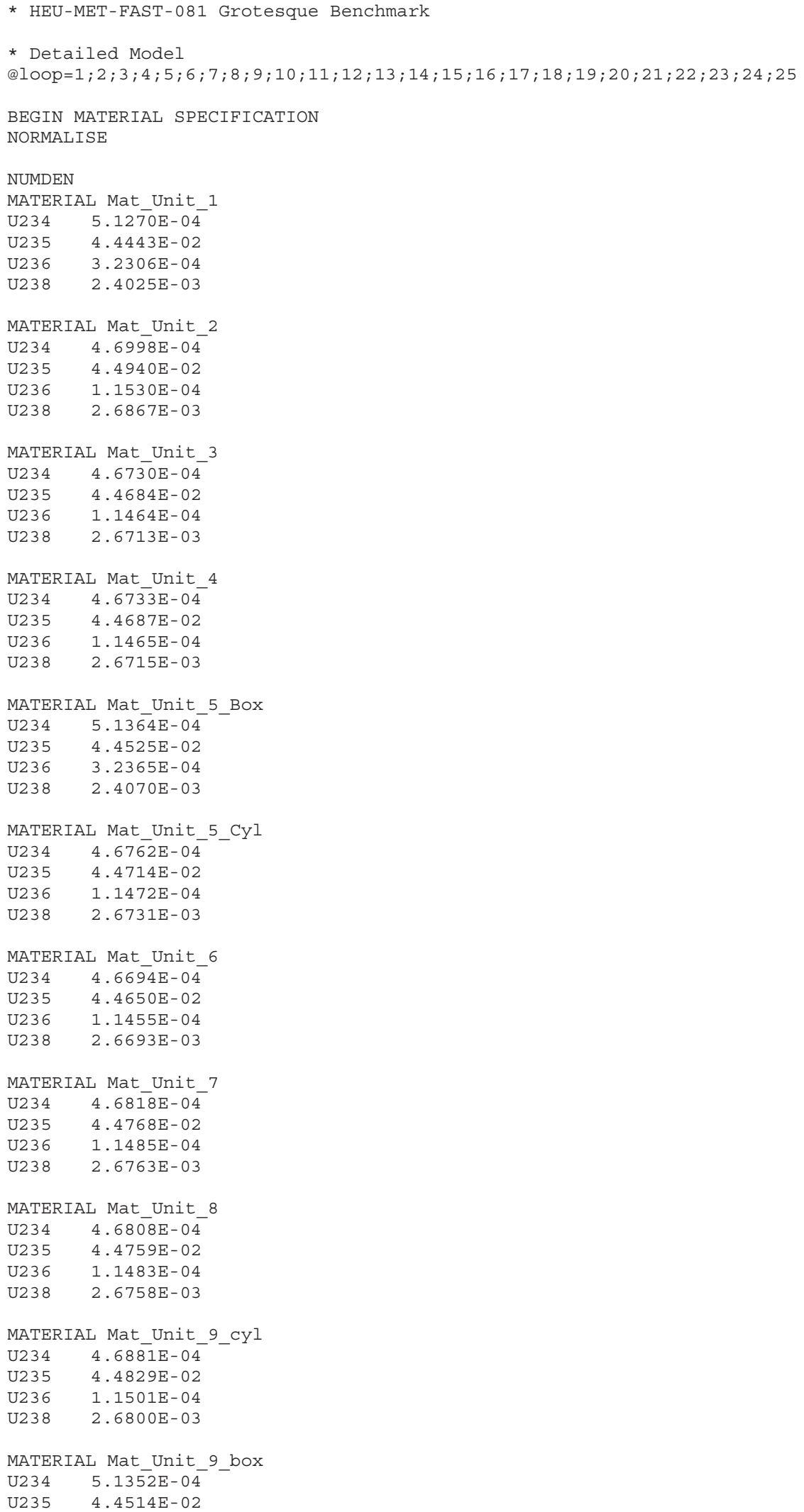


NEA/NSC/DOC/(95)03/II

Volume II

HEU-MET-FAST-081

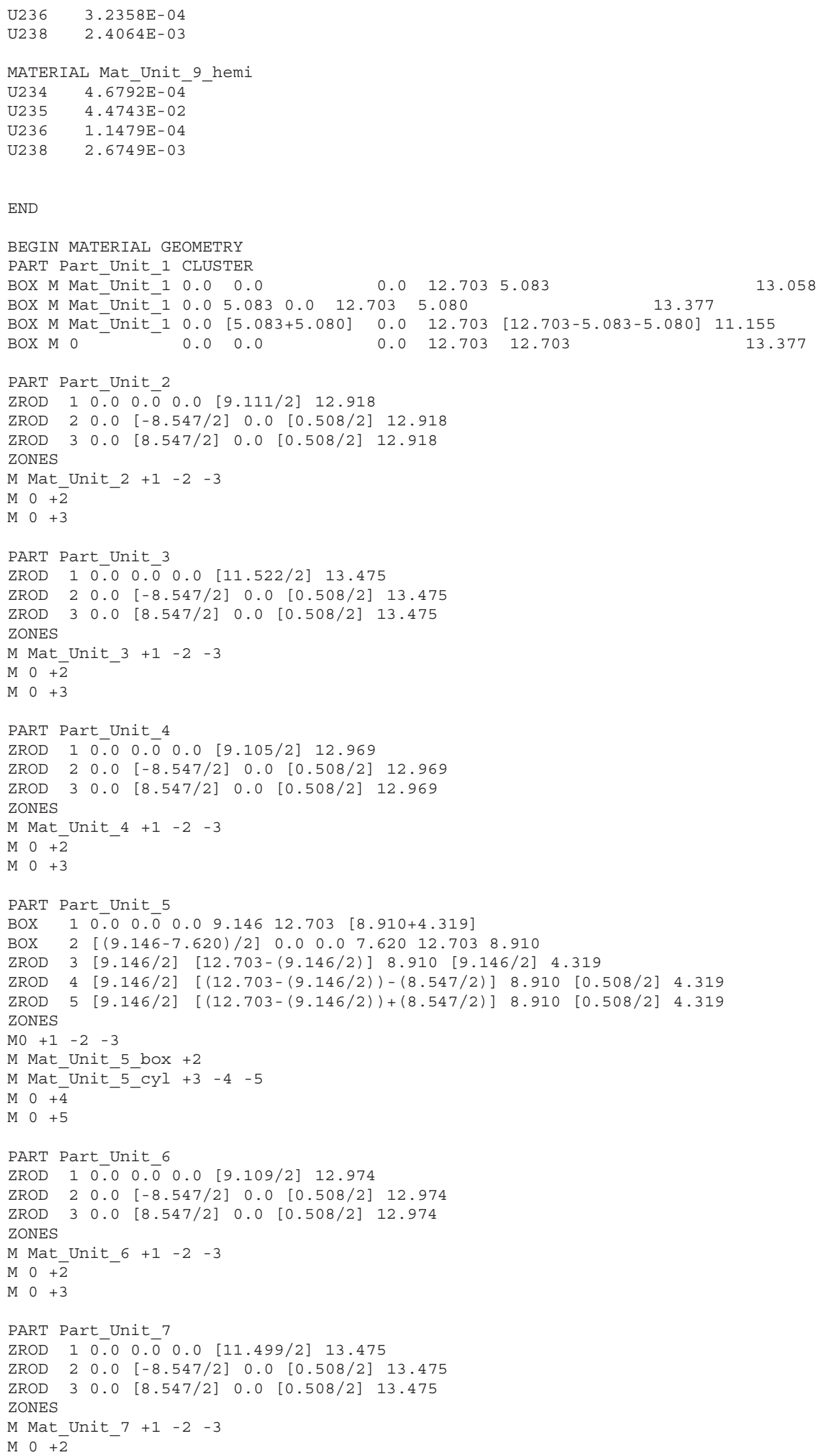


NEA/NSC/DOC/(95)03/II

Volume II

\section{HEU-MET-FAST-081}

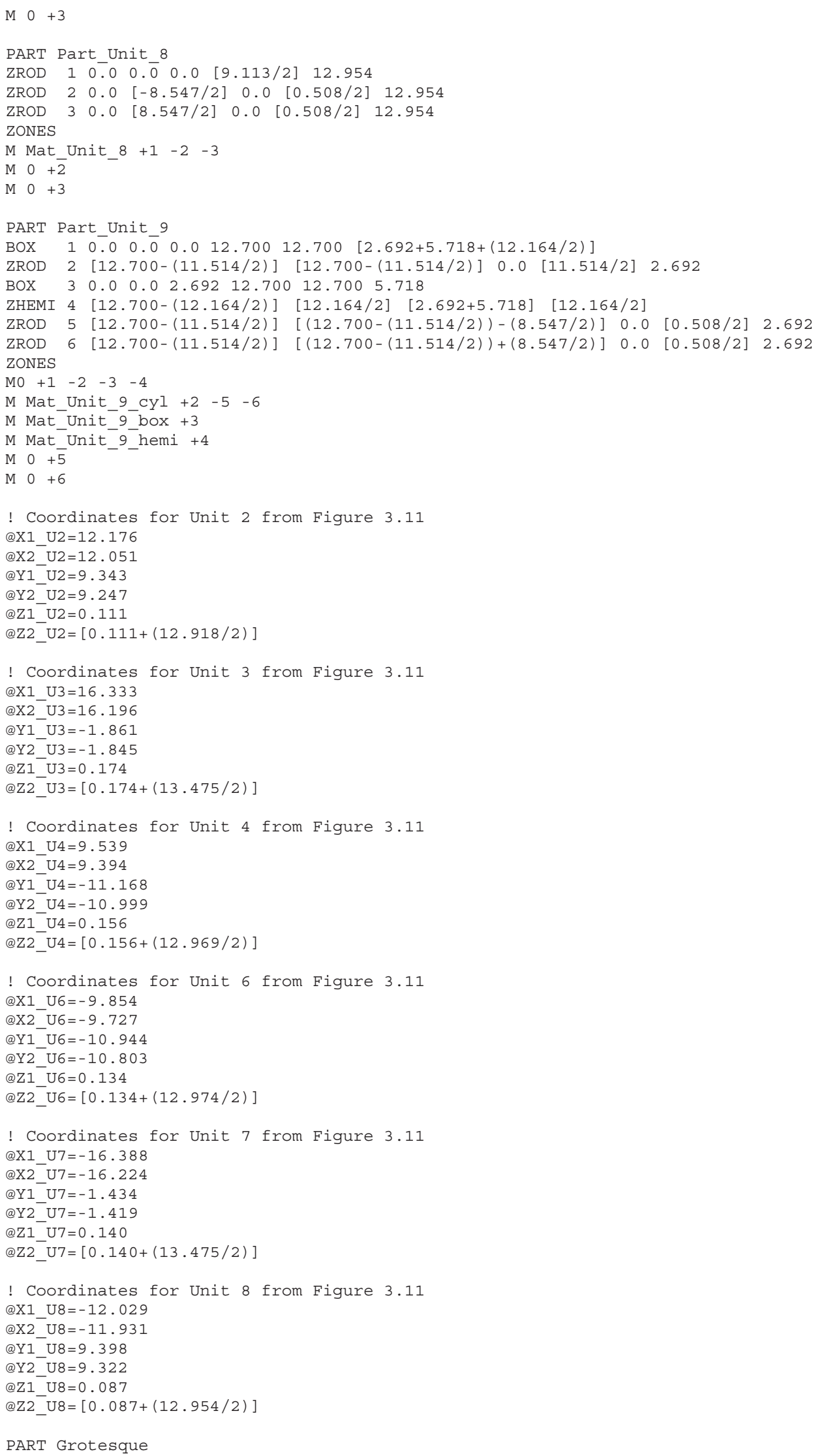


NEA/NSC/DOC/(95)03/II

Volume II

HEU-MET-FAST-081

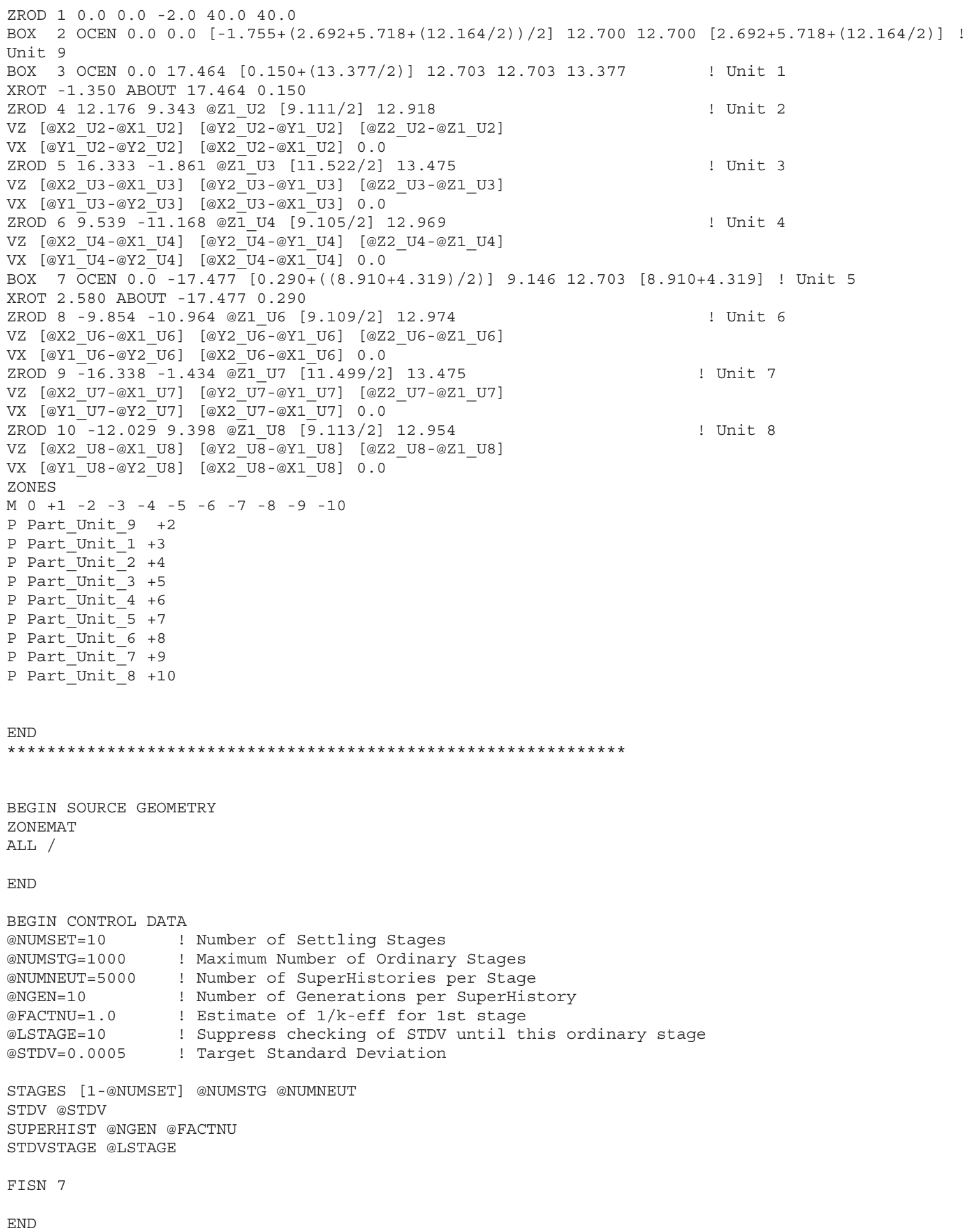


HEU-MET-FAST-081

\section{APPENDIX B: CALCULATED SPECTRAL DATA}

The neutron spectral calculations provided below were obtained from the output files for the input decks provided in Appendix A.1 and results in Section 4.1. Only spectral data using the ENDF/B-VII.0 neutron cross section libraries are provided here for the MCNP5 analyses and the ENDF/B-VII.0 (continuous energy) library for the KENO analyses. Cross sections are all continuous energy in the MCNP5 analyses.

\section{B.1 MCNP-Calculated Spectral Data}

A summary of the computed neutron spectral data using MCNP5 for the benchmark models is provided in Table B.1.

Table B.1. Neutron Spectral Data for Benchmark Models (MCNP5).

\begin{tabular}{|c||c|c|}
\hline \multicolumn{1}{|c||}{ Model } & Simple & Detailed \\
\hline $\begin{array}{c}\text { Neutron Cross } \\
\text { Section Library }\end{array}$ & ENDF/B-VII.0 & ENDF/B-VII.0 \\
\hline $\mathbf{k}_{\text {eff }}$ & 0.98810 & 0.99391 \\
\hline $\mathbf{\sigma}_{\mathbf{k}}$ & 0.00002 & 0.00002 \\
\hline $\begin{array}{c}\text { Fission Fraction, Thermal (<0.625 eV) } \\
\text { by Energy (\%) } \quad \text { Intermediate }\end{array}$ & 55.79 & 55.51 \\
\hline $\begin{array}{c}\text { Average Number of } \\
\text { Neutrons Produced } \\
\text { per Fission }\end{array}$ & 0.00 & 0.00 \\
\hline $\begin{array}{c}\text { Energy of Average } \\
\text { Neutron Lethargy } \\
\text { Causing Fission (MeV) }\end{array}$ & 5.06 & 5.07 \\
\hline
\end{tabular}

(a) The neutron leakage is calculated using the neutron balance tables provided in the MCNP output file. The weight fraction of neutrons lost due to escaping the boundaries of the benchmark model are divided by the total weight fraction of neutron loss. 
NEA/NSC/DOC/(95)03/II

Volume II

HEU-MET-FAST-081

\section{B.2 KENO-Calculated Spectral Data}

A summary of the computed neutron spectral data using KENO-VI for the benchmark models is provided in Table B.2.

Table B.2. Neutron Spectral Data for Benchmark Models (KENO).

\begin{tabular}{||c||c|c||}
\hline Model & Simple & Detailed \\
\hline $\begin{array}{c}\text { Neutron Cross } \\
\text { Section Library }\end{array}$ & $\begin{array}{c}\text { ENDF/B-VII.0 } \\
\text { (continuous energy) }\end{array}$ & $\begin{array}{c}\text { ENDF/B-VII.0 } \\
\text { (continuous energy) }\end{array}$ \\
\hline $\mathbf{k}_{\text {eff }}$ & 0.994891 & 1.001332 \\
$\pm \sigma_{\mathbf{k}}$ & 0.000091 & 0.000080 \\
\hline $\begin{array}{c}\text { Average Number of } \\
\text { Neutrons Produced } \\
\text { per Fission }\end{array}$ & 2.60076 & 2.60045 \\
\hline $\begin{array}{c}\text { Energy of Average } \\
\text { Neutron Lethargy } \\
\text { Causing Fission (MeV) }\end{array}$ & 0.836337 & 0.834440 \\
\hline Mean Free Path (cm) & 1.99267 & 1.99160 \\
\hline
\end{tabular}

